\title{
Synthesis of Vinylic Sulfones in Aqueous Media
}

Jeffrey Goh, ${ }^{\mathrm{c}}$ Manikantha Maraswami, ${ }^{\mathrm{c}}$ Teck-Peng Loh ${ }^{\mathrm{a}, \mathrm{b}, \mathrm{c}^{*}}$

${ }^{a}$ Institute of Advanced Synthesis (IAS), Northwestern Polytechnical University (NPU), 127 West Youyi Road, Xi'an 710072, China

${ }^{\mathrm{b}}$ Yangtze River Delta Research Institute, Northwestern Polytechnical University (NPU), 27 Zigang Road, Taicang Jiangsu, 215400, China

${ }^{c}$ Division of Chemistry and Biological Chemistry, School of Physical and Mathematical Sciences, Nanyang Technological University, Singapore 637371

Fax: (65) 6515-8229; email: teckpeng@ntu.edu.sg

Contents

Pages

General information

2

Preparation of starting materials

Optimization of reaction condition

General procedure for the water-based vinylic sulfination of allenic carbonyls \& Spectroscopic data obtained in this study

General procedure for competitive studies and spectra data

Synthetic transformations of vinylic sulfones

NMR Spectra 


\section{General Information:}

Unless otherwise stated, all commercial reagents and solvents were used without additional purification. Analytical thin layer chromatography (TLC) was performed on pre-coated silica gel 60 F254 plates. Visualization on TLC was achieved by the use of UV light $(254 \mathrm{~nm})$. Column chromatography was undertaken on silica gel (400-630 mesh) using a proper eluent system. ${ }^{1} \mathrm{H}$ NMR was recorded on Bruker Avance $500 \mathrm{MHz}$. Chemical shifts were quoted in parts per million (ppm) referenced to the appropriate solvent peak or $0.0 \mathrm{ppm}$ for tetramethylsilane. The following abbreviations were used to describe peak splitting patterns when appropriate: $\mathrm{br}=$ broad, $\mathrm{s}=$ singlet, $\mathrm{d}=$ doublet, $\mathrm{t}=$ triplet, $\mathrm{q}=$ quartet, $\mathrm{dd}=$ doublet of doublet, $\mathrm{td}=$ triplet of doublet, $\mathrm{ddd}=$ doublet of doublet of doublet, $\mathrm{m}=$ multiplet. Coupling constants, $J$, were reported in hertz unit $(\mathrm{Hz}) .{ }^{13} \mathrm{C}$ NMR and ${ }^{19} \mathrm{~F}\left\{{ }^{1} \mathrm{H}\right\}$ NMR were recorded on Bruker Avance $500 \mathrm{MHz}$ (126 MHz) and $300 \mathrm{MHz}(282 \mathrm{MHz})$, respectively, and were fully decoupled by broad band proton decoupling. Chemical shifts were reported in ppm referenced to the center of a triplet at $77.0 \mathrm{ppm}$ of chloroform- $d$. High resolution mass spectra were obtained on Waters Q-Tof Permier Spectrometer.

\section{General Procedure for the Preparation of Starting Materials}

\section{II-1. Preparation of allenic ketones ${ }^{1}$}

Allenic ketones (1) were prepared from the corresponding aldehydes according to the known procedures reported in the literature. ${ }^{1}$ Allenic ketones $\mathbf{1 m}-\mathbf{1 r}$ were prepared using general procedure 1a, $\mathbf{1 u}$ was prepared using reported procedures, ${ }^{1 \mathrm{c}}$ and $1 \mathbf{s}, 1 \mathbf{t}, 1 \mathbf{v}-\mathbf{1 z}$ were prepared using general procedure $1 \mathrm{~b}$.

\section{General Procedure 1a}

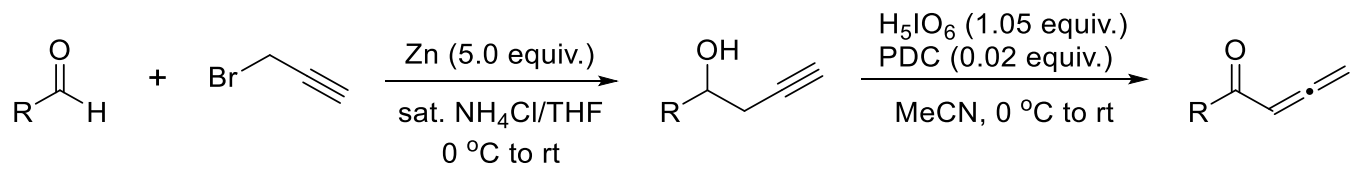

To a solution of aldehyde (10.0 mmol, 1.0 equiv.), propargyl bromide (20.0 mmol, 2.0 equiv., $80 \%$ in toluene) and $\mathrm{Zn}$ powder $\left(50.0 \mathrm{mmol}, 5.0\right.$ equiv.) in THF $(15 \mathrm{~mL})$, was added saturated $\mathrm{NH}_{4} \mathrm{Cl}$ dropwise at $0{ }^{\circ} \mathrm{C}$. The reaction mixture was warmed to room temperature and stirred overnight. After the completion of the reaction (i.e. monitored by TLC), the mixture was filtered over celite and the filter cake was washed with $\mathrm{CH}_{2} \mathrm{Cl}_{2}$. The filtrate was washed with saturated $\mathrm{NH}_{4} \mathrm{Cl}(50 \mathrm{~mL})$ and water $(100 \mathrm{~mL})$ and dried over $\mathrm{Na}_{2} \mathrm{SO}_{4}$. The volatiles were evaporated under reduced pressure and the crude product was purified by flash column chromatography to afford the corresponding propargylic alcohol.

A solution of propargylic alcohol (1.0 equiv.) in $\mathrm{MeCN}\left(20 \mathrm{~mL}\right.$ ) was added dropwise to a solution of $\mathrm{H}_{5} \mathrm{IO}_{6}$ (1.05 equiv.) at $0{ }^{\circ} \mathrm{C}$. Subsequently, PDC (0.02 equiv.) was added portionwise to the reaction mixture. The mixture was allowed to warm to ambient conditions and stirred overnight until the completion of the reaction (i.e. monitored by TLC). The mixture was diluted with EtOAc $(100 \mathrm{~mL})$ and the mixture was washed with brine: $\mathrm{H}_{2} \mathrm{O}(1: 1,50 \mathrm{~mL})$, saturated $\mathrm{Na}_{2} \mathrm{~S}_{2} \mathrm{O}_{3}(50 \mathrm{~mL})$, brine $(50 \mathrm{~mL})$ and dried over $\mathrm{Na}_{2} \mathrm{SO}_{4}$. The volatiles were evaporated under reduced pressure and the crude product was purified by flash column chromatography to afford the corresponding ketone allenes $\mathbf{1}$.

1 (a) Melen, R.L.; Wilkins, L.C.; Kariuki, B.M.; Wadepohl, H.; Gade, L.H.; Hashmi, A.S.K.; Stephan, D.W.; Hasmann, M.M. Diverging Pathways in the Activation of Allenes with Lewis Acids and Bases: Addition, 1,2Carboboration, and Cyclization. Organometallics. 2015, 34, 4127; (b) Li, Y.; Brand, J.P.; Waser, J. Gold-Catalyzed Regioselective Synthesis of 2- and 3-Alkynyl Furans. Angew. Chem. Int. Ed. 2013, 52, 6743; (c) Son, J.; Reidl, T.W.; Kim, K.H.; Wink, D.J.; Anderson, L.L. Generation and Rearrangement of N,O-Dialkenylhydroxylamines for the Synthesis of 2-Aminotetrahydrofurans. Angew. Chem. Int. Ed. 2018, 57, 6597. 


\section{General Procedure $1 b$}

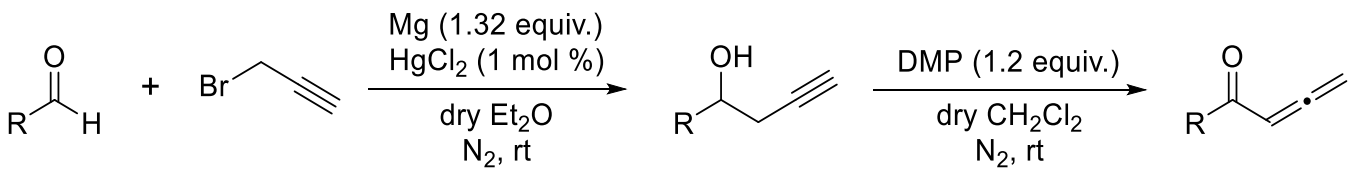

A solution of $\mathrm{Mg}$ (13.2 mmol, 1.32 equiv.) and $\mathrm{HgCl}_{2}(0.10 \mathrm{mmol}, 0.01$ equiv. $)$ in anhydrous $\mathrm{Et}_{2} \mathrm{O}(30 \mathrm{~mL})$ was stirred under nitrogen at room temperature. Subsequently, propargyl bromide (12.0 mmol, 1.2 equiv., $80 \%$ in toluene) was added dropwise. When the mixture became homogenous, the aldehyde (10.0 mmol, 1.0 equiv.) was added dropwise and the reaction was allowed to stir overnight. After the completion of the reaction (i.e. monitored by TLC), the mixture was quenched with saturated $\mathrm{NH}_{4} \mathrm{Cl}(30 \mathrm{~mL})$ and the layers were separated. The aqueous layer was extracted with $\mathrm{Et}_{2} \mathrm{O}(3 \times 20 \mathrm{~mL})$ and the combined organic layers were dried over $\mathrm{Na}_{2} \mathrm{SO}_{4}$. The volatiles were evaporated under reduced pressure and the crude product was purified by flash column chromatography to afford the corresponding propargylic alcohol.

A solution of propargylic alcohol (1.0 equiv.) in anhydrous $\mathrm{CH}_{2} \mathrm{Cl}_{2}(10 \mathrm{~mL})$ was added dropwise to a solution of DMP (1.2 equiv.) in anhydrous $\mathrm{CH}_{2} \mathrm{Cl}_{2}(20 \mathrm{~mL})$ under nitrogen at room temperature. The reaction was allowed to stir overnight and upon the completion of the reaction (i.e. monitored by TLC), the mixture was diluted with $\mathrm{Et}_{2} \mathrm{O}(30 \mathrm{~mL})$ and the layers were washed with $1 \mathrm{M} \mathrm{NaOH}(40 \mathrm{~mL})$. The aqueous layer was extracted with $\mathrm{Et}_{2} \mathrm{O}(3 \times 30 \mathrm{~mL})$ and the combined organic layers were washed with brine (30 $\mathrm{mL}$ ), dried over $\mathrm{Na}_{2} \mathrm{SO}_{4}$ and concentrated in vacuo. The residue was purified by flash column chromatography to yield the corresponding ketone allenes $\mathbf{1}$.

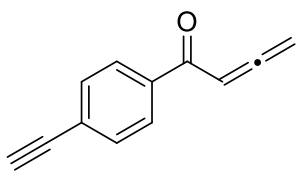

Following general procedure 1a, 1r was obtained as a biege solid (185 mg, $1.10 \mathrm{mmol}, 11 \%)$. M.p. $=46-$ $48^{\circ} \mathrm{C}$.

${ }^{1} \mathrm{H}$ NMR $\left(500 \mathrm{MHz}, \mathrm{CDCl}_{3}\right) \delta 7.85(\mathrm{~d}, J=8.6 \mathrm{~Hz}, 2 \mathrm{H}), 7.56(\mathrm{~d}, J=8.5 \mathrm{~Hz}, 2 \mathrm{H}), 6.41(\mathrm{t}, J=6.5 \mathrm{~Hz}, 1 \mathrm{H})$, $5.27(\mathrm{~d}, J=6.6 \mathrm{~Hz}, 2 \mathrm{H}), 3.24(\mathrm{~s}, 1 \mathrm{H})$.

${ }^{13} \mathrm{C} \mathrm{NMR}\left(126 \mathrm{MHz}, \mathrm{CDCl}_{3}\right) \delta 217.2,190.3,137.2,132.1,128.6,126.6,93.3,82.8,80.3,79.5$.

HRMS (ESI): $\mathrm{m} / \mathrm{z}$ calculated for $\mathrm{C}_{12} \mathrm{H}_{9} \mathrm{O}[\mathrm{M}+\mathrm{H}]^{+}: 169.0653$, found: 169.0654 .

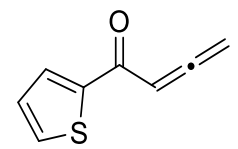

Following general procedure $1 \mathrm{~b}, 1 \mathrm{~s}$ was obtained as a brown oil $(81 \mathrm{mg}, 0.54 \mathrm{mmol}, 5 \%)$.

${ }^{1} \mathrm{H}$ NMR $\left(500 \mathrm{MHz}, \mathrm{CDCl}_{3}\right) \delta 7.83(\mathrm{dd}, J=3.9 \mathrm{~Hz}, 1.1 \mathrm{~Hz}, 1 \mathrm{H}), 7.64(\mathrm{dd}, J=5.0 \mathrm{~Hz}, 1.1 \mathrm{~Hz}, 1 \mathrm{H}), 7.12$ $(\mathrm{dd}, J=5.0 \mathrm{~Hz}, 3.9 \mathrm{~Hz}, 1 \mathrm{H}), 6.38(\mathrm{t}, J=6.6 \mathrm{~Hz}, 1 \mathrm{H}), 5.34(\mathrm{~d}, J=6.6 \mathrm{~Hz}, 2 \mathrm{H})$.

${ }^{13} \mathrm{C}$ NMR $\left(126 \mathrm{MHz}, \mathrm{CDCl}_{3}\right) \delta 216.1,182.0,143.8,133.9,132.5,128.0,93.4,80.0$.

HRMS (ESI): $\mathrm{m} / \mathrm{z}$ calculated for $\mathrm{C}_{8} \mathrm{H}_{7} \mathrm{OS}[\mathrm{M}+\mathrm{H}]^{+}: 151.0218$, found: 151.0218 . 


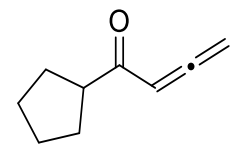

Following general procedure 1b, 1v was obtained as a yellowish oil (199 mg, $1.46 \mathrm{mmol}, 15 \%)$.

${ }^{1} \mathrm{H}$ NMR $\left(500 \mathrm{MHz}, \mathrm{CDCl}_{3}\right) \delta 5.79(\mathrm{t}, J=6.5 \mathrm{~Hz}, 1 \mathrm{H}), 5.22(\mathrm{~d}, J=6.5 \mathrm{~Hz}, 2 \mathrm{H}), 3.32(\mathrm{~m}, 1 \mathrm{H}), 1.83-1.73$ $(\mathrm{m}, 4 \mathrm{H}), 1.72-1.63(\mathrm{~m}, 2 \mathrm{H}), 1.61-1.54(\mathrm{~m}, 2 \mathrm{H})$.

${ }^{13} \mathrm{C}$ NMR (126 MHz, CDCl3) $\delta$ 216.6, 203.3, 96.2, 79.1, 47.7, 29.7, 26.2.

HRMS (ESI): m/z calculated for $\mathrm{C}_{9} \mathrm{H}_{13} \mathrm{O}[\mathrm{M}+\mathrm{H}]^{+}:$137.0966, found: 137.0966.

\section{II-2. Preparation of allenic esters ${ }^{2,3}$}

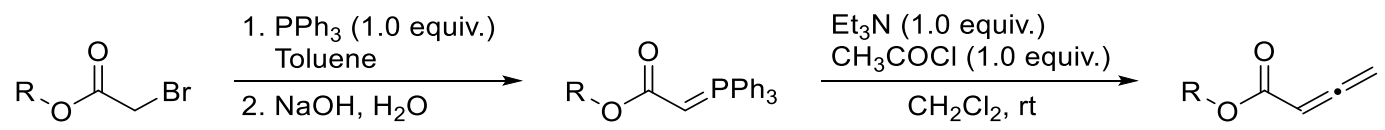

Allenic esters 1aa and 1ab were prepared using modified procedures. ${ }^{2}$ To a solution of bromoacetate (10.0 mmol, 1.0 equiv.) in toluene $(20 \mathrm{~mL})$ was added $\mathrm{PPh}_{3}(10.0 \mathrm{mmol}, 1.0$ equiv.) and the mixture was stirred overnight. The resulting white precipitate was filtered, washed with cold toluene and hexane, and dried under vacuum without further purification. The phosphonium salt was dissolved in deionized $\mathrm{H}_{2} \mathrm{O}$ (100 $\mathrm{mL}$ ) and $2 \mathrm{~N} \mathrm{NaOH}$ was added to the solution until the $\mathrm{pH}>7$, and the mixture was stirred for $30 \mathrm{~min}$. The resulting mixture was transferred to a separatory funnel and extracted with $\mathrm{CH}_{2} \mathrm{Cl}_{2}(3 \times 20 \mathrm{~mL})$. The combined organic layers were washed with brine $(30 \mathrm{~mL})$ and dried over $\mathrm{Na}_{2} \mathrm{SO}_{4}$. The volatiles were removed under reduced pressure to afford the corresponding stabilized ylide without any further purification which was used directly in the next step. The phosphorane was dissolved in $\mathrm{CH}_{2} \mathrm{Cl}_{2}(20 \mathrm{~mL})$ and $\mathrm{Et}_{3} \mathrm{~N}$ (1.0 equiv.) was added dropwise to the solution. Subsequently, a solution acetyl chloride (1.0 equiv.) in $\mathrm{CH}_{2} \mathrm{Cl}_{2}(10 \mathrm{~mL})$ was added dropwise to the mixture. After the completion of the reaction (i.e. monitored by TLC), the volatiles were evaporated under reduced pressure to afford a gummy residue and treated with hexane, stirred vigorously and allowed to sit undisturbed for 2 hours. The mixture was eventually filtered through celite and the filtrate was evaporated in vacuo. The crude product was purified by flash column chromatography to yield the pure allenic esters.

Menthol allenic ester 1ac was prepared according to the reported procedures. ${ }^{3}$

\footnotetext{
${ }^{2}$ Rout, L.; Harned, A.M. Allene Carboxylates as Dipolarophiles in Rh-Catalyzed Carbonyl Ylide Cycloadditions Chem. Eur. J. 2009, 15, 12926; (b) Cowen, B.J.; Saunders, L.B.; Miller, S.J. Pyridylalanine (Pal)-Peptide Catalyzed Enantioselective Allenoate Additions to N-Acyl Imines. J. Am. Chem. Soc. 2009, 131, 6105.

${ }^{3}$ Lin, L.-Z.; Che, Y.-Y.; Bai, P.-B.; Feng, C. Sulfinate-Engaged Nucleophilic Addition Induced Allylic Alkylation of Allenoates. Org. Lett. 2019, 21, 7424.
} 


\section{II-3. Preparation of allenic amides ${ }^{4}$}

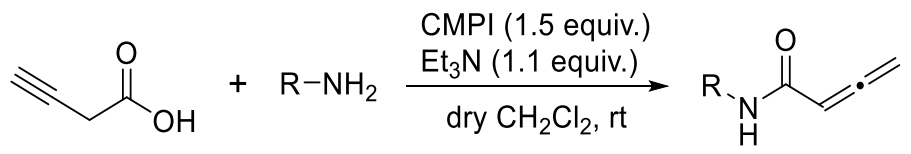

Allenic amides 1ad and 1ae were prepared according to the reported procedure. ${ }^{4}$<smiles>C=C=CC(=O)Nc1ccccc1</smiles>

Following the reported procedure, 1ad was obtained as a white solid (370 mg, 2.32 mmol, 23\%). M.p. = $112-114^{\circ} \mathrm{C}$.

${ }^{1} \mathrm{H}$ NMR (500 MHz, DMSO-d6) $\delta 9.99(\mathrm{~s}, 1 \mathrm{H}), 7.60(\mathrm{~d}, J=7.7 \mathrm{~Hz}, 2 \mathrm{H}), 7.31(\mathrm{t}, J=7.6 \mathrm{~Hz}, 2 \mathrm{H}), 7.05(\mathrm{t}, J$ $=7.4 \mathrm{~Hz}, 1 \mathrm{H}), 5.97(\mathrm{t}, J=6.6 \mathrm{~Hz}, 1 \mathrm{H}), 5.42(\mathrm{~d}, J=6.6 \mathrm{~Hz}, 2 \mathrm{H})$.

${ }^{13} \mathrm{C}$ NMR (126 MHz, DMSO-d6) $\delta$ 214.0, 162.6, 139.6, 129.2, 123.9, 119.7, 91.0, 80.7.

HRMS (ESI): $\mathrm{m} / \mathrm{z}$ calculated for $\mathrm{C}_{10} \mathrm{H}_{10} \mathrm{NO}[\mathrm{M}+\mathrm{H}]^{+}: 160.0762$, found: 160.0762 .

\section{II-4. Preparation of sulfinic acids ${ }^{5}$}

$$
\mathrm{R}-\mathrm{SO}_{2} \mathrm{Na} \underset{\mathrm{HCl}, \mathrm{H}_{2} \mathrm{O}}{\stackrel{t-\mathrm{BuOMe}}{\longrightarrow}} \mathrm{R}-\mathrm{SO}_{2} \mathrm{H}
$$

Sulfinic acids 2a-2l were prepared directly from the corresponding sodium salt using the reported procedure. $^{5}$

\footnotetext{
${ }^{4}$ Abbas, A.; Xing, B.; Loh, T.-P. Allenamides as Orthogonal Handles for Selective Modification of Cysteine in Peptides and Proteins. Angew. Chem. Int. Ed. 2014, 53, 7491.

${ }^{5}$ Liu, Y.; Xie, P.; Sun, Z.; Wo, X.; Gao, C.; Fu, W.; Loh, T.-P. Direct Substitution of Secondary and Tertiary Alcohols To Generate Sulfones under Catalyst- and Additive-Free Conditions. Org. Lett. 2018, 20, 5353.
} 


\section{Optimization Study}

Table 1: Screening of solvents ${ }^{a}$

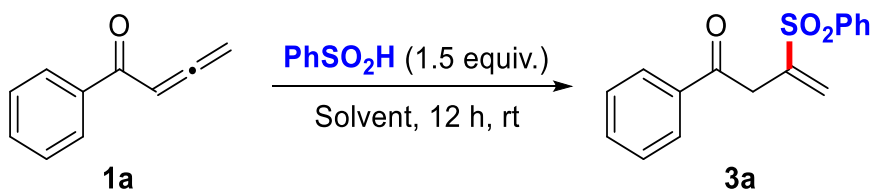

$1 \mathrm{a}$

$3 a$

\begin{tabular}{|c|c|c|c|}
\hline Entry & Solvent & Conversion $(\%)^{b}$ & Yield $(\%)^{b}$ \\
\hline 1 & PhMe & 100 & 13 \\
\hline 2 & $\mathrm{PhCF}_{3}$ & 100 & 18 \\
\hline 3 & $p$-xylene & 100 & 10 \\
\hline 4 & Mesitylene & 100 & 8 \\
\hline 5 & $\mathrm{Et}_{2} \mathrm{O}$ & 100 & 7 \\
\hline 6 & MTBE & 100 & 6 \\
\hline 7 & CPME & 100 & 7 \\
\hline 8 & 1,2-DME & 100 & 8 \\
\hline 9 & THF & 100 & 8 \\
\hline 10 & 1,4-dioxane & 100 & 12 \\
\hline 11 & EtOH & 100 & 75 \\
\hline 12 & $i \mathrm{PrOH}$ & 100 & 58 \\
\hline 13 & Cyclohexane & 100 & 18 \\
\hline 14 & $\mathrm{CH}_{3} \mathrm{CN}$ & 100 & 29 \\
\hline 15 & 1,2-DCE & 100 & 30 \\
\hline 16 & DMF & 100 & 37 \\
\hline 17 & $\mathrm{H}_{2} \mathrm{O}$ & 100 & 76 \\
\hline 18 & pH7 buffer & 100 & 75 \\
\hline 19 & $1 \mathrm{M} \mathrm{NaCl}$ & 100 & 67 \\
\hline 20 & $\mathrm{H}_{2} \mathrm{O}: \mathrm{EtOH}(1: 1)$ & 100 & $77^{c}$ \\
\hline
\end{tabular}

${ }^{a}$ Reaction Scale: 1a $(0.15 \mathrm{mmol})$ and $\mathrm{PhSO}_{2} \mathrm{H}(0.23 \mathrm{mmol})$ in the specified solvent $(1 \mathrm{~mL})$ was stirred at room temperature overnight. ${ }^{b}$ Conversion and yields were determined by ${ }^{1} \mathrm{H}$ NMR using $\mathrm{CH}_{2} \mathrm{I}_{2}$ as the internal standard. ${ }^{c}$ Isolated yield. 
Table 2: Kinetics study of the reaction ${ }^{a}$

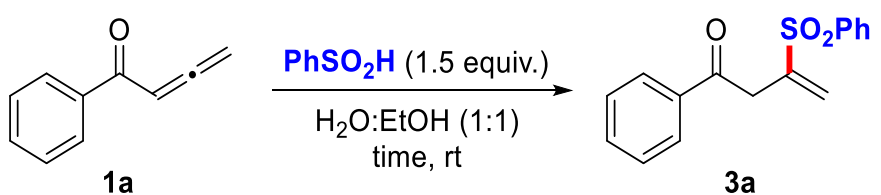

\begin{tabular}{cccc}
\hline Entry & Time (mins) & ${\text { Conversion }(\boldsymbol{\%})^{\boldsymbol{b}}}$ & ${\text { Yield }(\boldsymbol{\%})^{\boldsymbol{b}}}^{\mathbf{2}}$ \\
\hline 1 & 10 & 100 & 58 \\
2 & 20 & 100 & 61 \\
3 & 30 & 100 & 62 \\
4 & 40 & 100 & 66 \\
5 & 50 & 100 & 66 \\
$\mathbf{6}$ & $\mathbf{6 0}$ & $\mathbf{1 0 0}$ & $\mathbf{9 8}(\mathbf{9 9})^{\boldsymbol{c}}$ \\
$7^{d}$ & 60 & 91 & 58 \\
$8^{e}$ & 60 & 100 & 98 \\
\hline
\end{tabular}

${ }^{a}$ Reaction Scale: 1a $(0.15 \mathrm{mmol})$ and $\mathrm{PhSO}_{2} \mathrm{H}(0.23 \mathrm{mmol})$ in $\mathrm{H}_{2} \mathrm{O}: \mathrm{EtOH}(1: 1,1 \mathrm{~mL})$ was stirred at room temperature at the specified duration. ${ }^{b}$ Conversion and yields were determined by ${ }^{1} \mathrm{H}$ NMR using $\mathrm{CH}_{2} \mathrm{I}_{2}$ as the internal standard. ${ }^{c}$ Isolated yield. ${ }^{d} 1.0$ equiv. of $\mathrm{PhSO}_{2} \mathrm{H}$ was used. ${ }^{e} 2.0$ equiv. of $\mathrm{PhSO}_{2} \mathrm{H}$ was used.

IV. Experimental procedure for the water-based vinylic sulfination of allenic carbonyls \& spectroscopic data of compounds obtained in this study

\section{IV-1. General procedure for sulfination of 1a with sulfinic acids (Scheme 1)}

(a) A $3 \mathrm{~mL}$ vial was charged with allenic ketone $\mathbf{1 a}(0.15 \mathrm{mmol}, 1.0$ equiv.), sulfinic acid ( $0.23 \mathrm{mmol}, 1.5$ equiv.) and $\mathrm{H}_{2} \mathrm{O}: \mathrm{EtOH}(1: 1,1 \mathrm{~mL})$ under ambient conditions. The reaction was stirred at $25^{\circ} \mathrm{C}$ for $1 \mathrm{~h}$ and the mixture was diluted with $\mathrm{CH}_{2} \mathrm{Cl}_{2}(2 \mathrm{~mL})$ and the layers were separated. The organic layer was directly loaded into a column and purified by flash column chromatography ( $n$-hexane/EtOAc) to afford the corresponding vinylic sulfone 3 .

(b) Isolation by filtration (for solid products)

A $3 \mathrm{~mL}$ vial was charged with allenic ketone $1 \mathrm{a}(0.15 \mathrm{mmol}, 1.0$ equiv. $)$, sulfinic acid $(0.23 \mathrm{mmol}, 1.5$ equiv.) and $\mathrm{H}_{2} \mathrm{O}: \mathrm{EtOH}(1: 1,1 \mathrm{~mL})$ under ambient conditions. The reaction was stirred at $25^{\circ} \mathrm{C}$ for $1 \mathrm{~h}$ and the solid product obtained was filtered and washed with minimum amount of $\mathrm{H}_{2} \mathrm{O}$. The solid is collected and dried under vacuum to afford the pure vinylic sulfone $\mathbf{3}$.

(c) Gram scale reaction

A $100 \mathrm{~mL}$ RBF was charged with allenic ketone $1 \mathrm{a}(1.02 \mathrm{~g}, 7.07 \mathrm{mmol}, 1.0$ equiv.), sulfinic acid (1.51 g, 10.61 mmol, 1.5 equiv.) and $\mathrm{H}_{2} \mathrm{O}: \operatorname{EtOH}(1: 1,0.15 \mathrm{M})$ under ambient conditions. The reaction was stirred at $25{ }^{\circ} \mathrm{C}$ for $1 \mathrm{~h}$ and the mixture was extracted with $\mathrm{CH}_{2} \mathrm{Cl}_{2}(3 \times 20 \mathrm{~mL})$, dried over $\mathrm{Na}_{2} \mathrm{SO}_{4}$ and the volatiles were evaporated under reduced pressure. The crude product was directly loaded into a column and purified by flash column chromatography ( $n$-hexane/EtOAc) to afford the corresponding vinylic sulfone 3a as a beige solid (1.64 g, $5.73 \mathrm{mmol}, 81 \%)$. 


\section{1-phenyl-3-(phenylsulfonyl)but-3-en-1-one}<smiles>C=C(CC(=O)c1ccccc1)Sc1ccccc1</smiles>

Following the general procedure 1a, 3a was obtained as a beige solid (42.4 mg, 0.148 mmol, 99\%). M.p. = $75-76^{\circ} \mathrm{C}$. Spectroscopic data is line with reported literature. ${ }^{6}$

${ }^{1} \mathrm{H}$ NMR (500 MHz, $\left.\mathrm{CDCl}_{3}\right) \delta 7.91-7.84(\mathrm{~m}, 2 \mathrm{H}), 7.82-7.77(\mathrm{~m}, 2 \mathrm{H}), 7.61(\mathrm{t}, J=7.5 \mathrm{~Hz}, 1 \mathrm{H}), 7.56(\mathrm{t}, J$ $=7.4 \mathrm{~Hz}, 1 \mathrm{H}), 7.51(\mathrm{t}, J=7.8 \mathrm{~Hz}, 2 \mathrm{H}), 7.42(\mathrm{t}, J=7.8 \mathrm{~Hz}, 2 \mathrm{H}), 6.56(\mathrm{~s}, 1 \mathrm{H}), 5.93(\mathrm{~d}, J=0.8 \mathrm{~Hz}, 1 \mathrm{H}), 3.93$ (s, 2H).

${ }^{13} \mathrm{C}$ NMR $\left(126 \mathrm{MHz}, \mathrm{CDCl}_{3}\right) \delta 194.0,144.1,138.2,135.7,133.8,133.7,129.3,128.8,128.5,128.4,127.9$, 38.4 .

HRMS (ESI): m/z calculated for $\mathrm{C}_{16} \mathrm{H}_{15} \mathrm{O}_{3} \mathrm{~S}[\mathrm{M}+\mathrm{H}]^{+}:$: 287.0742, found: 287.0752.

\section{1-phenyl-3-tosylbut-3-en-1-one}<smiles>C=C(CC(=O)c1ccccc1)Sc1ccc(C)cc1</smiles>

Following the general procedure 1a, $\mathbf{3 b}$ was obtained as an orange oil (33.1 $\mathrm{mg}, 0.110 \mathrm{mmol}, 74 \%)$.

${ }^{1} \mathrm{H}$ NMR $\left(500 \mathrm{MHz}, \mathrm{CDCl}_{3}\right) \delta 7.80(\mathrm{~d}, J=8.3,2 \mathrm{H}), 7.74(\mathrm{~d}, J=8.3 \mathrm{~Hz}, 2 \mathrm{H}), 7.59-7.54(\mathrm{~m}, 1 \mathrm{H}), 7.42(\mathrm{~m}$, 2H), $7.29(\mathrm{~d}, J=8.0 \mathrm{~Hz}, 2 \mathrm{H}), 6.53(\mathrm{~s}, 1 \mathrm{H}), 5.89(\mathrm{~d}, J=1.0 \mathrm{~Hz}, 1 \mathrm{H}), 3.92(\mathrm{~d}, J=0.6 \mathrm{~Hz}, 2 \mathrm{H}), 2.42(\mathrm{~s}, 3 \mathrm{H})$.

${ }^{13} \mathrm{C} \mathrm{NMR}\left(126 \mathrm{MHz}, \mathrm{CDCl}_{3}\right) \delta 194.2,144.9,144.3,135.7,135.2,133.7,130.0,128.7,128.5,128.4,127.3$, 38.4, 21.6.

HRMS (ESI): $\mathrm{m} / \mathrm{z}$ calculated for $\mathrm{C}_{17} \mathrm{H}_{17} \mathrm{O}_{3} \mathrm{~S}[\mathrm{M}+\mathrm{H}]^{+}: 301.0898$, found: 301.0890 .

\footnotetext{
${ }^{6}$ Kippo, T.; Kimura, Y.; Ueda, M.; Fukuyama, T.; Ryu, I. Bromine-Radical-Mediated Synthesis of $\beta$-Functionalized $\beta, \gamma-$ and $\delta, \varepsilon$-Unsaturated Ketones via C-H Functionalization of Aldehydes. Synlett. 2017, 28, 1733.
} 


\section{3-((4-fluorophenyl)sulfonyl)-1-phenylbut-3-en-1-one}<smiles>C=C(CC(=O)c1ccccc1)Sc1ccc(F)cc1</smiles>

Following the general procedure 1a, 3c was obtained as a reddish oil (38.6 mg, $0.127 \mathrm{mmol}, 81 \%)$.

${ }^{1} \mathrm{H}$ NMR $\left(500 \mathrm{MHz}, \mathrm{CDCl}_{3}\right) \delta 7.90-7.84(\mathrm{~m}, 2 \mathrm{H}), 7.82(\mathrm{~d}, J=7.4 \mathrm{~Hz}, 2 \mathrm{H}), 7.58(\mathrm{t}, J=7.4 \mathrm{~Hz}, 1 \mathrm{H}), 7.44$ $(\mathrm{t}, J=7.8 \mathrm{~Hz}, 2 \mathrm{H}), 7.16(\mathrm{t}, J=8.5 \mathrm{~Hz}, 2 \mathrm{H}), 6.57(\mathrm{~s}, 1 \mathrm{H}), 5.95(\mathrm{~d}, J=0.6 \mathrm{~Hz}, 1 \mathrm{H}), 3.97(\mathrm{~s}, 2 \mathrm{H})$.

${ }^{13} \mathrm{C}$ NMR (126 MHz, CDCl3) $\delta 193.9,165.9$ (d, $\left.J=256.8 \mathrm{~Hz}\right), 144.0,135.7,134.3$ (d, $\left.J=3.0 \mathrm{~Hz}\right), 133.8$, $131.4(\mathrm{~d}, J=9.7 \mathrm{~Hz}), 128.8,128.3,116.6(\mathrm{~d}, J=22.7 \mathrm{~Hz}), 38.5$.

${ }^{19} \mathrm{~F}\left\{{ }^{1} \mathrm{H}\right\}$ NMR $\left(282 \mathrm{MHz}, \mathrm{CDCl}_{3}\right) \delta-103.16$.

HRMS (ESI): $\mathrm{m} / \mathrm{z}$ calculated for $\mathrm{C}_{16} \mathrm{H}_{14} \mathrm{FO}_{3} \mathrm{~S}[\mathrm{M}+\mathrm{H}]^{+}$: 305.0648, found: 305.0649 .

\section{3-((4-chlorophenyl)sulfonyl)-1-phenylbut-3-en-1-one}<smiles>C=C(CC(=O)c1ccccc1)Sc1ccc(Cl)cc1</smiles>

Following the general procedure $1 \mathrm{~b}, \mathbf{3 d}$ was obtained as an orange solid (38.9 mg, $0.121 \mathrm{mmol}, 79 \%)$. M.p. $=85-86^{\circ} \mathrm{C}$.

${ }^{1} \mathrm{H}$ NMR $\left(500 \mathrm{MHz}, \mathrm{CDCl}_{3}\right) \delta 7.80(\mathrm{~m}, 4 \mathrm{H}), 7.61-7.55(\mathrm{~m}, 1 \mathrm{H}), 7.49-7.41(\mathrm{~m}, 4 \mathrm{H}), 6.59(\mathrm{~s}, 1 \mathrm{H}), 5.97$ (d, $J=1.1 \mathrm{~Hz}, 1 \mathrm{H}), 3.96(\mathrm{~d}, J=0.7 \mathrm{~Hz}, 2 \mathrm{H})$.

${ }^{13} \mathrm{C} \mathrm{NMR}\left(126 \mathrm{MHz}, \mathrm{CDCl}_{3}\right) \delta 193.9,143.9,140.6,136.8,135.6,133.9,129.9,129.6,128.8,128.7,128.3$, 38.5.

HRMS (ESI): $\mathrm{m} / \mathrm{z}$ calculated for $\mathrm{C}_{16} \mathrm{H}_{14} \mathrm{ClO}_{3} \mathrm{~S}[\mathrm{M}+\mathrm{H}]^{+}: 321.0352$, found: 321.0361 .

\section{3-((4-bromophenyl)sulfonyl)-1-phenylbut-3-en-1-one}<smiles>C=C(CC(=O)c1ccccc1)Sc1ccc(Br)cc1</smiles>

Following the general procedure $1 \mathrm{~b}, \mathbf{3 e}$ was obtained as an orange solid (45.1 mg, $0.123 \mathrm{mmol}, 79 \%)$. M.p. $=102-104^{\circ} \mathrm{C}$. 
${ }^{1} \mathrm{H}$ NMR (500 MHz, $\left.\mathrm{CDCl}_{3}\right) \delta 7.83-7.78(\mathrm{~m}, 2 \mathrm{H}), 7.73-7.68(\mathrm{~m}, 2 \mathrm{H}), 7.65-7.61(\mathrm{~m}, 2 \mathrm{H}), 7.61-7.56$ $(\mathrm{m}, 1 \mathrm{H}), 7.44(\mathrm{t}, J=7.8 \mathrm{~Hz}, 2 \mathrm{H}), 6.59(\mathrm{~s}, 1 \mathrm{H}), 5.98(\mathrm{~d}, J=1.0 \mathrm{~Hz}, 1 \mathrm{H}), 3.96(\mathrm{~d}, J=0.7 \mathrm{~Hz}, 2 \mathrm{H})$.

${ }^{13} \mathrm{C}$ NMR $\left(126 \mathrm{MHz}, \mathrm{CDCl}_{3}\right) \delta 193.8,143.8,137.4,135.6,133.9,132.6,130.0,129.2,128.8,128.7,128.3$, 38.5.

HRMS (ESI): $\mathrm{m} / \mathrm{z}$ calculated for $\mathrm{C}_{16} \mathrm{H}_{14} \mathrm{BrO}_{3} \mathrm{~S}$ [M+H] $]^{+}: 364.9847$, found: 364.9851 .

\section{1-phenyl-3-((3-(trifluoromethyl)phenyl)sulfonyl)but-3-en-1-one}<smiles>C=C(CC(=O)c1ccccc1)Sc1cccc(C(F)(F)F)c1</smiles>

Following the general procedure $1 \mathrm{~b}, \mathbf{3 f}$ was obtained as an orange solid (46.0 mg, $0.130 \mathrm{mmol}, 86 \%)$. M.p. $=73-74{ }^{\circ} \mathrm{C}$.

${ }^{1} \mathrm{H}$ NMR $\left(500 \mathrm{MHz}, \mathrm{CDCl}_{3}\right) \delta 8.11(\mathrm{~s}, 1 \mathrm{H}), 8.06(\mathrm{~d}, J=7.9 \mathrm{~Hz}, 1 \mathrm{H}), 7.85(\mathrm{~d}, J=7.8 \mathrm{~Hz}, 1 \mathrm{H}), 7.80(\mathrm{dd}, J$ $=8.3,1.1 \mathrm{~Hz}, 2 \mathrm{H}), 7.66(\mathrm{t}, J=7.9 \mathrm{~Hz}, 1 \mathrm{H}), 7.61-7.55(\mathrm{~m}, 1 \mathrm{H}), 7.44(\mathrm{t}, J=7.8 \mathrm{~Hz}, 2 \mathrm{H}), 6.66(\mathrm{~s}, 1 \mathrm{H}), 6.04$ $(\mathrm{d}, J=1.1 \mathrm{~Hz}, 1 \mathrm{H}), 3.99(\mathrm{~d}, J=0.8 \mathrm{~Hz}, 2 \mathrm{H})$.

${ }^{13} \mathrm{C}$ NMR (126 MHz, CDCl3) $\delta$ 193.6, 143.5, 139.9, 135.5, 133.9, 132.1, 131.8 (d, $\left.J=5.2 \mathrm{~Hz}\right), 130.4$ (d, $J$ $=3.5 \mathrm{~Hz}), 130.1,129.7,128.9,128.3,125.5(\mathrm{~d}, J=3.8 \mathrm{~Hz}), 121.9,38.6$.

${ }^{19} \mathrm{~F}\left\{{ }^{1} \mathrm{H}\right\}$ NMR $\left(282 \mathrm{MHz}, \mathrm{CDCl}_{3}\right) \delta-62.87$.

HRMS (ESI): m/z calculated for $\mathrm{C}_{17} \mathrm{H}_{14} \mathrm{~F}_{3} \mathrm{O}_{3} \mathrm{~S}[\mathrm{M}+\mathrm{H}]^{+}$: 355.0616, found: 355.0620 .

\section{3-((3-chloro-4-methylphenyl)sulfonyl)-1-phenylbut-3-en-1-one}<smiles>C=C(CC(=O)c1ccccc1)Sc1ccc(C)c(Cl)c1</smiles>

Following the general procedure 1a, $\mathbf{3 g}$ was obtained as a brown solid (41.3 mg, $0.123 \mathrm{mmol}, 83 \%)$. M.p. $=64-66^{\circ} \mathrm{C}$.

${ }^{1} \mathrm{H}$ NMR $\left(500 \mathrm{MHz}, \mathrm{CDCl}_{3}\right) \delta 7.81(\mathrm{~m}, 3 \mathrm{H}), 7.63(\mathrm{dd}, J=8.0,1.9 \mathrm{~Hz}, 1 \mathrm{H}), 7.60-7.55(\mathrm{~m}, 1 \mathrm{H}), 7.44(\mathrm{t}, J$ $=7.8 \mathrm{~Hz}, 2 \mathrm{H}), 7.35(\mathrm{~d}, J=8.0 \mathrm{~Hz}, 1 \mathrm{H}), 6.57(\mathrm{~s}, 1 \mathrm{H}), 5.96(\mathrm{~d}, J=1.1 \mathrm{~Hz}, 1 \mathrm{H}), 3.94(\mathrm{~d}, J=0.6 \mathrm{~Hz}, 2 \mathrm{H})$, $2.42(\mathrm{~s}, 3 \mathrm{H})$.

${ }^{13} \mathrm{C}$ NMR $\left(126 \mathrm{MHz}, \mathrm{CDCl}_{3}\right) \delta 194.0,143.9,142.9,137.2,135.6,135.5,133.8,131.7,128.9,128.8,128.4$, $128.4,126.6,38.4,20.4$.

HRMS (ESI): $\mathrm{m} / \mathrm{z}$ calculated for $\mathrm{C}_{17} \mathrm{H}_{16} \mathrm{ClO}_{3} \mathrm{~S}[\mathrm{M}+\mathrm{H}]^{+}:$335.0509, found: 335.0509 . 


\section{3-(naphthalen-2-ylsulfonyl)-1-phenylbut-3-en-1-one}<smiles>C=C(CC(=O)c1ccccc1)Sc1ccc2ccccc2c1</smiles>

Following the general procedure 1a, $3 \mathbf{h}$ was obtained as a brown oil (39.7 mg, $0.118 \mathrm{mmol}, 78 \%)$.

${ }^{1} \mathrm{H}$ NMR $(500 \mathrm{MHz}, \mathrm{CDCl} 3) \delta 8.45(\mathrm{~s}, 1 \mathrm{H}), 7.95(\mathrm{~d}, J=8.7 \mathrm{~Hz}, 1 \mathrm{H}), 7.90(\mathrm{~d}, J=8.7 \mathrm{~Hz}, 2 \mathrm{H}), 7.79(\mathrm{dd}, J$ $=8.7,1.8 \mathrm{~Hz}, 1 \mathrm{H}), 7.74-7.70(\mathrm{~m}, 2 \mathrm{H}), 7.69-7.64(\mathrm{~m}, 1 \mathrm{H}), 7.60(\mathrm{~m}, 1 \mathrm{H}), 7.50(\mathrm{t}, J=7.4 \mathrm{~Hz}, 1 \mathrm{H}), 7.32$ (t, $J=7.8 \mathrm{~Hz}, 2 \mathrm{H}), 6.63(\mathrm{~s}, 1 \mathrm{H}), 5.97(\mathrm{~d}, J=0.8 \mathrm{~Hz}, 1 \mathrm{H}), 3.96(\mathrm{~s}, 2 \mathrm{H})$.

${ }^{13} \mathrm{C}$ NMR $(126 \mathrm{MHz}, \mathrm{CDCl} 3) \delta 194.1,144.1,135.7,135.3,135.0,133.7,132.1,130.5,129.7,129.4,129.4$, 128.7, 128.3, 128.0, 128.0, 127.7, 123.0, 38.4.

HRMS (ESI): m/z calculated for $\mathrm{C}_{20} \mathrm{H}_{17} \mathrm{O}_{3} \mathrm{~S}[\mathrm{M}+\mathrm{H}]^{+}: 337.0898$, found: 337.0898 .

\section{3-(methylsulfonyl)-1-phenylbut-3-en-1-one}<smiles>C=C(CC(=O)c1ccccc1)S(C)(C)C</smiles>

Following the general procedure 1a, 3i was obtained as a brown oil (28.4 mg, $0.127 \mathrm{mmol}, 83 \%)$.

${ }^{1} \mathrm{H}$ NMR $\left(500 \mathrm{MHz}, \mathrm{CDCl}_{3}\right) \delta 8.02-7.97(\mathrm{~m}, 2 \mathrm{H}), 7.66-7.60(\mathrm{~m}, 1 \mathrm{H}), 7.51(\mathrm{t}, J=7.8 \mathrm{~Hz}, 2 \mathrm{H}), 6.52(\mathrm{~d}$, $J=0.6 \mathrm{~Hz}, 1 \mathrm{H}), 5.98(\mathrm{~d}, J=0.9 \mathrm{~Hz}, 1 \mathrm{H}), 4.25(\mathrm{~d}, J=0.8 \mathrm{~Hz}, 2 \mathrm{H}), 3.03(\mathrm{~s}, 3 \mathrm{H})$.

${ }^{13} \mathrm{C}$ NMR $\left(126 \mathrm{MHz}, \mathrm{CDCl}_{3}\right) \delta 195.0,144.8,135.7,134.1,129.7,129.0,128.4,42.6,40.4$.

HRMS (ESI): m/z calculated for $\mathrm{C}_{11} \mathrm{H}_{13} \mathrm{O}_{3} \mathrm{~S}[\mathrm{M}+\mathrm{H}]^{+}: 225.0585$, found: 225.0585.

\section{3-(ethylsulfonyl)-1-phenylbut-3-en-1-one}<smiles>C=C(CC(=O)c1ccccc1)SCC</smiles>

Following the general procedure 1a, $\mathbf{3 j}$ was obtained as a brown oil ( $34.3 \mathrm{mg}, 0.144 \mathrm{mmol}, 98 \%$ ).

${ }^{1} \mathrm{H}$ NMR (500 MHz, $\left.\mathrm{CDCl}_{3}\right) \delta 8.01-7.97(\mathrm{~m}, 2 \mathrm{H}), 7.62(\mathrm{t}, J=7.4 \mathrm{~Hz}, 1 \mathrm{H}), 7.50(\mathrm{t}, J=7.8 \mathrm{~Hz}, 2 \mathrm{H}), 6.47$ $(\mathrm{s}, 1 \mathrm{H}), 6.03(\mathrm{~d}, J=0.6 \mathrm{~Hz}, 1 \mathrm{H}), 4.21(\mathrm{~d}, J=0.6 \mathrm{~Hz}, 2 \mathrm{H}), 3.07(\mathrm{q}, J=7.4 \mathrm{~Hz}, 2 \mathrm{H}), 1.38(\mathrm{t}, J=7.4 \mathrm{~Hz}, 3 \mathrm{H})$.

${ }^{13} \mathrm{C}$ NMR $\left(126 \mathrm{MHz}, \mathrm{CDCl}_{3}\right) \delta 195.1,142.5,135.7,134.0,131.1,128.9,128.4,48.3,40.1,6.9$.

HRMS (ESI): m/z calculated for $\mathrm{C}_{12} \mathrm{H}_{15} \mathrm{O}_{3} \mathrm{~S}[\mathrm{M}+\mathrm{H}]^{+}:$: 239.0742, found: 239.0747 . 


\section{3-(cyclopropylsulfonyl)-1-phenylbut-3-en-1-one}<smiles>C=C(CC(=O)c1ccccc1)SC1CC1</smiles>

Following the general procedure 1a, 3k was obtained as a brown oil (30.0 mg, $0.120 \mathrm{mmol}, 81 \%)$.

${ }^{1} \mathrm{H}$ NMR $\left(500 \mathrm{MHz}, \mathrm{CDCl}_{3}\right) \delta 8.03-7.98(\mathrm{~m}, 2 \mathrm{H}), 7.62(\mathrm{t}, J=7.4 \mathrm{~Hz}, 1 \mathrm{H}), 7.50(\mathrm{t}, J=7.8 \mathrm{~Hz}, 2 \mathrm{H}), 6.44$ $(\mathrm{s}, 1 \mathrm{H}), 5.92(\mathrm{~d}, J=0.6 \mathrm{~Hz}, 1 \mathrm{H}), 4.19(\mathrm{~s}, 2 \mathrm{H}), 2.49-2.42(\mathrm{~m}, 1 \mathrm{H}), 1.26-1.21(\mathrm{~m}, 2 \mathrm{H}), 1.05-1.00(\mathrm{~m}$, $2 \mathrm{H})$.

${ }^{13} \mathrm{C}$ NMR $\left(126 \mathrm{MHz}, \mathrm{CDCl}_{3}\right) \delta 194.7,143.9,135.8,133.9,128.9,128.7,128.4,39.8,30.4,5.7$.

HRMS (ESI): $\mathrm{m} / \mathrm{z}$ calculated for $\mathrm{C}_{13} \mathrm{H}_{15} \mathrm{O}_{3} \mathrm{~S}[\mathrm{M}+\mathrm{H}]^{+}:$251.0742, found: 251.0745.

\section{3-(cyclohexylsulfonyl)-1-phenylbut-3-en-1-one}<smiles>C=C(CC(=O)c1ccccc1)SC1CCCCC1</smiles>

Following the general procedure 1a, 31 was obtained as a brown oil (37.2 $\mathrm{mg}, 0.127 \mathrm{mmol}, 86 \%)$.

${ }^{1} \mathrm{H}$ NMR (500 MHz, CDCl3) $\delta 8.03-7.97(\mathrm{~m}, 2 \mathrm{H}), 7.64-7.59(\mathrm{~m}, 1 \mathrm{H}), 7.50(\mathrm{~m}, 2 \mathrm{H}), 6.42(\mathrm{~s}, 1 \mathrm{H}), 6.05$ $(\mathrm{d}, J=0.5 \mathrm{~Hz}, 1 \mathrm{H}), 4.16(\mathrm{~d}, J=0.7 \mathrm{~Hz}, 2 \mathrm{H}), 2.85(\mathrm{~m}, 1 \mathrm{H}), 2.22-2.14(\mathrm{~m}, 2 \mathrm{H}), 1.95-1.86(\mathrm{~m}, 2 \mathrm{H}), 1.71$ - 1.69 (m, 2H), $1.51-1.46(\mathrm{~m}, 2 \mathrm{H}), 1.33-1.18(\mathrm{~m}, 3 \mathrm{H})$.

${ }^{13} \mathrm{C}$ NMR (126 MHz, $\left.\mathrm{CDCl}_{3}\right) \delta 195.0,141.1,135.8,133.9,131.6,128.9,128.5,60.7,39.9,25.2,25.1,24.7$. HRMS (ESI): m/z calculated for $\mathrm{C}_{16} \mathrm{H}_{21} \mathrm{O}_{3} \mathrm{~S}[\mathrm{M}+\mathrm{H}]^{+}:$: 293.1211, found: 293.1213 .

\section{IV-2. General procedure for sulfination of allenic carbonyls with benzene sulfinic acid (Scheme 2)}

A $3 \mathrm{~mL}$ vial was charged with allenic carbonyl compound 1 ( $0.15 \mathrm{mmol}, 1.0$ equiv.), benzene sulfinic acid 2a (0.23 mmol, 1.5 equiv.) and $\mathrm{H}_{2} \mathrm{O}: \mathrm{EtOH}(1: 1,1 \mathrm{~mL})$ under ambient conditions. The reaction was stirred at $25^{\circ} \mathrm{C}$ for $1 \mathrm{~h}$ and the mixture was diluted with $\mathrm{CH}_{2} \mathrm{Cl}_{2}(2 \mathrm{~mL})$ and the layers were separated. The organic layer was directly loaded into a column and purified by flash column chromatography ( $n$-hexane/EtOAc) to afford the corresponding vinylic sulfone 3 . 


\section{1-(4-fluorophenyl)-3-(phenylsulfonyl)but-3-en-1-one}<smiles>C=C(CC(=O)c1ccc(F)cc1)S(=O)(=O)c1ccccc1</smiles>

Following the general procedure, $\mathbf{3 m}$ was obtained as a brown oil (38.5 mg, $0.127 \mathrm{mmol}, 85 \%)$.

${ }^{1} \mathrm{H}$ NMR $\left(500 \mathrm{MHz}, \mathrm{CDCl}_{3}\right) \delta 7.90-7.82(\mathrm{~m}, 4 \mathrm{H}), 7.63(\mathrm{t}, J=7.5 \mathrm{~Hz}, 1 \mathrm{H}), 7.52(\mathrm{t}, J=7.8 \mathrm{~Hz}, 2 \mathrm{H}), 7.14$ $-7.06(\mathrm{~m}, 2 \mathrm{H}), 6.55(\mathrm{~s}, 1 \mathrm{H}), 5.92(\mathrm{~d}, J=1.1 \mathrm{~Hz}, 1 \mathrm{H}), 3.90(\mathrm{~d}, J=0.7 \mathrm{~Hz}, 2 \mathrm{H})$.

${ }^{13} \mathrm{C}$ NMR (126 MHz, CDCl3) $\delta 192.5,166.1(\mathrm{~d}, J=256.1 \mathrm{~Hz}), 144.0,138.2,133.9,132.1(\mathrm{~d}, J=3.0 \mathrm{~Hz})$, $131.2(\mathrm{~d}, J=9.5 \mathrm{~Hz}), 129.4,128.5,127.9,116.0(\mathrm{~d}, J=22.0 \mathrm{~Hz}), 38.4$.

${ }^{19} \mathrm{~F}\left\{{ }^{1} \mathrm{H}\right\}$ NMR $\left(282 \mathrm{MHz}, \mathrm{CDCl}_{3}\right) \delta-103.71$.

HRMS (ESI): $\mathrm{m} / \mathrm{z}$ calculated for $\mathrm{C}_{16} \mathrm{H}_{14} \mathrm{FO}_{3} \mathrm{~S}[\mathrm{M}+\mathrm{H}]^{+}: 305.0648$, found: 305.0648 .

\section{1-(4-chlorophenyl)-3-(phenylsulfonyl)but-3-en-1-one}<smiles>C=C(CC(=O)c1ccc(Cl)cc1)S(=O)(=O)c1ccccc1</smiles>

Following the general procedure, 3n was obtained as an orange oil (35.8 mg, $0.112 \mathrm{mmol}, 74 \%)$.

${ }^{1} \mathrm{H}$ NMR $\left(500 \mathrm{MHz}, \mathrm{CDCl}_{3}\right) \delta 7.87(\mathrm{dd}, J=8.4,1.1 \mathrm{~Hz}, 2 \mathrm{H}), 7.78-7.73(\mathrm{~m}, 2 \mathrm{H}), 7.66-7.61(\mathrm{~m}, 1 \mathrm{H})$, $7.52(\mathrm{~m}, 2 \mathrm{H}), 7.43-7.38(\mathrm{~m}, 2 \mathrm{H}), 6.55(\mathrm{~s}, 1 \mathrm{H}), 5.91(\mathrm{~d}, J=1.1 \mathrm{~Hz}, 1 \mathrm{H}), 3.90(\mathrm{~d}, J=0.6 \mathrm{~Hz}, 2 \mathrm{H})$.

${ }^{13} \mathrm{C} \mathrm{NMR}\left(126 \mathrm{MHz}, \mathrm{CDCl}_{3}\right) \delta 192.9,143.9,140.3,138.1,134.0,133.9,129.8,129.4,129.1,128.5,127.9$, 38.4.

HRMS (ESI): $\mathrm{m} / \mathrm{z}$ calculated for $\mathrm{C}_{16} \mathrm{H}_{14} \mathrm{ClO}_{3} \mathrm{~S}[\mathrm{M}+\mathrm{H}]^{+}:$321.0352, found: 321.0350 .

\section{1-(2,6-dichlorophenyl)-3-(phenylsulfonyl)but-3-en-1-one}<smiles>C=C(CC(=O)c1c(Cl)cccc1Cl)S(=O)(=O)c1ccccc1</smiles>

Following the general procedure, $\mathbf{3 o}$ was obtained as a yellowish oil (42.4 mg, $0.119 \mathrm{mmol}, 79 \%)$.

${ }^{1} \mathrm{H}$ NMR $\left(500 \mathrm{MHz}, \mathrm{CDCl}_{3}\right) \delta 7.94-7.89(\mathrm{~m}, 2 \mathrm{H}), 7.62(\mathrm{~m}, 1 \mathrm{H}), 7.53(\mathrm{t}, J=7.7 \mathrm{~Hz}, 2 \mathrm{H}), 7.28-7.25(\mathrm{~m}$, $3 \mathrm{H}), 6.77(\mathrm{~s}, 1 \mathrm{H}), 6.24(\mathrm{~d}, J=0.8 \mathrm{~Hz}, 1 \mathrm{H}), 3.88(\mathrm{~d}, J=0.7 \mathrm{~Hz}, 2 \mathrm{H})$.

${ }^{13} \mathrm{C}$ NMR $\left(126 \mathrm{MHz}, \mathrm{CDCl}_{3}\right) \delta 195.3,141.4,138.4,138.2,133.8,131.1,130.5,129.5,129.2,128.6,128.2$, 42.5 .

HRMS (ESI): $\mathrm{m} / \mathrm{z}$ calculated for $\mathrm{C}_{16} \mathrm{H}_{13} \mathrm{Cl}_{2} \mathrm{O}_{3} \mathrm{~S}[\mathrm{M}+\mathrm{H}]^{+}:$354.9962, found: 354.9962 . 


\section{1-(4-bromophenyl)-3-(phenylsulfonyl)but-3-en-1-one}<smiles>C=C(CC(=O)c1ccc(Br)cc1)S(=O)(=O)c1ccccc1</smiles>

Following the general procedure, $\mathbf{3 p}$ was obtained as a brown oil (46.6 mg, $0.128 \mathrm{mmol}, 86 \%$ ).

${ }^{1} \mathrm{H}$ NMR $\left(500 \mathrm{MHz}, \mathrm{CDCl}_{3}\right) \delta 7.87(\mathrm{dd}, J=8.4,1.1 \mathrm{~Hz}, 2 \mathrm{H}), 7.70-7.65(\mathrm{~m}, 2 \mathrm{H}), 7.65-7.61(\mathrm{~m}, 1 \mathrm{H})$, $7.59-7.55(\mathrm{~m}, 2 \mathrm{H}), 7.52(\mathrm{~m}, 2 \mathrm{H}), 6.55(\mathrm{~s}, 1 \mathrm{H}), 5.91(\mathrm{~d}, J=1.1 \mathrm{~Hz}, 1 \mathrm{H}), 3.89(\mathrm{~d}, J=0.6 \mathrm{~Hz}, 2 \mathrm{H})$.

${ }^{13} \mathrm{C} \mathrm{NMR}\left(126 \mathrm{MHz}, \mathrm{CDCl}_{3}\right) \delta 193.1,143.9,138.1,134.4,133.9,132.1,129.9,129.4,129.1,128.5,127.9$, 38.4 .

HRMS (ESI): $\mathrm{m} / \mathrm{z}$ calculated for $\mathrm{C}_{16} \mathrm{H}_{14} \mathrm{BrO}_{3} \mathrm{~S}[\mathrm{M}+\mathrm{H}]^{+}: 364.9847$, found: 364.9846.

\section{1-(2-nitrophenyl)-3-(phenylsulfonyl)but-3-en-1-one}<smiles>C=C(CC(=O)c1ccccc1[N+](=O)[O-])S(=O)(=O)c1ccccc1</smiles>

Following the general procedure, $\mathbf{3 q}$ was obtained as a yellowish oil (23.4 mg, $0.071 \mathrm{mmol}, 47 \%)$.

${ }^{1} \mathrm{H}$ NMR $\left(500 \mathrm{MHz}, \mathrm{CDCl}_{3}\right) \delta 8.11(\mathrm{dd}, J=8.2,0.8 \mathrm{~Hz}, 1 \mathrm{H}), 7.87(\mathrm{dd}, J=8.3,1.1 \mathrm{~Hz}, 2 \mathrm{H}), 7.72(\mathrm{td}, J=$ 7.5, 1.1 Hz, 1H), $7.67-7.59(\mathrm{~m}, 2 \mathrm{H}), 7.54(\mathrm{~m}, 2 \mathrm{H}), 7.39$ (dd, $J=7.6,1.3 \mathrm{~Hz}, 1 \mathrm{H}), 6.59(\mathrm{~d}, J=0.7 \mathrm{~Hz}, 1 \mathrm{H})$, $6.17(\mathrm{~d}, J=1.0 \mathrm{~Hz}, 1 \mathrm{H}), 3.81(\mathrm{~d}, J=0.9 \mathrm{~Hz}, 2 \mathrm{H})$.

${ }^{13} \mathrm{C} \mathrm{NMR}\left(126 \mathrm{MHz}, \mathrm{CDCl}_{3}\right) \delta 196.2,145.4,142.9,138.1,136.7,134.6,133.9,131.0,129.4,129.3,128.4$, $128.1,124.4,42.3$.

HRMS (ESI): $\mathrm{m} / \mathrm{z}$ calculated for $\mathrm{C}_{16} \mathrm{H}_{14} \mathrm{NO}_{5} \mathrm{~S}[\mathrm{M}+\mathrm{H}]^{+}: 332.0593$, found: 332.0593 .

\section{1-(4-ethynylphenyl)-3-(phenylsulfonyl)but-3-en-1-one}

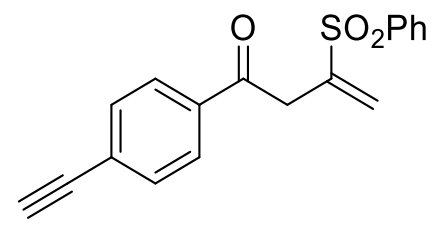

Following the general procedure, $\mathbf{3 r}$ was obtained as a white flaky solid (40.5 mg, $0.130 \mathrm{mmol}, 87 \%)$. M.p. $=107-108^{\circ} \mathrm{C}$.

${ }^{1} \mathrm{H}$ NMR $\left(500 \mathrm{MHz}, \mathrm{CDCl}_{3}\right) \delta 7.87(\mathrm{~m}, 2 \mathrm{H}), 7.77-7.73(\mathrm{~m}, 2 \mathrm{H}), 7.65-7.60(\mathrm{~m}, 1 \mathrm{H}), 7.55-7.49(\mathrm{~m}, 4 \mathrm{H})$, $6.56(\mathrm{~s}, 1 \mathrm{H}), 5.92(\mathrm{~d}, J=1.1 \mathrm{~Hz}, 1 \mathrm{H}), 3.92(\mathrm{~d}, J=0.7 \mathrm{~Hz}, 2 \mathrm{H}), 3.28(\mathrm{~s}, 1 \mathrm{H})$.

${ }^{13} \mathrm{C}$ NMR $\left(126 \mathrm{MHz}, \mathrm{CDCl}_{3}\right) \delta 193.3,143.9,138.2,135.3,133.9,132.4,129.4,128.5,128.3,128.0,127.6$, $82.5,81.0,38.5$.

HRMS (ESI): m/z calculated for $\mathrm{C}_{18} \mathrm{H}_{15} \mathrm{O}_{3} \mathrm{~S}[\mathrm{M}+\mathrm{H}]^{+}: 311.0742$, found: 311.0742 . 


\section{3-(phenylsulfonyl)-1-(thiophen-2-yl)but-3-en-1-one}<smiles>C=C(CC(=O)c1cccs1)S(=O)(=O)c1ccccc1</smiles>

Following the general procedure, $3 \mathrm{~s}$ was obtained as a yellowish oil (39.0 mg, $0.133 \mathrm{mmol}, 89 \%)$.

${ }^{1} \mathrm{H}$ NMR $\left(500 \mathrm{MHz}, \mathrm{CDCl}_{3}\right) \delta 7.90-7.84(\mathrm{~m}, 2 \mathrm{H}), 7.66(\mathrm{dd}, J=4.9,1.1 \mathrm{~Hz}, 1 \mathrm{H}), 7.64-7.59(\mathrm{~m}, 2 \mathrm{H})$, $7.54-7.48(\mathrm{~m}, 2 \mathrm{H}), 7.10(\mathrm{dd}, J=4.9,3.9 \mathrm{~Hz}, 1 \mathrm{H}), 6.57(\mathrm{~s}, 1 \mathrm{H}), 6.01(\mathrm{~d}, J=1.1 \mathrm{~Hz}, 1 \mathrm{H}), 3.86(\mathrm{~d}, J=0.7$ $\mathrm{Hz}, 2 \mathrm{H})$.

${ }^{13} \mathrm{C}$ NMR $\left(126 \mathrm{MHz}, \mathrm{CDCl}_{3}\right) \delta 186.7,143.7,142.9,138.1,135.0,133.9,133.1,129.3,128.5,128.4,127.9$, 38.9.

HRMS (ESI): $\mathrm{m} / \mathrm{z}$ calculated for $\mathrm{C}_{14} \mathrm{H}_{13} \mathrm{O}_{3} \mathrm{~S}_{2}[\mathrm{M}+\mathrm{H}]^{+}:$293.0306, found: 293.0306 .

\section{1-(furan-2-yl)-3-(phenylsulfonyl)but-3-en-1-one}<smiles>C=C(CC(=O)c1ccco1)S(=O)(=O)O</smiles>

Following the general procedure, $\mathbf{3 t}$ was obtained as a yellowish oil (18.3 $\mathrm{mg}, 0.066 \mathrm{mmol}, 43 \%)$.

${ }^{1} \mathrm{H}$ NMR $\left(500 \mathrm{MHz}, \mathrm{CDCl}_{3}\right) \delta 7.87(\mathrm{~d}, \mathrm{~J}=7.4 \mathrm{~Hz}, 2 \mathrm{H}), 7.61(\mathrm{t}, \mathrm{J}=7.4 \mathrm{~Hz}, 1 \mathrm{H}), 7.54(\mathrm{~s}, 1 \mathrm{H}), 7.51(\mathrm{t}, \mathrm{J}=$ $7.7 \mathrm{~Hz}, 2 \mathrm{H}), 7.14(\mathrm{~d}, \mathrm{~J}=3.5 \mathrm{~Hz}, 1 \mathrm{H}), 6.57(\mathrm{~s}, 1 \mathrm{H}), 6.51(\mathrm{dd}, \mathrm{J}=3.5,1.6 \mathrm{~Hz}, 1 \mathrm{H}), 6.01(\mathrm{~s}, 1 \mathrm{H}), 3.80(\mathrm{~s}, 2 \mathrm{H})$.

${ }^{13} \mathrm{C}$ NMR $\left(126 \mathrm{MHz}, \mathrm{CDCl}_{3}\right) \delta 182.6,151.6,147.0,143.4,138.2,133.8,129.2,128.5,128.0,118.4,112.7$, 38.1 .

HRMS (ESI): $\mathrm{m} / \mathrm{z}$ calculated for $\mathrm{C}_{14} \mathrm{H}_{13} \mathrm{O}_{4} \mathrm{~S}[\mathrm{M}+\mathrm{H}]^{+}:$: 277.0535, found: 277.0534.

\section{1-phenyl-3-(phenylsulfonyl)pent-3-en-1-one}<smiles>CC(=CC(=O)c1ccccc1)S(=O)(=O)c1ccccc1</smiles>

Following the general procedure, $3 \mathbf{u}$ was obtained as a brown oil (26.5 mg, $0.088 \mathrm{mmol}, 57 \%)$.

${ }^{1} \mathrm{H}$ NMR (500 MHz, $\left.\mathrm{CDCl}_{3}\right) \delta 7.80(\mathrm{~m}, 4 \mathrm{H}), 7.57(\mathrm{~m}, 1 \mathrm{H}), 7.54-7.49(\mathrm{~m}, 1 \mathrm{H}), 7.42(\mathrm{~m}, 4 \mathrm{H}), 7.31(\mathrm{q}, J=$ $7.1 \mathrm{~Hz}, 1 \mathrm{H}), 4.06$ (s, 2H), 1.83 (d, $J=7.1 \mathrm{~Hz}, 3 \mathrm{H})$.

${ }^{13} \mathrm{C}$ NMR $\left(126 \mathrm{MHz}, \mathrm{CDCl}_{3}\right) \delta 192.8,141.5,139.1,136.0,135.9,133.5,133.3,129.0,128.7,128.2,128.1$, 35.4, 14.9 .

HRMS (ESI): m/z calculated for $\mathrm{C}_{17} \mathrm{H}_{17} \mathrm{O}_{3} \mathrm{~S}[\mathrm{M}+\mathrm{H}]^{+}: 301.0898$, found: 301.0896 . 


\section{1-cyclopentyl-3-(phenylsulfonyl)but-3-en-1-one}<smiles>C=C(CC(=O)C1CCCC1)S(=O)(=O)Oc1ccccc1</smiles>

Following the general procedure, $\mathbf{3 v}$ was obtained as a colorless oil (26.7 mg, $0.096 \mathrm{mmol}, 64 \%)$.

${ }^{1} \mathrm{H}$ NMR $\left(500 \mathrm{MHz}, \mathrm{CDCl}_{3}\right) \delta 7.90-7.84(\mathrm{~m}, 2 \mathrm{H}), 7.63(\mathrm{~m}, 1 \mathrm{H}), 7.58-7.51(\mathrm{~m}, 2 \mathrm{H}), 6.54(\mathrm{~s}, 1 \mathrm{H}), 5.95$ $(\mathrm{d}, J=0.7 \mathrm{~Hz}, 1 \mathrm{H}), 3.42(\mathrm{~d}, J=1.0 \mathrm{~Hz}, 2 \mathrm{H}), 2.81(\mathrm{tt}, J=8.7,6.9 \mathrm{~Hz}, 1 \mathrm{H}), 1.76-1.64(\mathrm{~m}, 2 \mathrm{H}), 1.64-1.48$ $(\mathrm{m}, 6 \mathrm{H})$.

${ }^{13} \mathrm{C} \mathrm{NMR}\left(126 \mathrm{MHz}, \mathrm{CDCl}_{3}\right) \delta$ 206.2, 143.5, 138.3, 133.7, 129.3, 128.4, 128.0, 51.2, 41.4, 28.8, 25.9.

HRMS (ESI): m/z calculated for $\mathrm{C}_{15} \mathrm{H}_{19} \mathrm{O}_{3} \mathrm{~S}[\mathrm{M}+\mathrm{H}]^{+}: 279.1055$, found: 279.1054 .

\section{1-cyclohexyl-3-(phenylsulfonyl)but-3-en-1-one}<smiles>C=C(CC(=O)C1CCCCC1)S(=O)(=O)O</smiles>

Following the general procedure, $\mathbf{3 w}$ was obtained as a yellowish oil (36.9 mg, $0.126 \mathrm{mmol}, 84 \%)$.

${ }^{1} \mathrm{H}$ NMR $\left(500 \mathrm{MHz}, \mathrm{CDCl}_{3}\right) \delta 7.89-7.84(\mathrm{~m}, 2 \mathrm{H}), 7.66-7.61(\mathrm{~m}, 1 \mathrm{H}), 7.57-7.52(\mathrm{~m}, 2 \mathrm{H}), 6.53(\mathrm{~s}, 1 \mathrm{H})$, $5.93(\mathrm{~d}, J=0.8 \mathrm{~Hz}, 1 \mathrm{H}), 3.41(\mathrm{~d}, J=1.0 \mathrm{~Hz}, 2 \mathrm{H}), 2.31-2.23(\mathrm{~m}, 1 \mathrm{H}), 1.76-1.59(\mathrm{~m}, 5 \mathrm{H}), 1.27-1.10(\mathrm{~m}$, $5 \mathrm{H})$.

${ }^{13} \mathrm{C}$ NMR $\left(126 \mathrm{MHz}, \mathrm{CDCl}_{3}\right) \delta 206.9,143.5,138.3,133.7,129.3,128.4,128.1,50.6,40.3,28.2,25.7,25.4$. HRMS (ESI): m/z calculated for $\mathrm{C}_{16} \mathrm{H}_{21} \mathrm{O}_{3} \mathrm{~S}[\mathrm{M}+\mathrm{H}]^{+}: 293.1211$, found: 293.1214 .

\section{2-(phenylsulfonyl)dec-1-en-4-one}

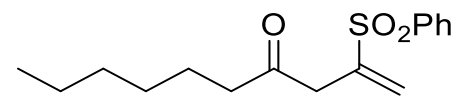

Following the general procedure, $\mathbf{3 x}$ was obtained as an oil (40.6 mg, $0.138 \mathrm{mmol}, 92 \%)$.

${ }^{1} \mathrm{H}$ NMR $\left(500 \mathrm{MHz}, \mathrm{CDCl}_{3}\right) \delta 7.90-7.84(\mathrm{~m}, 2 \mathrm{H}), 7.64(\mathrm{~m}, 1 \mathrm{H}), 7.55(\mathrm{~m}, 2 \mathrm{H}), 6.53(\mathrm{~s}, 1 \mathrm{H}), 5.95(\mathrm{~d}, J=$ $0.8 \mathrm{~Hz}, 1 \mathrm{H}), 3.35(\mathrm{~d}, J=0.7 \mathrm{~Hz}, 2 \mathrm{H}), 2.35$ (t, $J=7.4 \mathrm{~Hz}, 2 \mathrm{H}), 1.44(\mathrm{~m}, 2 \mathrm{H}), 1.31-1.15(\mathrm{~m}, 6 \mathrm{H}), 0.87(\mathrm{t}, J$ $=7.1 \mathrm{~Hz}, 3 \mathrm{H})$.

${ }^{13} \mathrm{C}$ NMR $\left(126 \mathrm{MHz}, \mathrm{CDCl}_{3}\right) \delta 204.3,143.6,138.2,133.8,129.3,128.5,128.0,42.6,42.4,31.5,28.6,23.4$, 22.4, 14.0.

HRMS (ESI): m/z calculated for $\mathrm{C}_{16} \mathrm{H}_{23} \mathrm{O}_{3} \mathrm{~S}[\mathrm{M}+\mathrm{H}]^{+}:$: 295.1368, found: 295.1367.

\section{1-phenyl-4-(phenylsulfonyl)pent-4-en-2-one}<smiles>C=C(CC(=O)Cc1ccccc1)S(=O)(=O)c1ccccc1</smiles> 
Following the general procedure, $\mathbf{3 y}$ was obtained as a yellowish oil (31.6 mg, $0.105 \mathrm{mmol}, 70 \%)$.

${ }^{1} \mathrm{H}$ NMR $\left(500 \mathrm{MHz}, \mathrm{CDCl}_{3}\right) \delta 7.83-7.78(\mathrm{~m}, 2 \mathrm{H}), 7.66-7.59(\mathrm{~m}, 1 \mathrm{H}), 7.51(\mathrm{~m}, 2 \mathrm{H}), 7.34-7.24(\mathrm{~m}, 3 \mathrm{H})$, $7.13-7.07(\mathrm{~m}, 2 \mathrm{H}), 6.52(\mathrm{~s}, 1 \mathrm{H}), 5.90(\mathrm{~d}, J=0.8 \mathrm{~Hz}, 1 \mathrm{H}), 3.66(\mathrm{~s}, 2 \mathrm{H}), 3.38(\mathrm{~d}, J=0.6 \mathrm{~Hz}, 2 \mathrm{H})$.

${ }^{13} \mathrm{C}$ NMR $\left(126 \mathrm{MHz}, \mathrm{CDCl}_{3}\right) \delta 201.6,143.5,138.1,133.8,133.2,129.5,129.3,128.9,128.4,128.3,127.3$, 49.6, 41.7 .

HRMS (ESI): m/z calculated for $\mathrm{C}_{17} \mathrm{H}_{17} \mathrm{O}_{3} \mathrm{~S}[\mathrm{M}+\mathrm{H}]^{+}:$301.0898, found: 301.0893 .

\section{1-phenyl-5-(phenylsulfonyl)hex-5-en-3-one}<smiles>C=C(CC(=O)CCc1ccccc1)S(=O)(=O)c1ccccc1</smiles>

Following the general procedure, $\mathbf{3 z}$ was obtained as an oil (29.7 $\mathrm{mg}, 0.094 \mathrm{mmol}, 62 \%)$.

${ }^{1} \mathrm{H}$ NMR (500 MHz, $\left.\mathrm{CDCl}_{3}\right) \delta 7.85(\mathrm{~m}, 2 \mathrm{H}), 7.63(\mathrm{~m}, 1 \mathrm{H}), 7.53(\mathrm{~m}, 2 \mathrm{H}), 7.28-7.23(\mathrm{~m}, 2 \mathrm{H}), 7.19(\mathrm{t}, J=$ $7.4 \mathrm{~Hz}, 1 \mathrm{H}), 7.11(\mathrm{~d}, J=7.0 \mathrm{~Hz}, 2 \mathrm{H}), 6.48(\mathrm{~s}, 1 \mathrm{H}), 5.87(\mathrm{~d}, J=0.8 \mathrm{~Hz}, 1 \mathrm{H}), 3.31(\mathrm{~s}, 2 \mathrm{H}), 2.79$ (t, $J=7.4$ $\mathrm{Hz}, 2 \mathrm{H}), 2.69(\mathrm{t}, J=7.4 \mathrm{~Hz}, 2 \mathrm{H})$.

${ }^{13} \mathrm{C}$ NMR $\left(126 \mathrm{MHz}, \mathrm{CDCl}_{3}\right) \delta 203.3,143.5,140.5,138.2,133.9,129.4,128.5,128.5,128.3,128.0,126.3$, $44.0,42.8,29.5$.

HRMS (ESI): $\mathrm{m} / \mathrm{z}$ calculated for $\mathrm{C}_{18} \mathrm{H}_{19} \mathrm{O}_{3} \mathrm{~S}[\mathrm{M}+\mathrm{H}]^{+}: 315.1055$, found: 315.1053 .

phenyl 3-(phenylsulfonyl)but-3-enoate<smiles>C=C(CC(=O)Oc1ccccc1)S(=O)(=O)c1ccccc1</smiles>

Following the general procedure, 3aa was obtained as an oil (41.2 $\mathrm{mg}, 0.136 \mathrm{mmol}, 92 \%)$.

${ }^{1} \mathrm{H}$ NMR $\left(500 \mathrm{MHz}, \mathrm{CDCl}_{3}\right) \delta 7.94(\mathrm{~d}, J=7.6 \mathrm{~Hz}, 2 \mathrm{H}), 7.65(\mathrm{t}, J=7.4 \mathrm{~Hz}, 1 \mathrm{H}), 7.56(\mathrm{t}, J=7.7 \mathrm{~Hz}, 2 \mathrm{H})$, $7.34(\mathrm{t}, J=7.9 \mathrm{~Hz}, 2 \mathrm{H}), 7.21(\mathrm{t}, J=7.4 \mathrm{~Hz}, 1 \mathrm{H}), 6.97(\mathrm{~d}, J=8.0 \mathrm{~Hz}, 2 \mathrm{H}), 6.61(\mathrm{~s}, 1 \mathrm{H}), 6.15(\mathrm{~s}, 1 \mathrm{H}), 3.53$ $(\mathrm{s}, 2 \mathrm{H})$.

${ }^{13} \mathrm{C}$ NMR $\left(126 \mathrm{MHz}, \mathrm{CDCl}_{3}\right) \delta 167.0,150.4,143.3,138.2,134.0,129.4,128.6,128.4,126.2,121.3,35.4$. HRMS (ESI): m/z calculated for $\mathrm{C}_{16} \mathrm{H}_{15} \mathrm{O}_{4} \mathrm{~S}[\mathrm{M}+\mathrm{H}]^{+}: 303.0691$, found: 303.0690 . 


\section{benzyl 3-(phenylsulfonyl)but-3-enoate}<smiles>C=C(CC(=O)OCc1ccccc1)S(=O)(=O)c1ccccc1</smiles>

Following the general procedure, 3ab was obtained as a colorless oil (43.6 mg, $0.138 \mathrm{mmol}, 91 \%$ ). Spectroscopic data is line with reported literature. ${ }^{7}$

${ }^{1} \mathrm{H}$ NMR $\left(500 \mathrm{MHz}, \mathrm{CDCl}_{3}\right) \delta 7.90-7.83(\mathrm{~m}, 2 \mathrm{H}), 7.61(\mathrm{~m}, 1 \mathrm{H}), 7.50(\mathrm{t}, J=7.8 \mathrm{~Hz}, 2 \mathrm{H}), 7.38-7.32(\mathrm{~m}$, $3 \mathrm{H}), 7.29-7.24(\mathrm{~m}, 2 \mathrm{H}), 6.55(\mathrm{~s}, 1 \mathrm{H}), 6.03(\mathrm{~d}, J=0.8 \mathrm{~Hz}, 1 \mathrm{H}), 4.98(\mathrm{~s}, 2 \mathrm{H}), 3.35$ (d, $J=0.7 \mathrm{~Hz}, 2 \mathrm{H})$.

${ }^{13} \mathrm{C} \mathrm{NMR}\left(126 \mathrm{MHz}, \mathrm{CDCl}_{3}\right) \delta 168.2,143.4,138.3,135.2,133.8,129.3,128.6,128.5,128.3,128.0,67.2$, 35.1 .

HRMS (ESI): m/z calculated for $\mathrm{C}_{17} \mathrm{H}_{17} \mathrm{O}_{4} \mathrm{~S}[\mathrm{M}+\mathrm{H}]^{+}: 317.0848$, found: 317.0848 .

\section{$(1 R, 2 S, 5 R)$-2-isopropyl-5-methylcyclohexyl 3-(phenylsulfonyl)but-3-enoate}<smiles>C=C(CC(=O)OC1CC(C)CCC1C(C)C)S(=O)(=O)c1ccccc1</smiles>

Following the general procedure, 3ac was obtained as an oil $(37.6 \mathrm{mg}, 0.103 \mathrm{mmol}, 68 \%) .[\alpha]_{\mathrm{D}}-17.1(c$ $0.14, \mathrm{CH}_{2} \mathrm{Cl}_{2}$ ).

${ }^{1} \mathrm{H}$ NMR $\left(500 \mathrm{MHz}, \mathrm{CDCl}_{3}\right) \delta 7.89(\mathrm{~m}, 2 \mathrm{H}), 7.67-7.61(\mathrm{~m}, 1 \mathrm{H}), 7.54(\mathrm{~m}, 2 \mathrm{H}), 6.56(\mathrm{~s}, 1 \mathrm{H}), 6.05(\mathrm{~d}, J=$ $0.8 \mathrm{~Hz}, 1 \mathrm{H}), 4.58(\mathrm{td}, J=10.9,4.4 \mathrm{~Hz}, 1 \mathrm{H}), 3.29(\mathrm{~d}, J=0.8 \mathrm{~Hz}, 2 \mathrm{H}), 1.85-1.79(\mathrm{~m}, 1 \mathrm{H}), 1.76-1.61(\mathrm{~m}$, $3 \mathrm{H}), 1.46-1.38(\mathrm{~m}, 1 \mathrm{H}), 1.33-1.24(\mathrm{~m}, 1 \mathrm{H}), 1.05-0.95(\mathrm{~m}, 1 \mathrm{H}), 0.91-0.78(\mathrm{~m}, 8 \mathrm{H}), 0.69(\mathrm{~d}, J=7.0$ $\mathrm{Hz}, 3 \mathrm{H})$.

${ }^{13} \mathrm{C}$ NMR $\left(126 \mathrm{MHz}, \mathrm{CDCl}_{3}\right) \delta 168.0,143.7,138.4,133.8,129.3,128.5,127.6,75.6,46.8,40.5,35.2,34.1$, $31.3,26.1,23.3,22.0,20.7,16.2$.

HRMS (ESI): m/z calculated for $\mathrm{C}_{20} \mathrm{H}_{29} \mathrm{O}_{4} \mathrm{~S}[\mathrm{M}+\mathrm{H}]^{+}: 365.1787$, found: 365.1786 .

\section{$N$-phenyl-3-(phenylsulfonyl)but-3-enamide}<smiles>C=C(CC(=O)Nc1ccccc1)S(=O)(=O)c1ccccc1</smiles>

Following the general procedure, $\mathbf{3 a d}$ was obtained as an oil (44.7 mg, $0.148 \mathrm{mmol}, 99 \%)$.

\footnotetext{
${ }^{7}$ Huang, Z.; Lu, Q.; Liu, Y.; Liu, D.; Zhang, J.; Lei, A. Regio- and Stereoselective Oxysulfonylation of Allenes. Org. Lett. 2016, 18, 3940.
} 
${ }^{1} \mathrm{H}$ NMR $\left(500 \mathrm{MHz}, \mathrm{CDCl}_{3}\right) \delta 8.40(\mathrm{~s}, 1 \mathrm{H}), 7.90(\mathrm{~d}, J=7.4 \mathrm{~Hz}, 2 \mathrm{H}), 7.61(\mathrm{t}, J=7.5 \mathrm{~Hz}, 1 \mathrm{H}), 7.52(\mathrm{t}, J=$ $7.8 \mathrm{~Hz}, 2 \mathrm{H}), 7.44(\mathrm{~d}, J=7.8 \mathrm{~Hz}, 2 \mathrm{H}), 7.27(\mathrm{~m}, 2 \mathrm{H}), 7.09$ (t, $J=7.4 \mathrm{~Hz}, 1 \mathrm{H}), 6.50(\mathrm{~s}, 1 \mathrm{H}), 6.14$ (s, 1H), 3.35 (s, 2H).

${ }^{13} \mathrm{C}$ NMR $\left(126 \mathrm{MHz}, \mathrm{CDCl}_{3}\right) \delta 165.7,144.0,137.7,137.7,134.2,129.5,128.9,128.4,128.2,124.6,120.0$, 38.5.

HRMS (ESI): $\mathrm{m} / \mathrm{z}$ calculated for $\mathrm{C}_{16} \mathrm{H}_{16} \mathrm{NO}_{3} \mathrm{~S}[\mathrm{M}+\mathrm{H}]^{+}: 302.0851$, found: 302.0851 .

$N$-benzyl-3-(phenylsulfonyl)but-3-enamide<smiles>C=C(CC(=O)NCc1ccccc1)S(=O)(=O)c1ccccc1</smiles>

Following the general procedure, 3ae was obtained as an oil (43.1 $\mathrm{mg}, 0.137 \mathrm{mmol}, 92 \%)$.

${ }^{1} \mathrm{H}$ NMR $\left(500 \mathrm{MHz}, \mathrm{CDCl}_{3}\right) \delta 7.88-7.82(\mathrm{~m}, 2 \mathrm{H}), 7.63(\mathrm{t}, J=7.5 \mathrm{~Hz}, 1 \mathrm{H}), 7.53(\mathrm{t}, J=7.8 \mathrm{~Hz}, 2 \mathrm{H}), 7.31$ $(\mathrm{t}, J=7.2 \mathrm{~Hz}, 2 \mathrm{H}), 7.28-7.24(\mathrm{~m}, 1 \mathrm{H}), 7.22(\mathrm{~d}, J=7.0 \mathrm{~Hz}, 2 \mathrm{H}), 6.55(\mathrm{~s}, 1 \mathrm{H}), 6.45(\mathrm{~s}, 1 \mathrm{H}), 6.08(\mathrm{~d}, J=0.7$ $\mathrm{Hz}, 1 \mathrm{H}), 4.33(\mathrm{~d}, J=5.7 \mathrm{~Hz}, 2 \mathrm{H}), 3.19(\mathrm{~s}, 2 \mathrm{H})$.

${ }^{13} \mathrm{C}$ NMR $\left(126 \mathrm{MHz}, \mathrm{CDCl}_{3}\right) \delta 167.4,144.3,137.9,137.7,134.0,129.4,128.7,128.4,127.8,127.7,127.6$, 43.9, 37.3.

HRMS (ESI): $\mathrm{m} / \mathrm{z}$ calculated for $\mathrm{C}_{17} \mathrm{H}_{18} \mathrm{NO}_{3} \mathrm{~S}[\mathrm{M}+\mathrm{H}]^{+}: 316.1007$, found: 316.1006 .

\section{Experimental Procedures of Competitive Study}

Competitive Experiments (Scheme 3)

A $3 \mathrm{~mL}$ vial was charged with the appropriate allenic carbonyl compound 1 ( $0.15 \mathrm{mmol}, 1.0$ equiv.), benzene sulfinic acid $2 \mathrm{a}(0.23 \mathrm{mmol}, 1.5$ equiv. $)$ and $\mathrm{H}_{2} \mathrm{O}: \mathrm{EtOH}(1: 1,1 \mathrm{~mL})$ under ambient conditions. The reaction was stirred at $25{ }^{\circ} \mathrm{C}$ for $1 \mathrm{~h}$ and the mixture was diluted with $\mathrm{CH}_{2} \mathrm{Cl}_{2}(2 \mathrm{~mL})$ and the layers were separated. The organic layer was evaporated under reduced pressure and subjected to ${ }^{1} \mathrm{H}$ NMR analysis. The ${ }^{1} \mathrm{H}$ NMR yields and conversions were determined based on $\mathrm{CH}_{2} \mathrm{I}_{2}$ as the internal standard. 

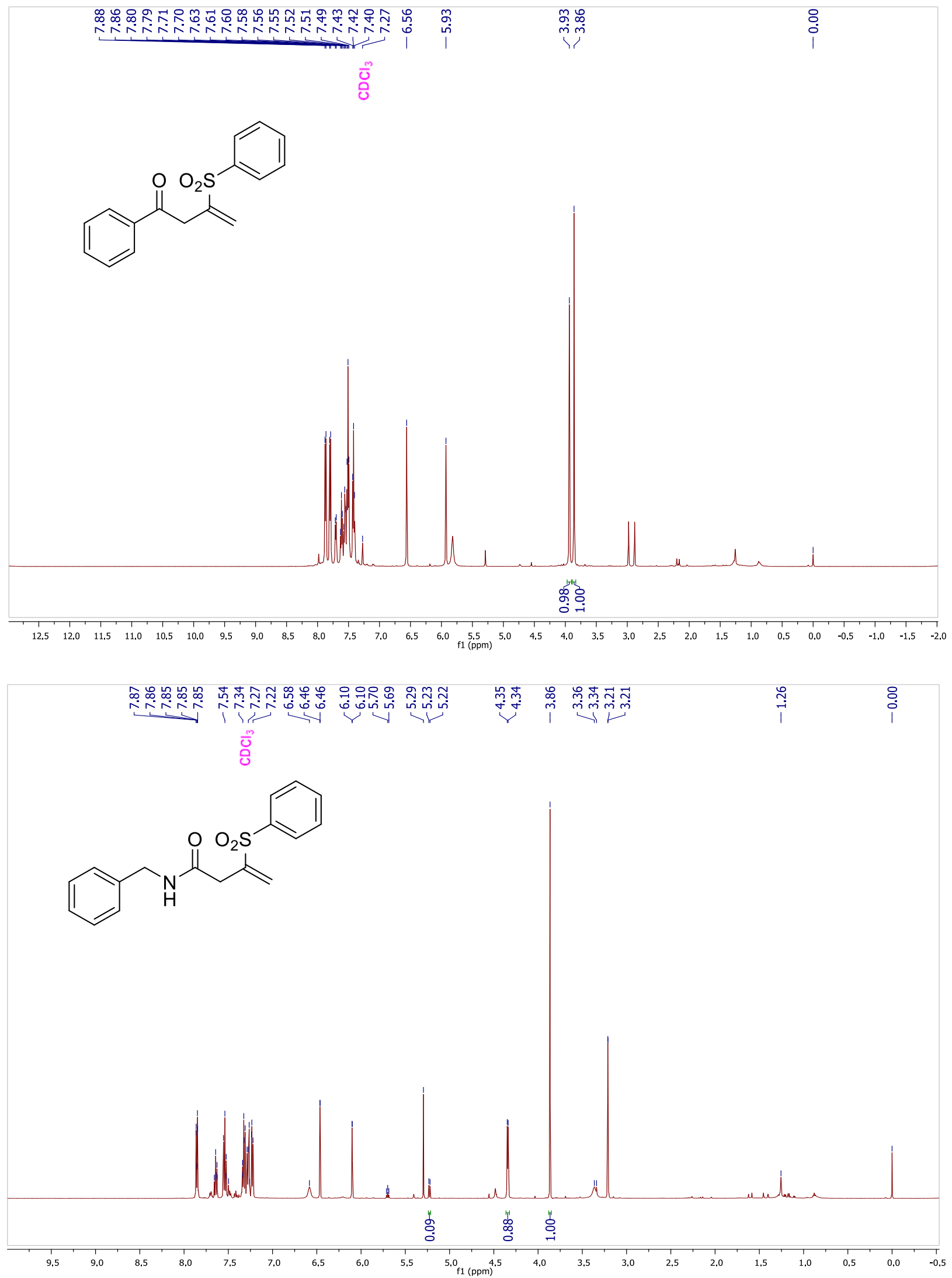


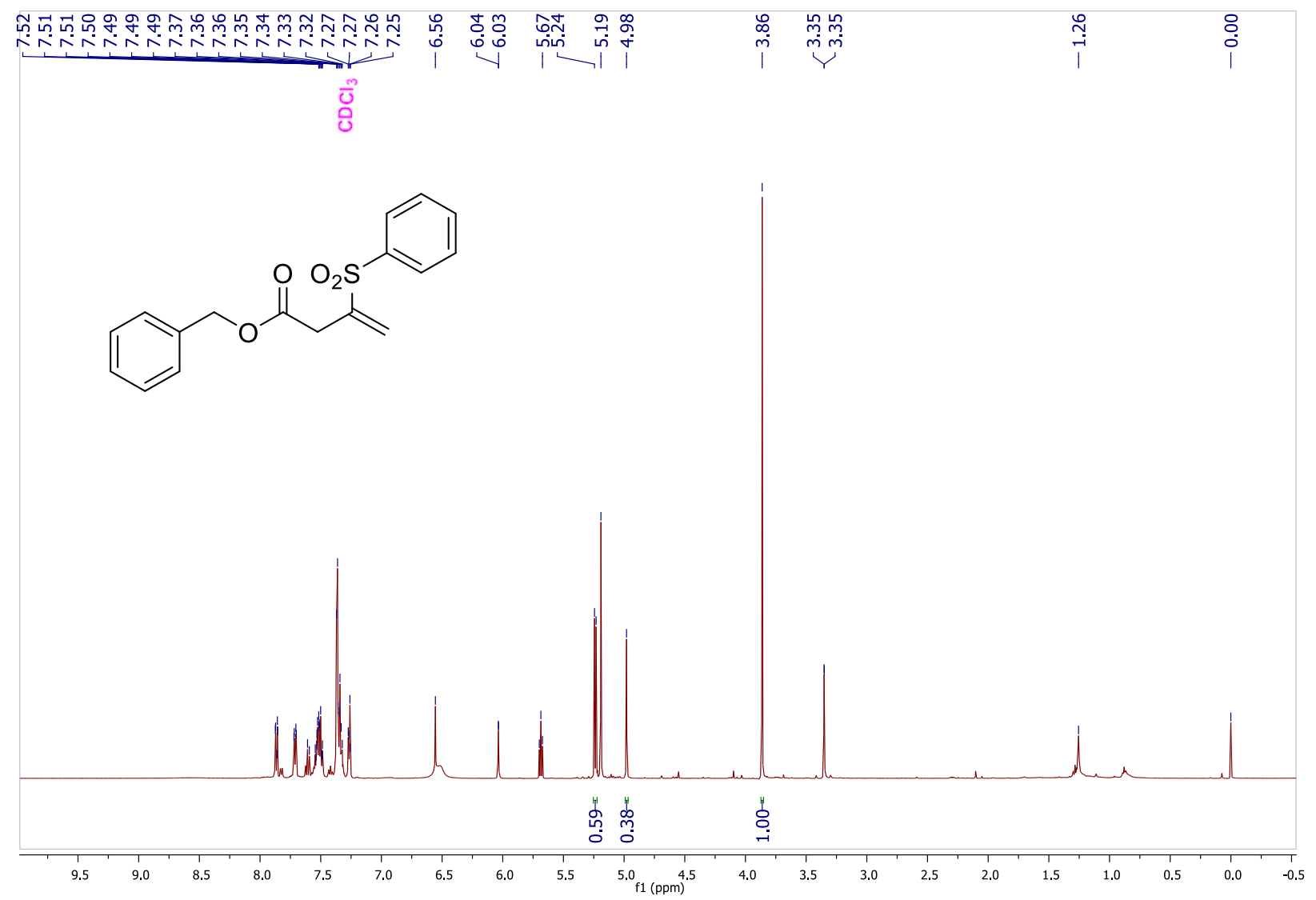

\section{Synthetic Transformations of Vinylic Sulfones}<smiles>C/C(=C\C(=O)c1ccccc1)NCc1ccccc1</smiles>

A $3 \mathrm{~mL}$ vial was charged with vinylic sulfone $3 \mathbf{a}(0.15 \mathrm{mmol}, 1.0$ equiv.), benzyl amine $(0.23 \mathrm{mmol}, 1.5$ equiv.) and $\mathrm{H}_{2} \mathrm{O}: \mathrm{EtOH}(1: 1,1 \mathrm{~mL})$ under ambient conditions. The reaction was stirred at $25^{\circ} \mathrm{C}$ overnight and the mixture was diluted with $\mathrm{CH}_{2} \mathrm{Cl}_{2}(2 \mathrm{~mL})$ and the layers were separated. The organic layer was directly loaded into a column and purified by flash column chromatography ( $n$-hexane/EtOAc) to afford enaminone 4 as a brown solid $(30.1 \mathrm{mg}, 0.120 \mathrm{mmol}, 80 \%)$. M.p. $=58-59{ }^{\circ} \mathrm{C}$. Spectroscopic data is line with reported literature. ${ }^{8}$

${ }^{1} \mathrm{H}$ NMR $\left(500 \mathrm{MHz}, \mathrm{CDCl}_{3}\right) \delta 7.90-7.85(\mathrm{~m}, 2 \mathrm{H}), 7.43-7.33(\mathrm{~m}, 5 \mathrm{H}), 7.29(\mathrm{~m}, 3 \mathrm{H}), 5.75(\mathrm{~s}, 1 \mathrm{H}), 4.55$ $(\mathrm{d}, J=6.3 \mathrm{~Hz}, 2 \mathrm{H}), 2.07$ (s, 3H).

${ }^{13} \mathrm{C}$ NMR $\left(126 \mathrm{MHz}, \mathrm{CDCl}_{3}\right) \delta 188.1,164.9,140.3,137.8,130.6,128.9,128.2,127.6,127.0,126.9,92.7$, 47.1, 19.5.

HRMS (ESI): $\mathrm{m} / \mathrm{z}$ calculated for $\mathrm{C}_{17} \mathrm{H}_{18} \mathrm{NO}[\mathrm{M}+\mathrm{H}]^{+}:$252.1388, found: 252.1388 .

${ }^{8}$ Feng, T.; Tian, M.; Zhang, X.; Fan, X. Tunable Synthesis of Functionalized Cyclohexa-1,3-dienes and 2Aminobenzophenones/Benzoate from the Cascade Reactions of Allenic Ketones/Allenoate with Amines and Enones. J. Org. Chem. 2018, 83, 5313. 
<smiles></smiles>

Following a modified procedure reported in the literature, ${ }^{9}$ the corresponding alkylated sulfone $\mathbf{5}$ was obtained as an oil (22.9 $\mathrm{mg}, 0.066 \mathrm{mmol}, 66 \%)$.

${ }^{1} \mathrm{H}$ NMR $\left(500 \mathrm{MHz}, \mathrm{CDCl}_{3}\right) \delta 7.89(\mathrm{~m}, 4 \mathrm{H}), 7.58(\mathrm{~m}, 2 \mathrm{H}), 7.47(\mathrm{~m}, 4 \mathrm{H}), 4.19(\mathrm{t}, J=8.1 \mathrm{~Hz}, 1 \mathrm{H}), 4.01(\mathrm{dd}$, $J=18.7,8.0 \mathrm{~Hz}, 1 \mathrm{H}), 2.95(\mathrm{~d}, J=18.3 \mathrm{~Hz}, 1 \mathrm{H}), 2.03(\mathrm{~d}, J=14.7 \mathrm{~Hz}, 1 \mathrm{H}), 1.53(\mathrm{dd}, J=14.7,8.8 \mathrm{~Hz}, 1 \mathrm{H})$, $0.81(\mathrm{~s}, 9 \mathrm{H})$.

${ }^{13} \mathrm{C} \mathrm{NMR}\left(126 \mathrm{MHz}, \mathrm{CDCl}_{3}\right) \delta 195.2,137.5,136.0,133.7,133.5,129.1,129.1,128.7,128.1,56.1,41.7$, 39.6, 31.1, 29.1.

HRMS (ESI): $\mathrm{m} / \mathrm{z}$ calculated for $\mathrm{C}_{20} \mathrm{H}_{25} \mathrm{O}_{3} \mathrm{~S}[\mathrm{M}+\mathrm{H}]^{+}: 345.1524$, found: 345.1523 .<smiles>C=C(CC1(c2ccccc2)OCCO1)[Sb](=O)(=O)O</smiles>

Following a modified procedure reported in the literature, ${ }^{10}$ protected vinylic sulfone $\mathbf{6}$ was obtained as a yellowish oil (52.3 $\mathrm{mg}, 0.158 \mathrm{mmol}, 32 \%)$.

${ }^{1} \mathrm{H}$ NMR $\left(500 \mathrm{MHz}, \mathrm{CDCl}_{3}\right) \delta 7.81-7.76(\mathrm{~m}, 2 \mathrm{H}), 7.59(\mathrm{t}, J=7.5 \mathrm{~Hz}, 1 \mathrm{H}), 7.48(\mathrm{t}, J=7.8 \mathrm{~Hz}, 2 \mathrm{H}), 7.27$ $-7.22(\mathrm{~m}, 5 \mathrm{H}), 6.50(\mathrm{~s}, 1 \mathrm{H}), 6.11(\mathrm{~s}, 1 \mathrm{H}), 3.80-3.74(\mathrm{~m}, 2 \mathrm{H}), 3.70-3.64(\mathrm{~m}, 2 \mathrm{H}), 2.94(\mathrm{~d}, J=0.6 \mathrm{~Hz}$, $2 \mathrm{H})$.

${ }^{13} \mathrm{C}$ NMR $\left(126 \mathrm{MHz}, \mathrm{CDCl}_{3}\right) \delta 145.0,141.1,139.1,133.1,128.9,128.5,128.2,128.2,128.1,125.6,108.8$, $64.7,38.5$.

HRMS (ESI): m/z calculated for $\mathrm{C}_{18} \mathrm{H}_{19} \mathrm{O}_{4} \mathrm{~S}[\mathrm{M}+\mathrm{H}]^{+}: 331.1004$, found: 331.1004 .

\footnotetext{
${ }^{9}$ Zhao, M.M.; Qu, C.; Lynch, J.E. Zn/CuI-Mediated Coupling of Al-kyl Halides with Vinyl Sulfones, Vinyl Sulfonates, and Vinyl Sul-fonamides. J. Org. Chem. 2005, 70, 6944.

${ }^{10}$ Auvray, P.; Knochel, P.; Normant, J.F. 3-bromq-2-t-butylsulfonyl-1-propene: A versatile multi-coupling reagent part II. Tetrahedron. 1988, 44, 4509.
} 


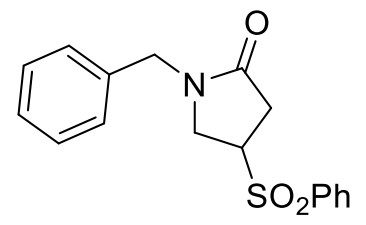

Following the procedure reported in the literature, ${ }^{11} \gamma$-lactam 7 was obtained as an oil $(19.5 \mathrm{mg}, 0.062$ mmol, 62\%).

${ }^{1} \mathrm{H}$ NMR $\left(500 \mathrm{MHz}, \mathrm{CDCl}_{3}\right) \delta 7.84(\mathrm{~d}, J=7.4 \mathrm{~Hz}, 2 \mathrm{H}), 7.69(\mathrm{t}, J=7.5 \mathrm{~Hz}, 1 \mathrm{H}), 7.57(\mathrm{t}, J=7.8 \mathrm{~Hz}, 2 \mathrm{H})$, $7.33(\mathrm{~m}, 3 \mathrm{H}), 7.19(\mathrm{~d}, J=6.7 \mathrm{~Hz}, 2 \mathrm{H}), 4.47(\mathrm{~d}, J=14.7 \mathrm{~Hz}, 1 \mathrm{H}), 4.32(\mathrm{~d}, J=14.7 \mathrm{~Hz}, 1 \mathrm{H}), 3.83(\mathrm{tt}, J=$ 9.4, $5.9 \mathrm{~Hz}, 1 \mathrm{H}), 3.70(\mathrm{dd}, J=11.2,5.3 \mathrm{~Hz}, 1 \mathrm{H}), 3.46(\mathrm{dd}, J=11.1,8.9 \mathrm{~Hz}, 1 \mathrm{H}), 2.94(\mathrm{dd}, J=17.7,6.2 \mathrm{~Hz}$, $1 \mathrm{H}), 2.69(\mathrm{dd}, J=17.7,9.8 \mathrm{~Hz}, 1 \mathrm{H})$.

${ }^{13} \mathrm{C}$ NMR $\left(126 \mathrm{MHz}, \mathrm{CDCl}_{3}\right) \delta 170.2,136.8,135.2,134.5,129.7,128.9,128.6,128.2,128.0,55.7,46.6$, 45.7, 32.0.

HRMS (ESI): $\mathrm{m} / \mathrm{z}$ calculated for $\mathrm{C}_{17} \mathrm{H}_{18} \mathrm{NO}_{3} \mathrm{~S}[\mathrm{M}+\mathrm{H}]^{+}: 316.1007$, found: 316.1007 .<smiles>C=C(CC(=O)c1ccc(-c2cnnn2[C@@H]2CC(CO)O[C@H]2n2cc(C)c(=O)[nH]c2=O)cc1)S(=O)(=O)c1ccccc1</smiles>

Following the procedure reported in the literature, ${ }^{12}$ vinylic sulfone $\mathbf{8}$ was obtained as a colorless oil (58.7 mg, $0.102 \mathrm{mmol}, 51 \%)$. [ $\alpha]_{\mathrm{D}}-40.9\left(c 0.23, \mathrm{CH}_{2} \mathrm{Cl}_{2}\right)$.

${ }^{1} \mathrm{H}$ NMR (500 MHz, DMSO) $\delta 11.37(\mathrm{~s}, 1 \mathrm{H}), 8.96(\mathrm{~s}, 1 \mathrm{H}), 7.97(\mathrm{~m}, 4 \mathrm{H}), 7.86(\mathrm{~m}, 3 \mathrm{H}), 7.73(\mathrm{t}, J=7.4 \mathrm{~Hz}$, $1 \mathrm{H}), 7.61(\mathrm{t}, J=7.7 \mathrm{~Hz}, 2 \mathrm{H}), 6.51(\mathrm{~s}, 1 \mathrm{H}), 6.46(\mathrm{t}, J=6.6 \mathrm{~Hz}, 1 \mathrm{H}), 6.14(\mathrm{~s}, 1 \mathrm{H}), 5.75(\mathrm{~s}, 1 \mathrm{H}), 5.44(\mathrm{dt}, J=$ 10.6, $5.4 \mathrm{~Hz}, 1 \mathrm{H}), 5.32(\mathrm{t}, J=5.2 \mathrm{~Hz}, 1 \mathrm{H}), 4.34-4.26(\mathrm{~m}, 1 \mathrm{H}), 4.15(\mathrm{~s}, 2 \mathrm{H}), 3.78-3.72(\mathrm{~m}, 1 \mathrm{H}), 3.72-$ $3.65(\mathrm{~m}, 1 \mathrm{H}), 2.82(\mathrm{~m}, 1 \mathrm{H}), 2.72(\mathrm{~m}, 1 \mathrm{H}), 1.82(\mathrm{~s}, 3 \mathrm{H})$.

${ }^{13} \mathrm{C}$ NMR (126 MHz, DMSO) $\delta$ 193.9, 164.2, 150.9, 145.9, 144.7, 139.0, 136.7, 135.7, 135.4, 134.4, 130.1, 130.0, 129.5, 128.5, 125.6, 122.9, 110.2, 84.9, 84.4, 61.3, 60.1, 55.4, 37.6, 12.7.

HRMS (ESI): $\mathrm{m} / \mathrm{z}$ calculated for $\mathrm{C}_{28} \mathrm{H}_{28} \mathrm{~N}_{5} \mathrm{O}_{7} \mathrm{~S}[\mathrm{M}+\mathrm{H}]^{+}:$578.1709, found: 578.1710.

\footnotetext{
${ }^{11}$ Lin, L.-Z.; Che, Y.-Y.; Bai, P.-B.; Feng, C. Sulfinate-Engaged Nucle-ophilic Addition Induced Allylic Alkylation of Allenoates. Org. Lett. 2019, 21, 7424.

${ }^{12}$ Xie, P.; Sun, Z.; Li, S.; Cai, X.; Qiu, J.; Fu, W.; Gao, C.; Wu, S.; Yang, X.; Loh, T.-P. Reciprocal-Activation Strategy for Allylic Sul-fination with Unactivated Allylic Alcohols. Org. Lett. 2020, 22, 4893.
} 

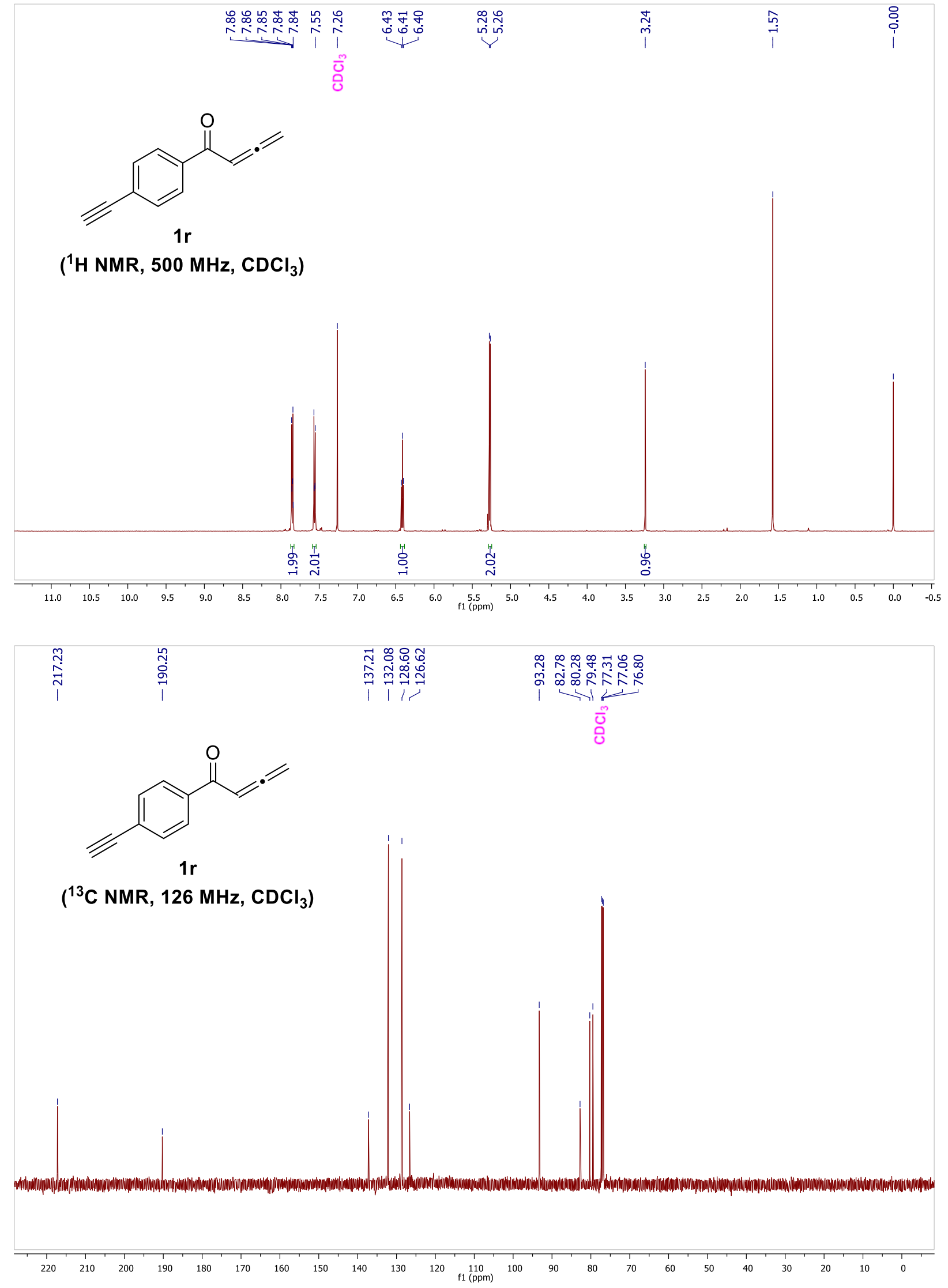

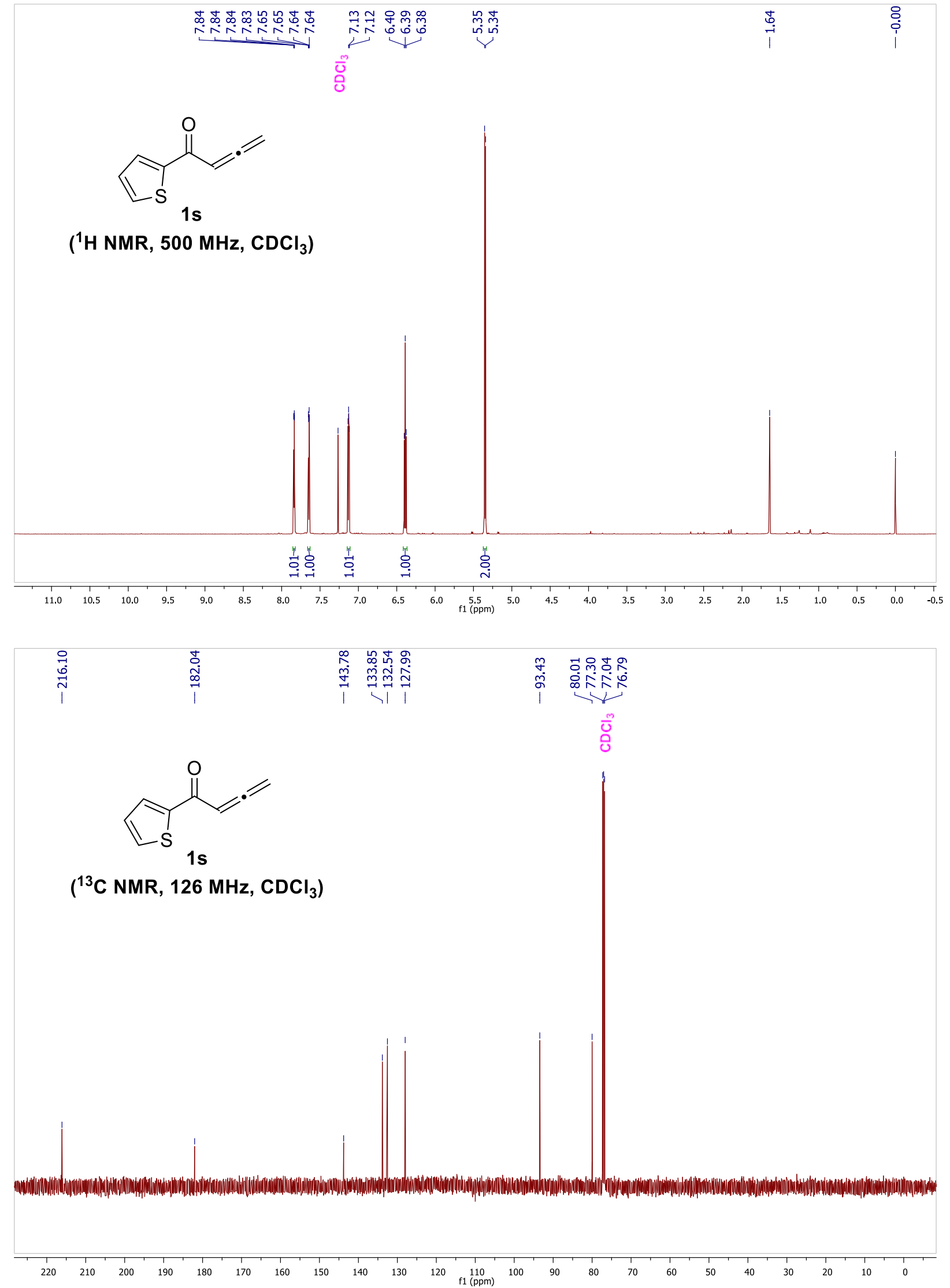

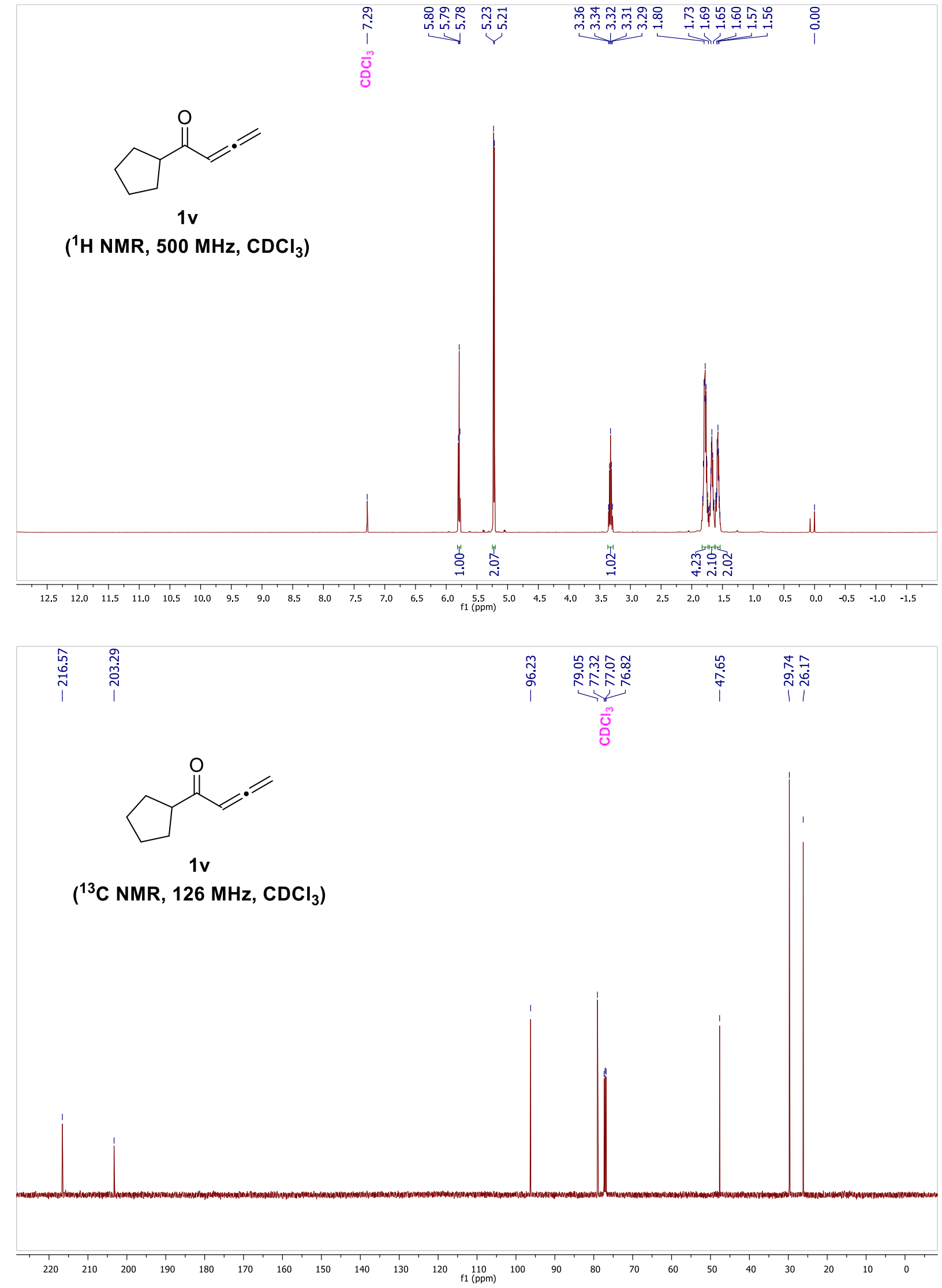

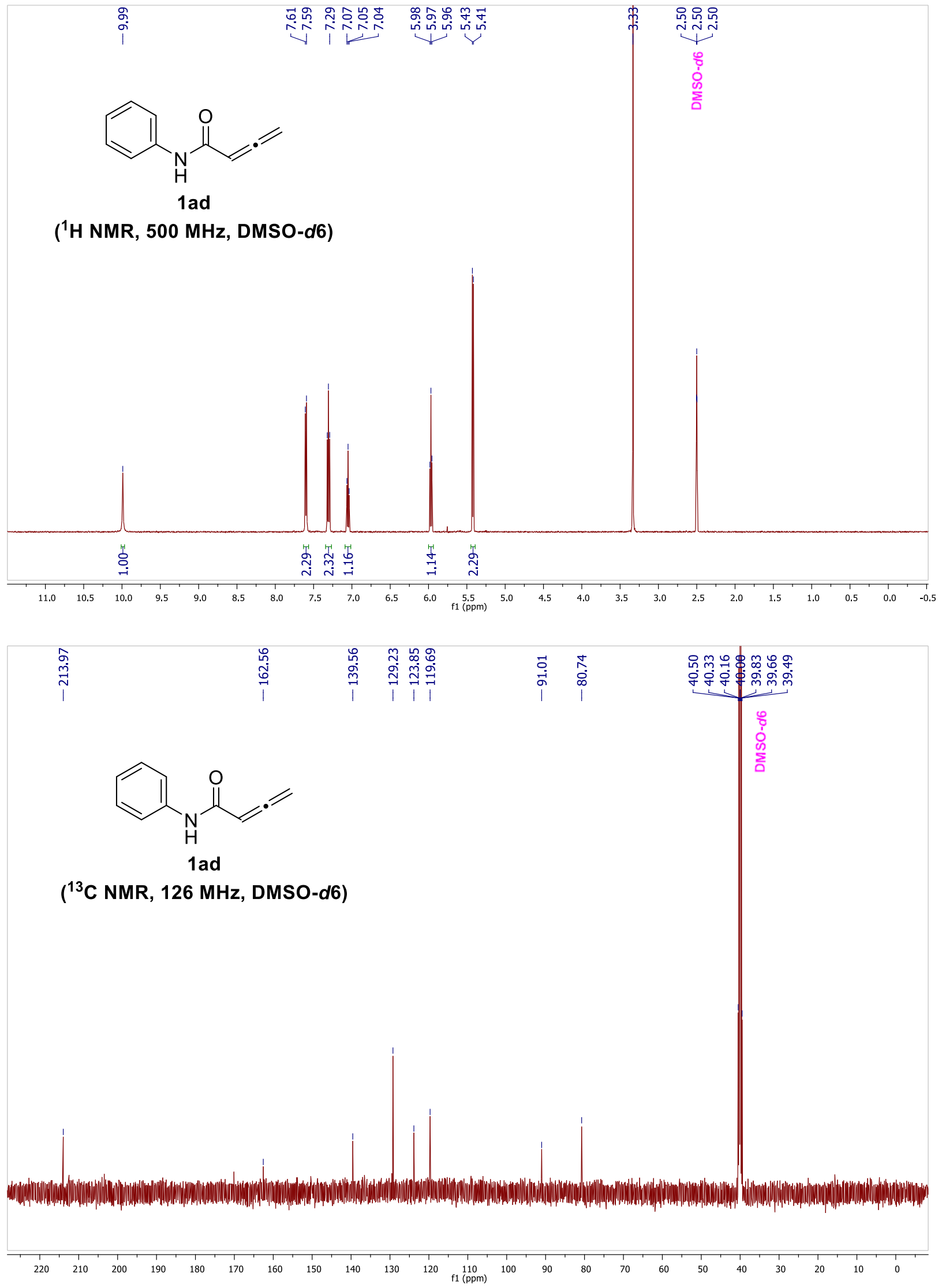

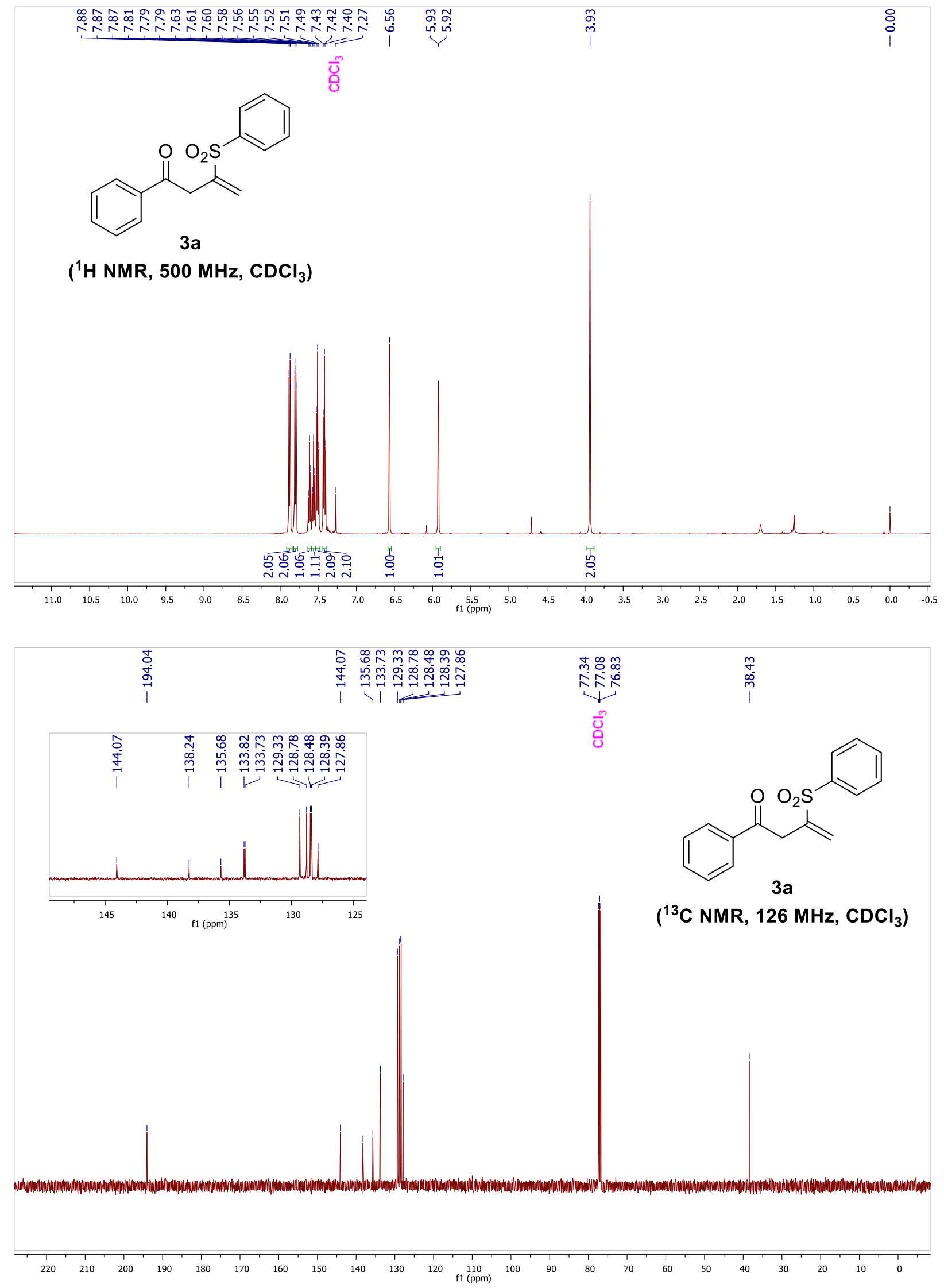

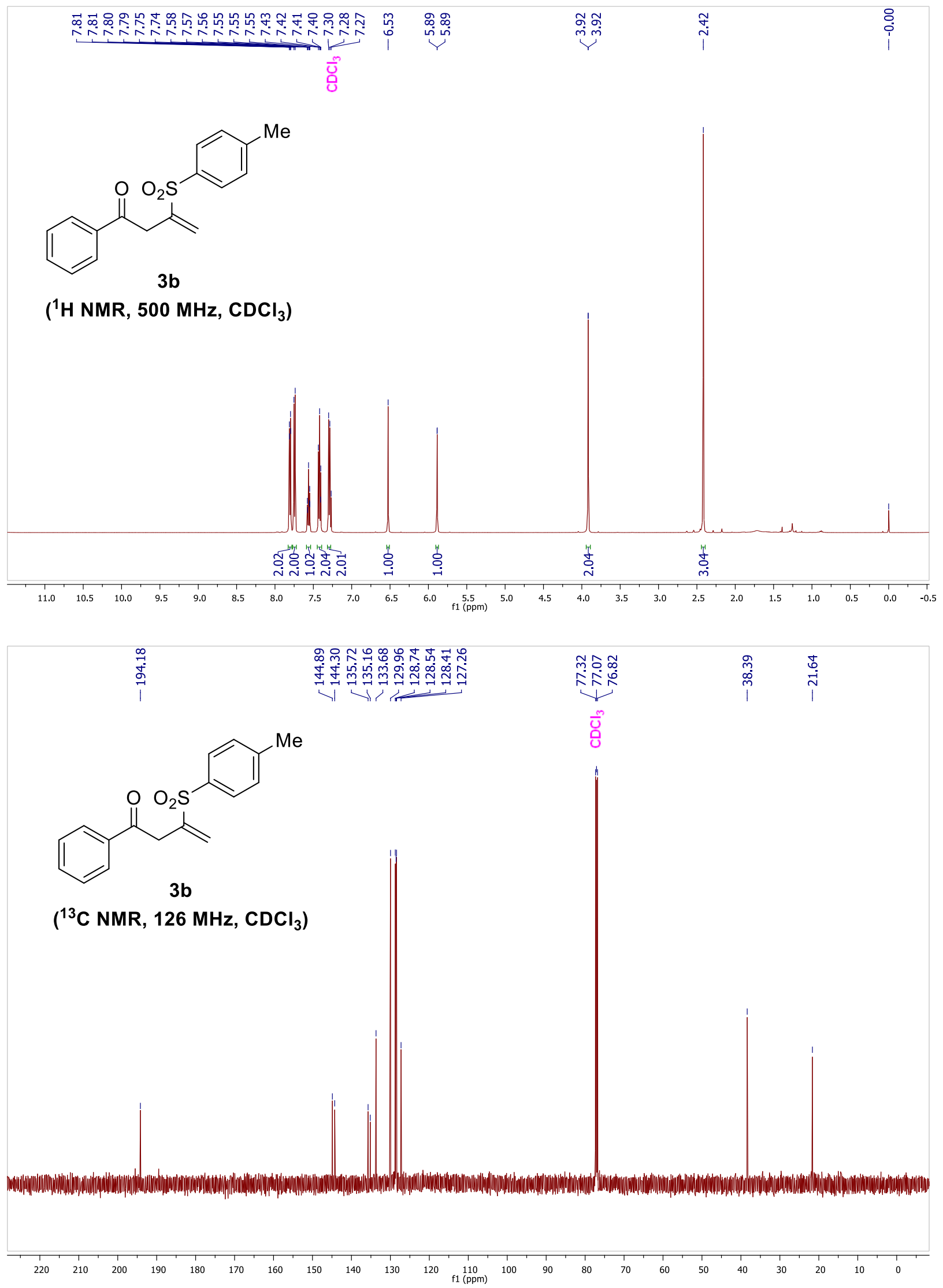

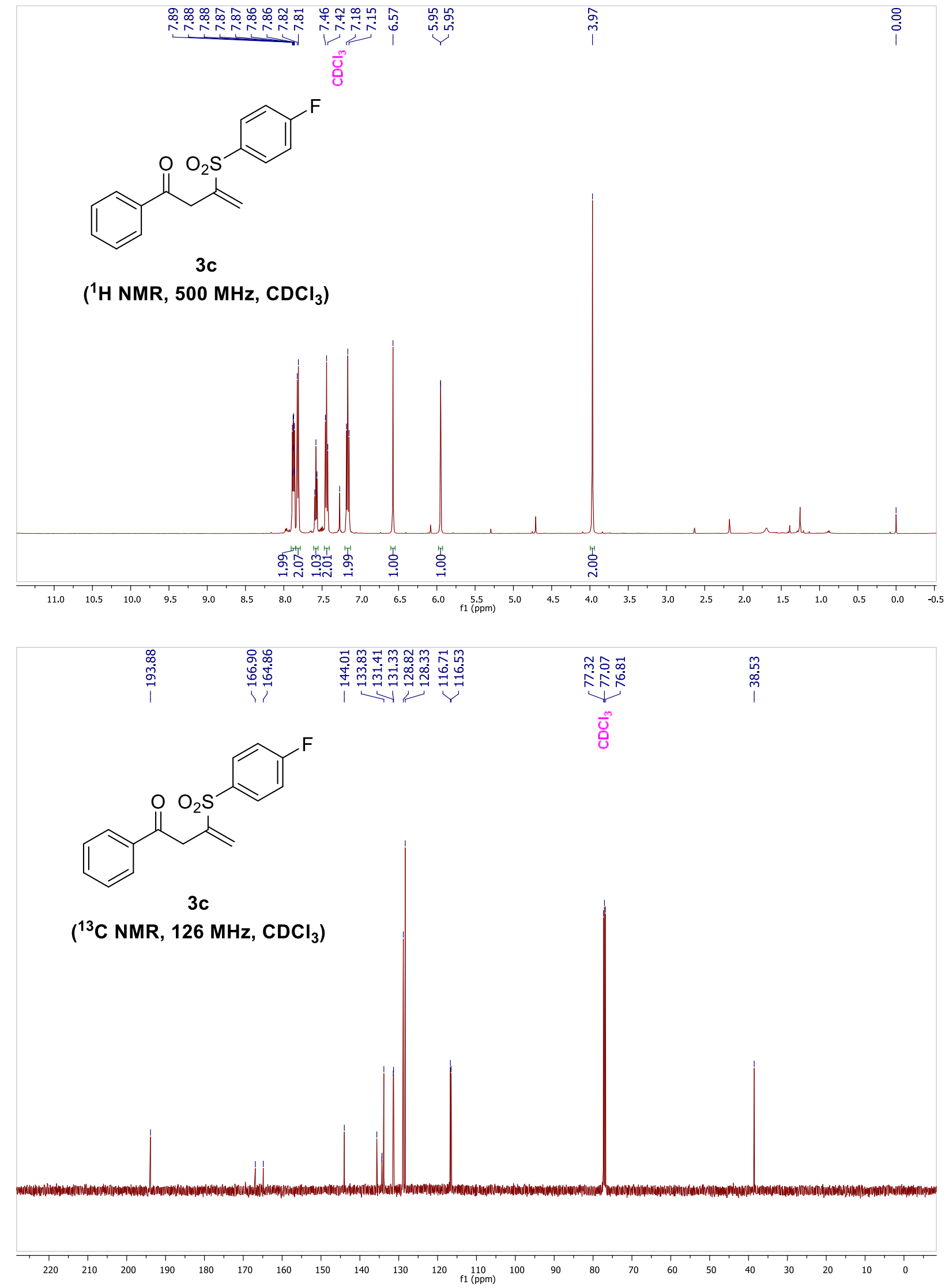


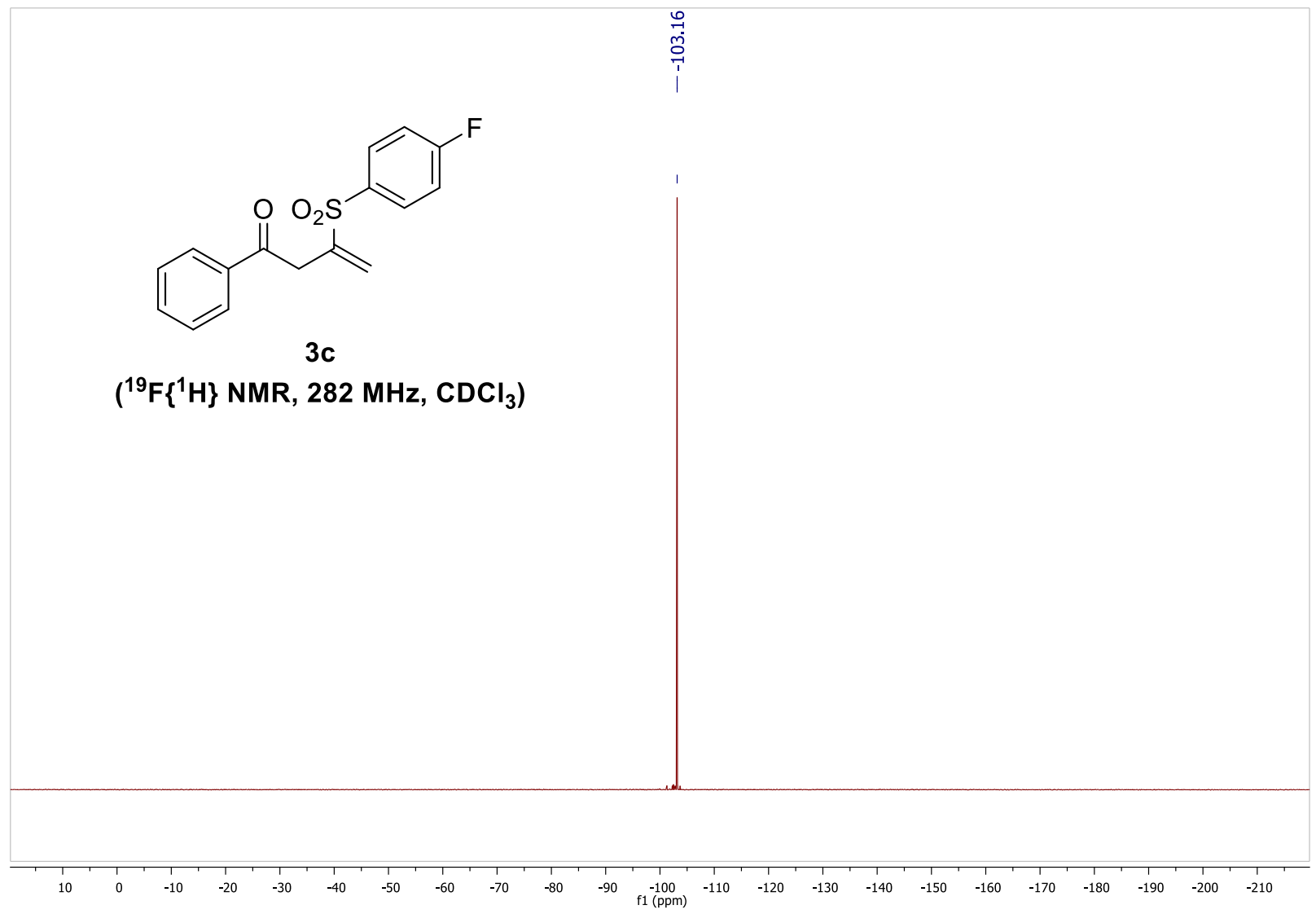



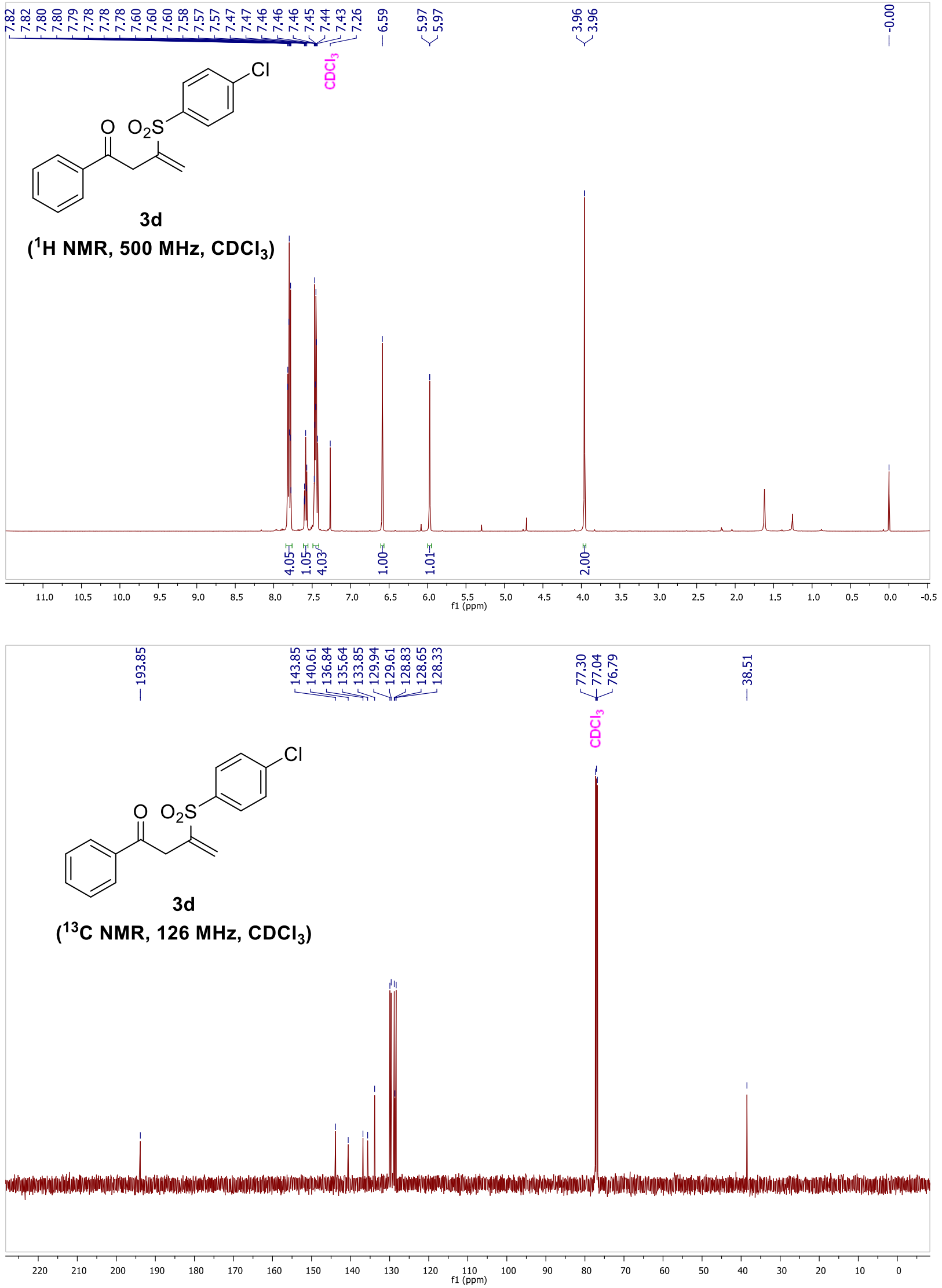

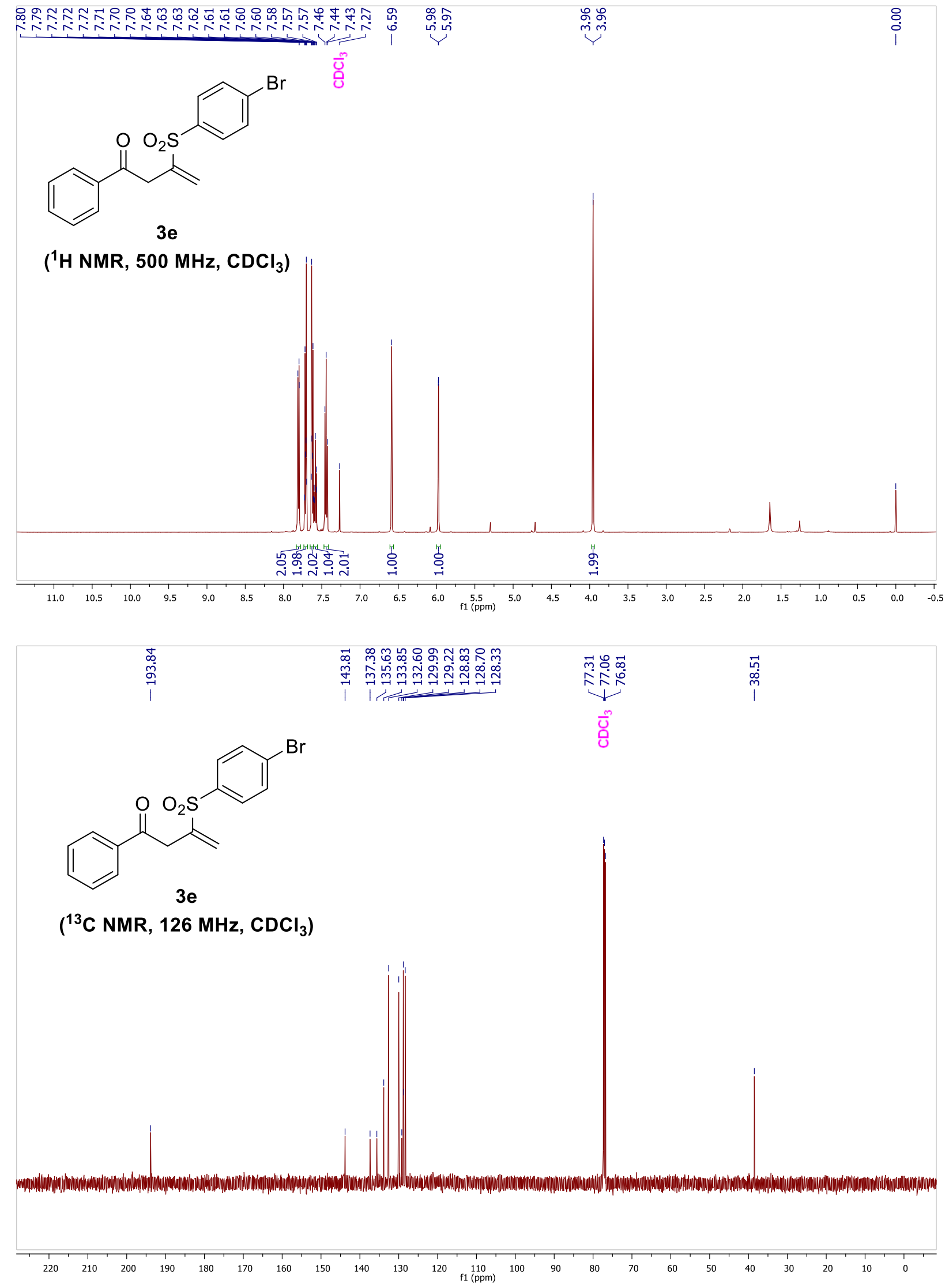

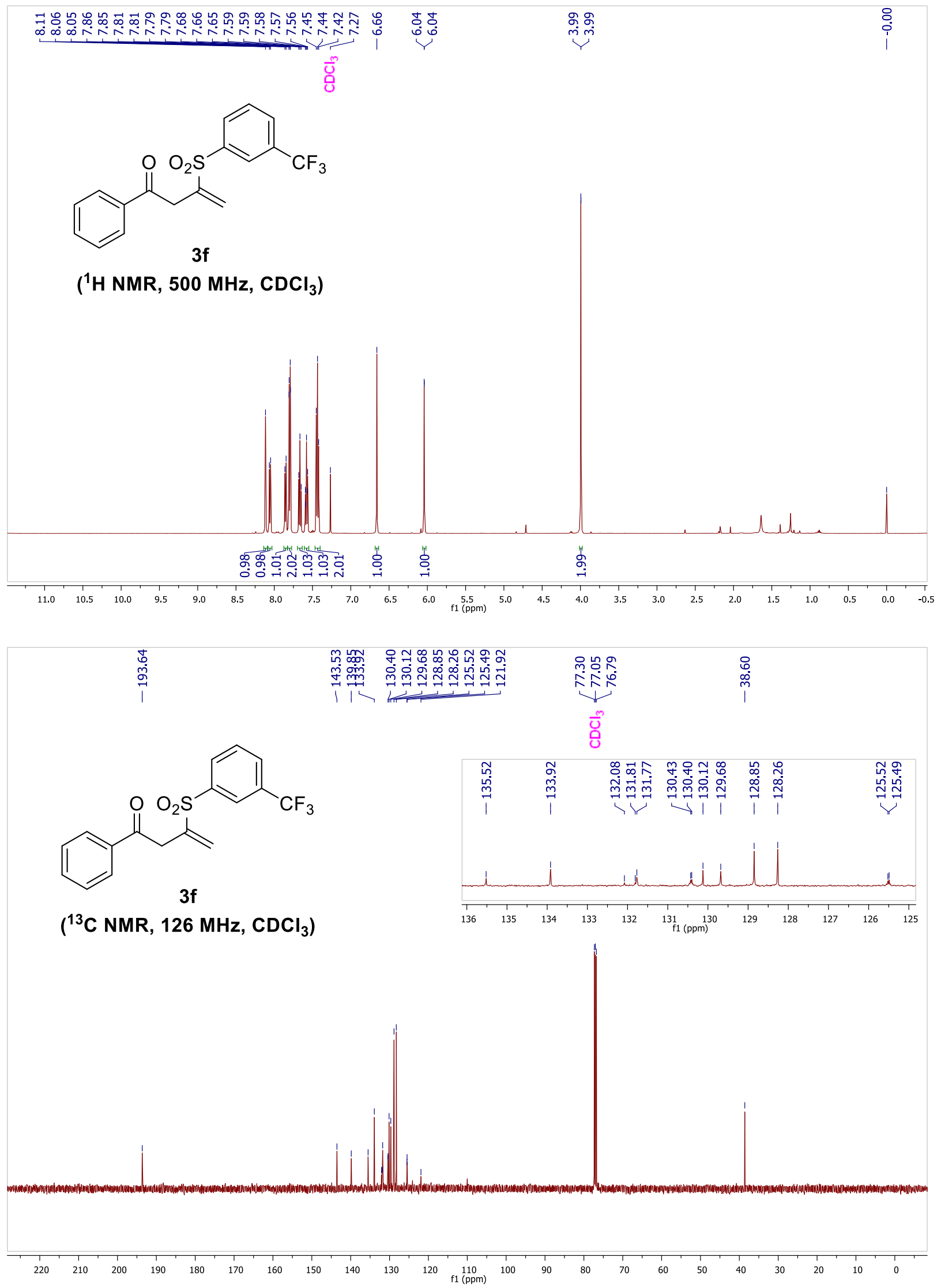


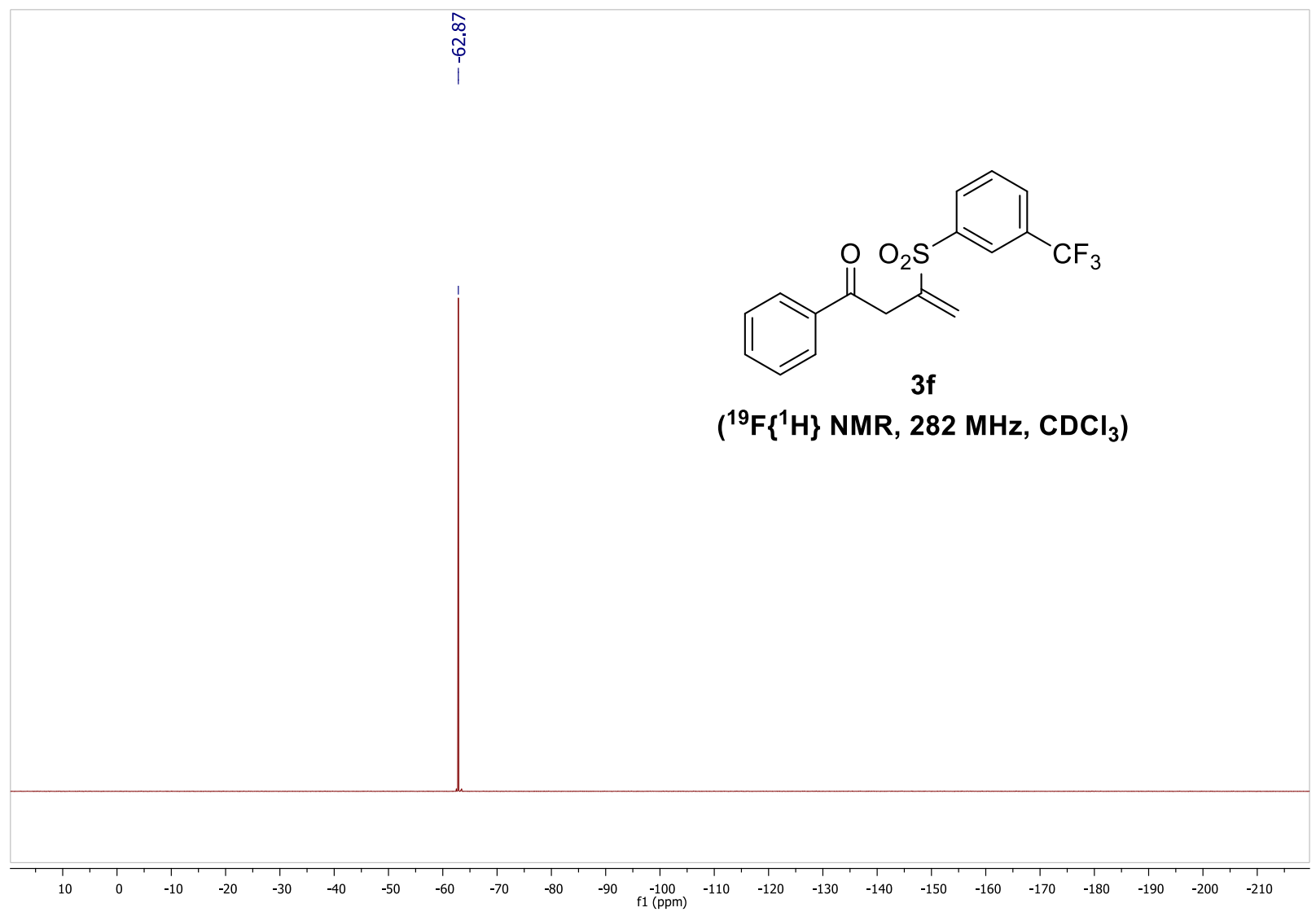



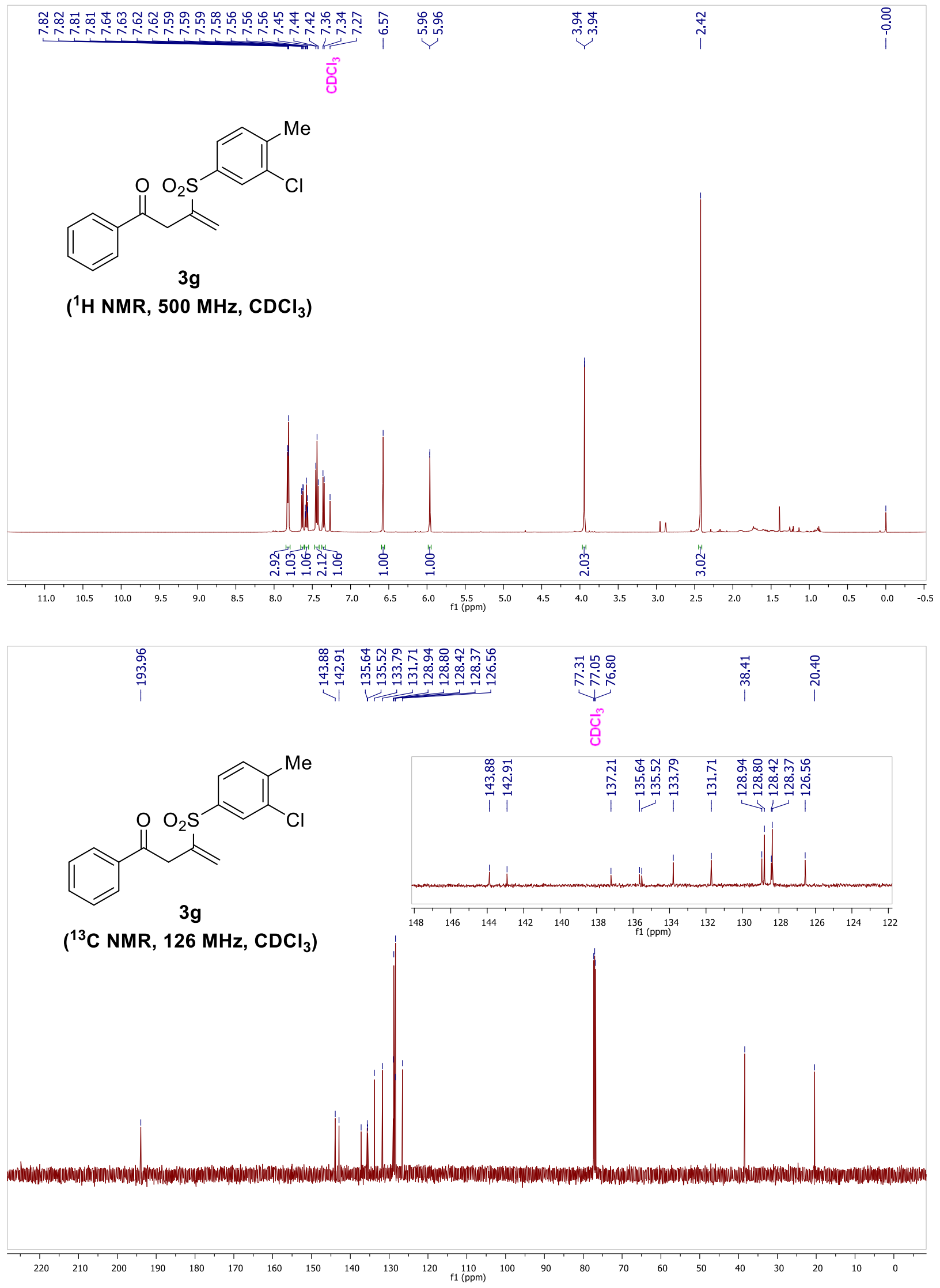

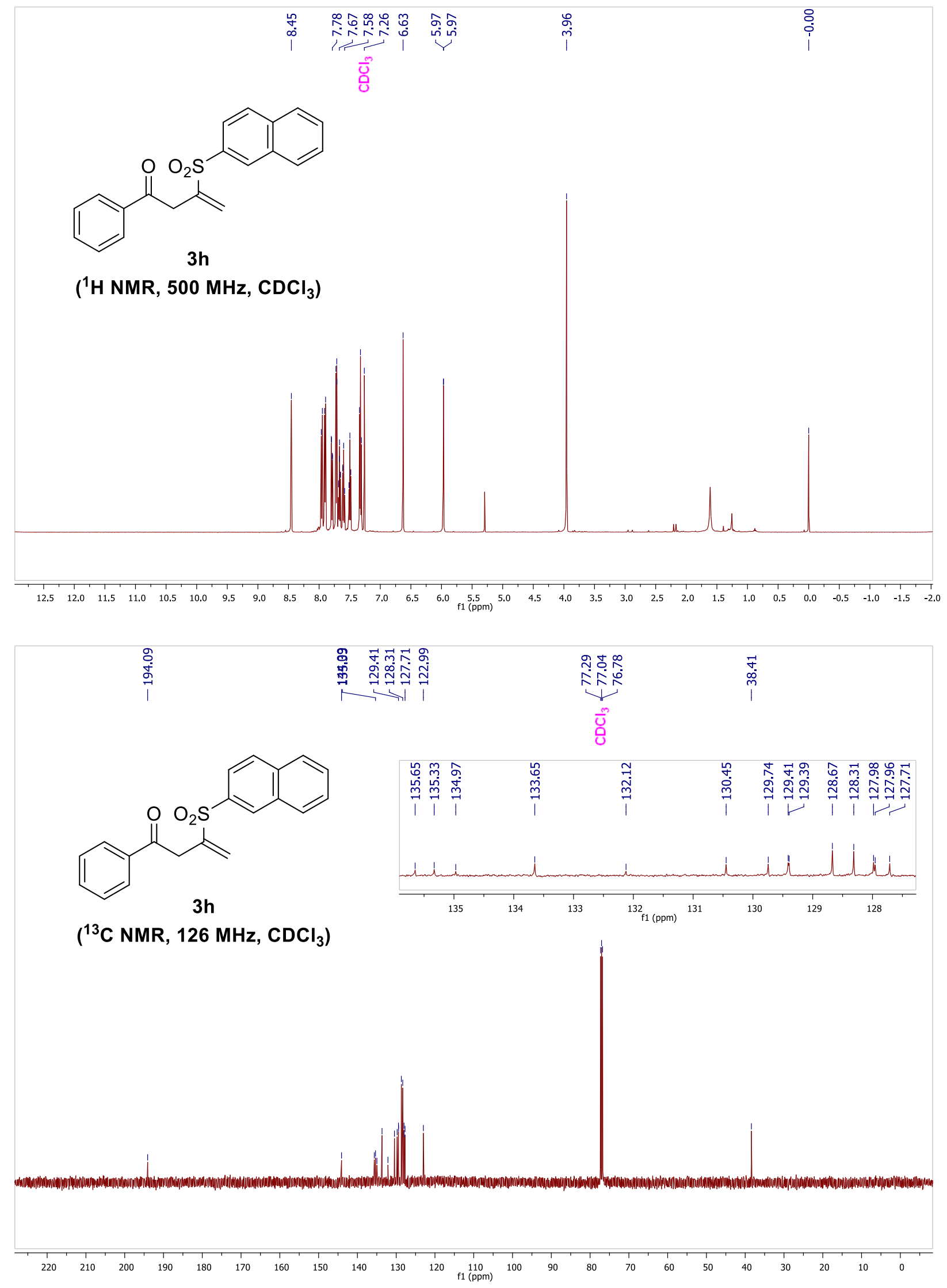

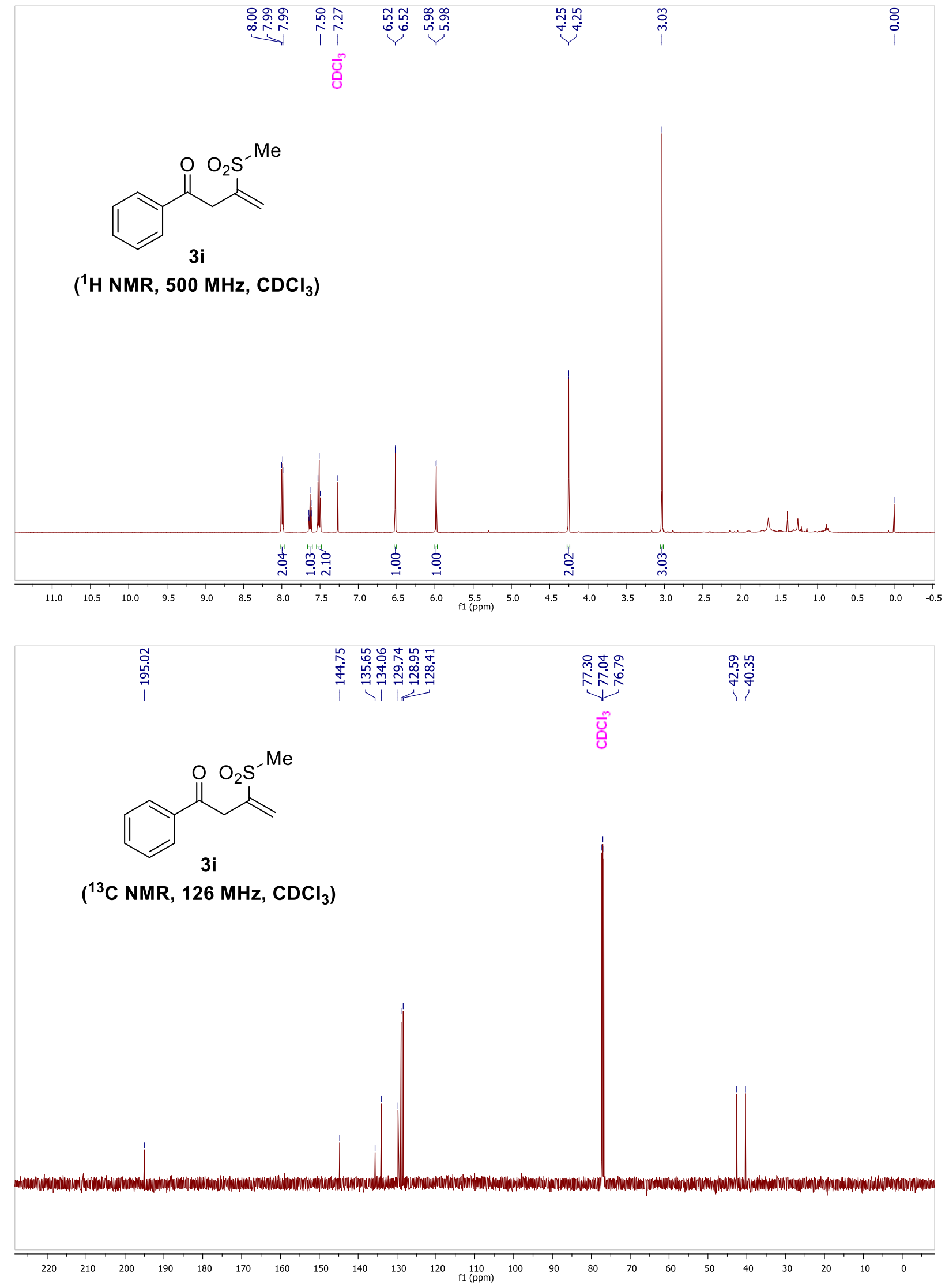

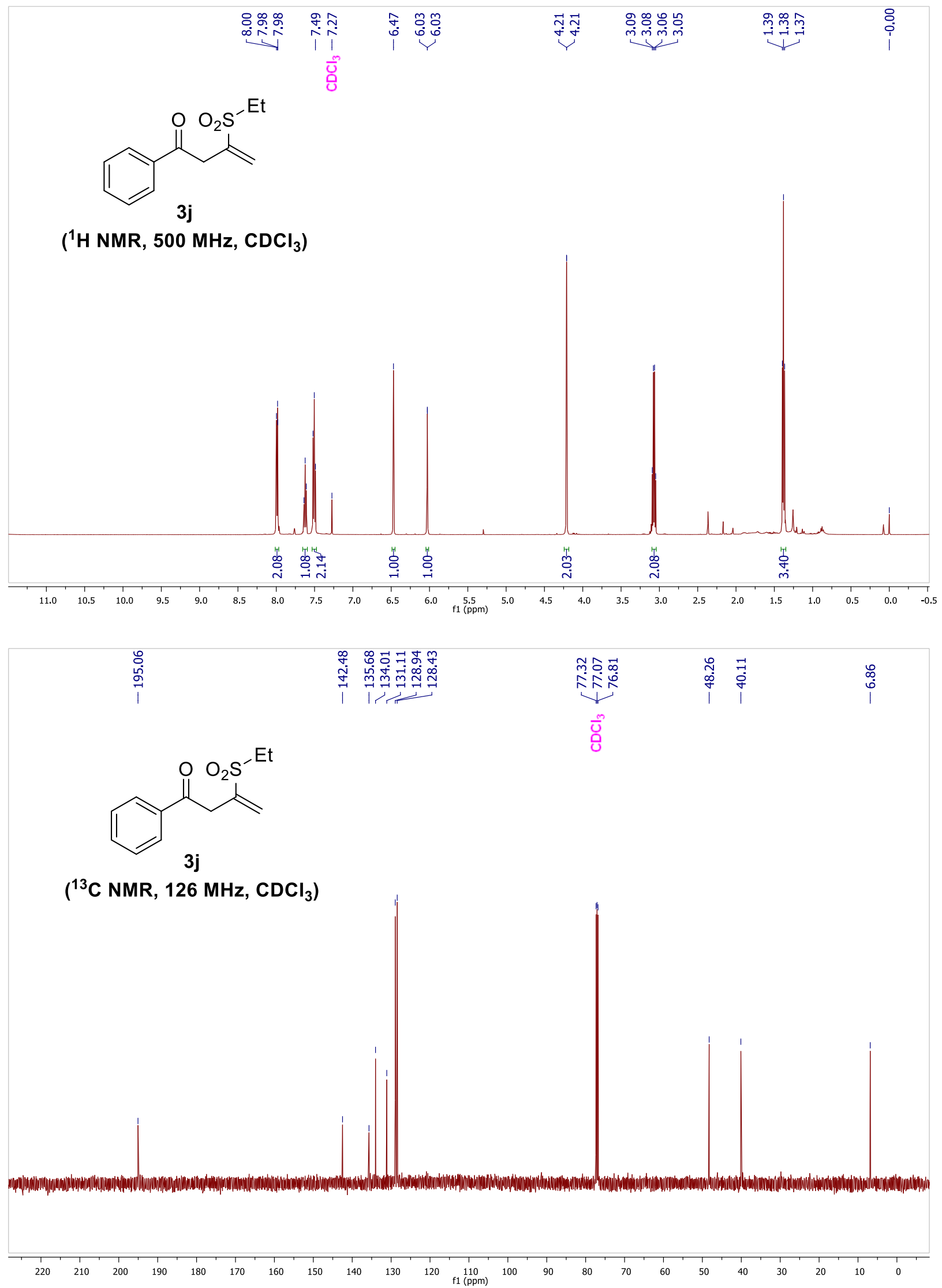

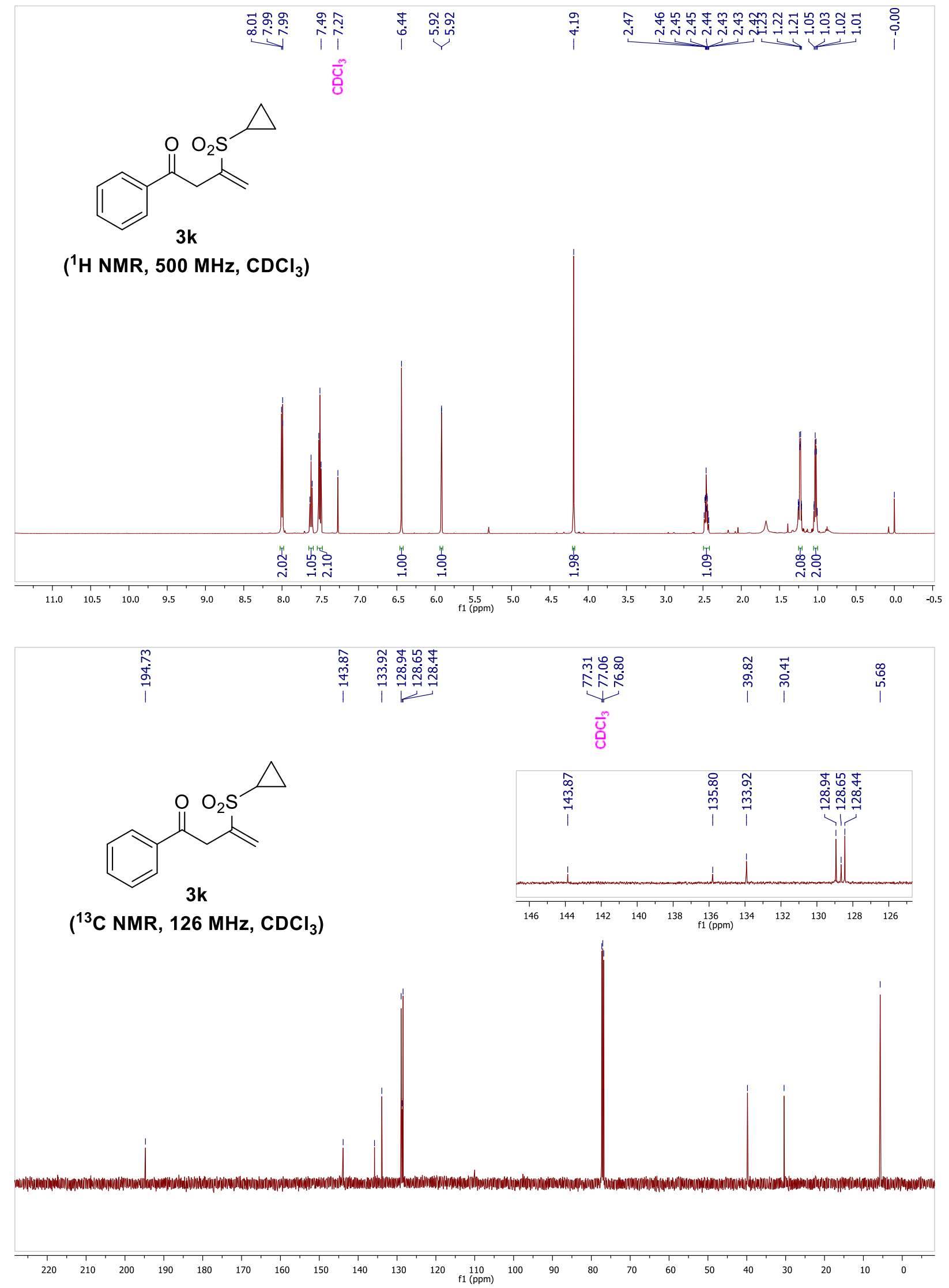

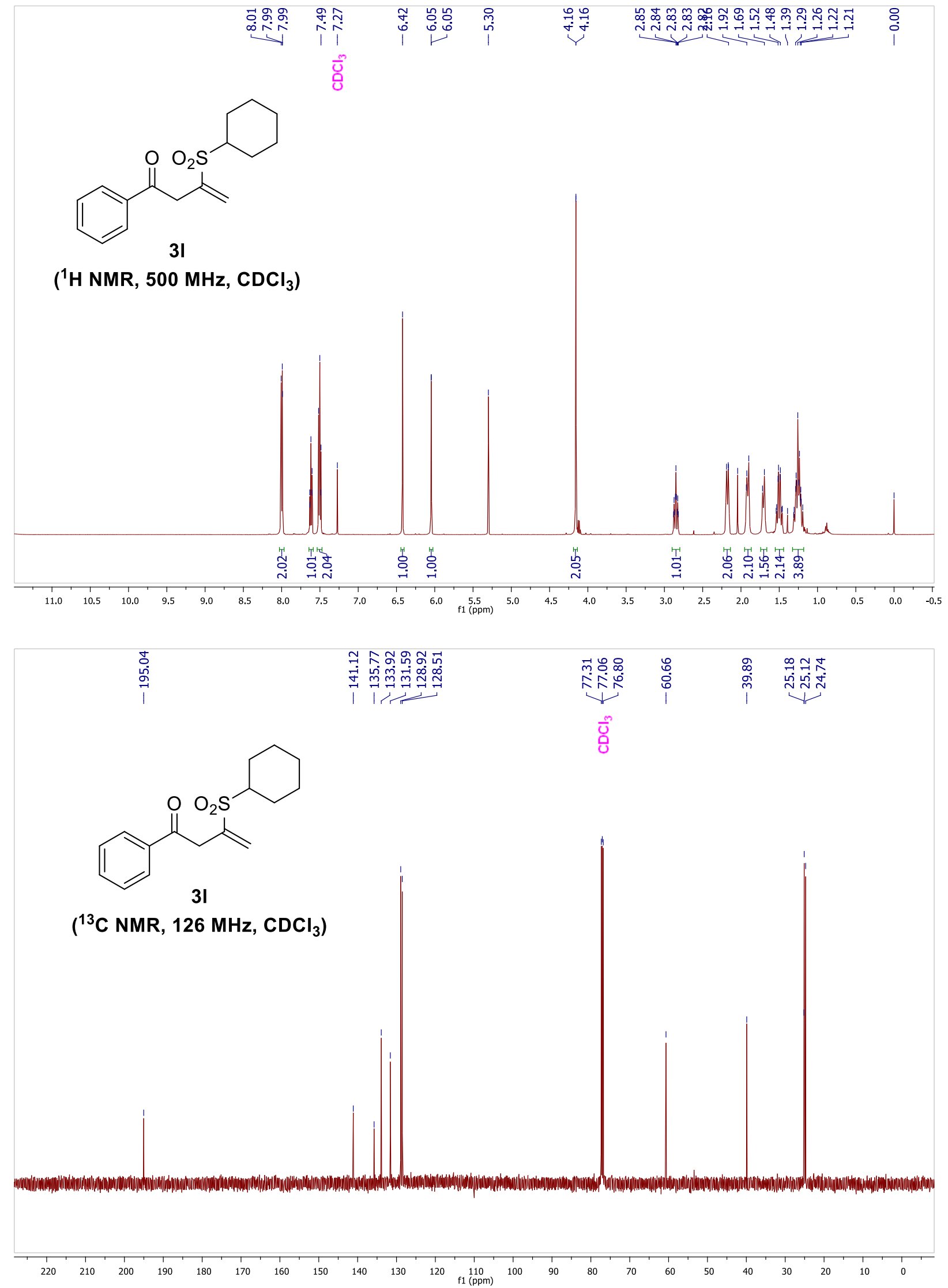

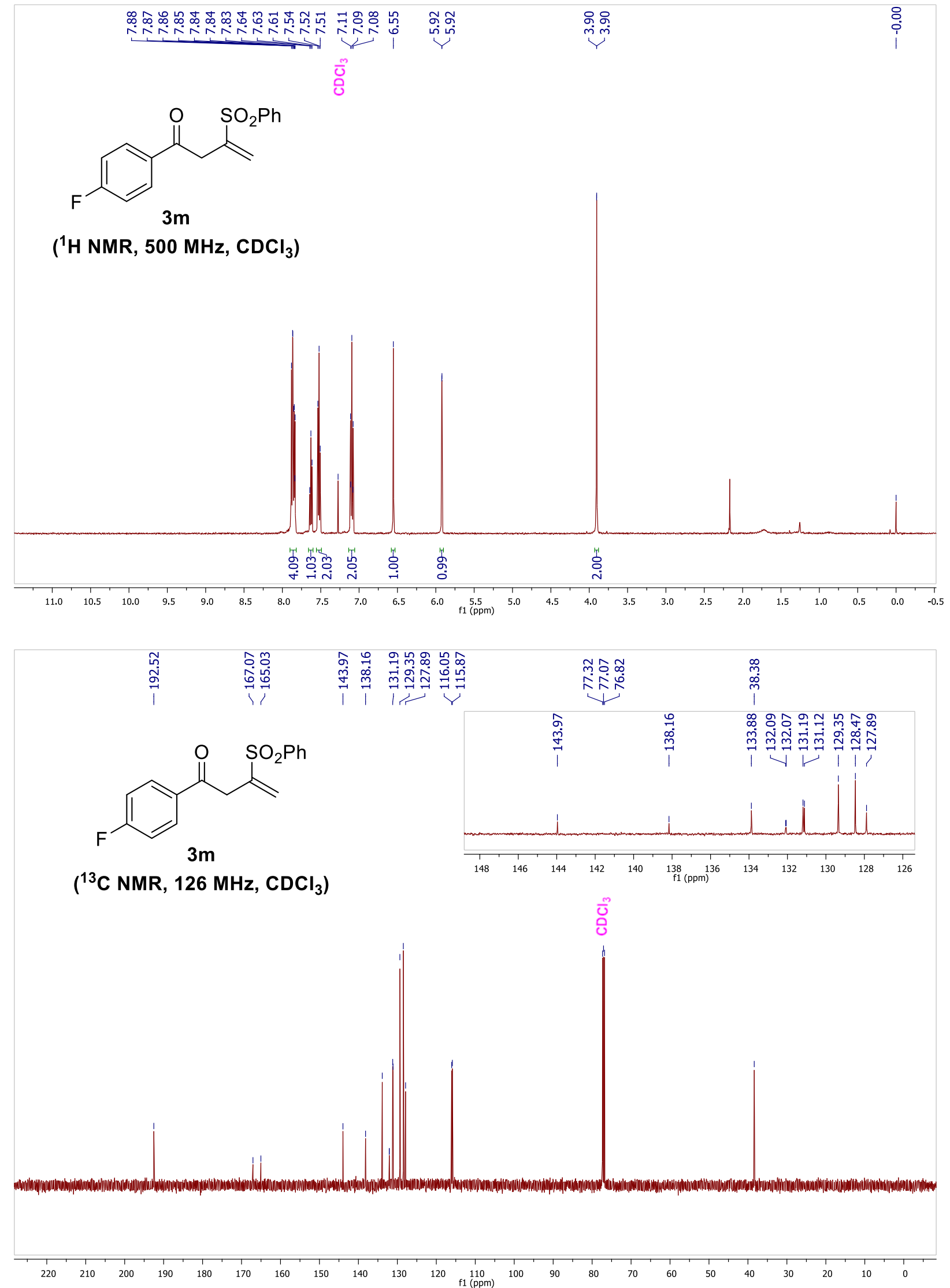


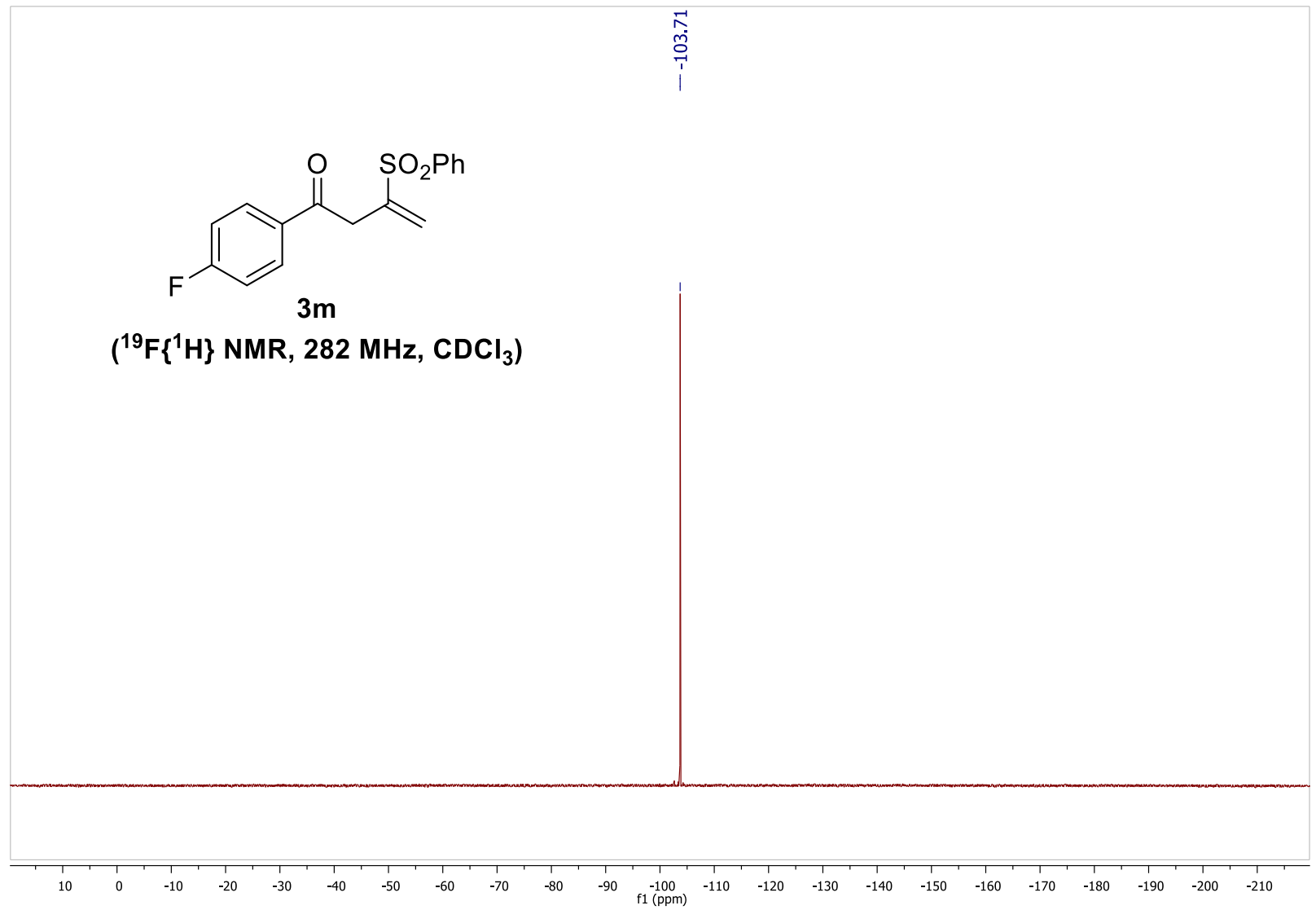



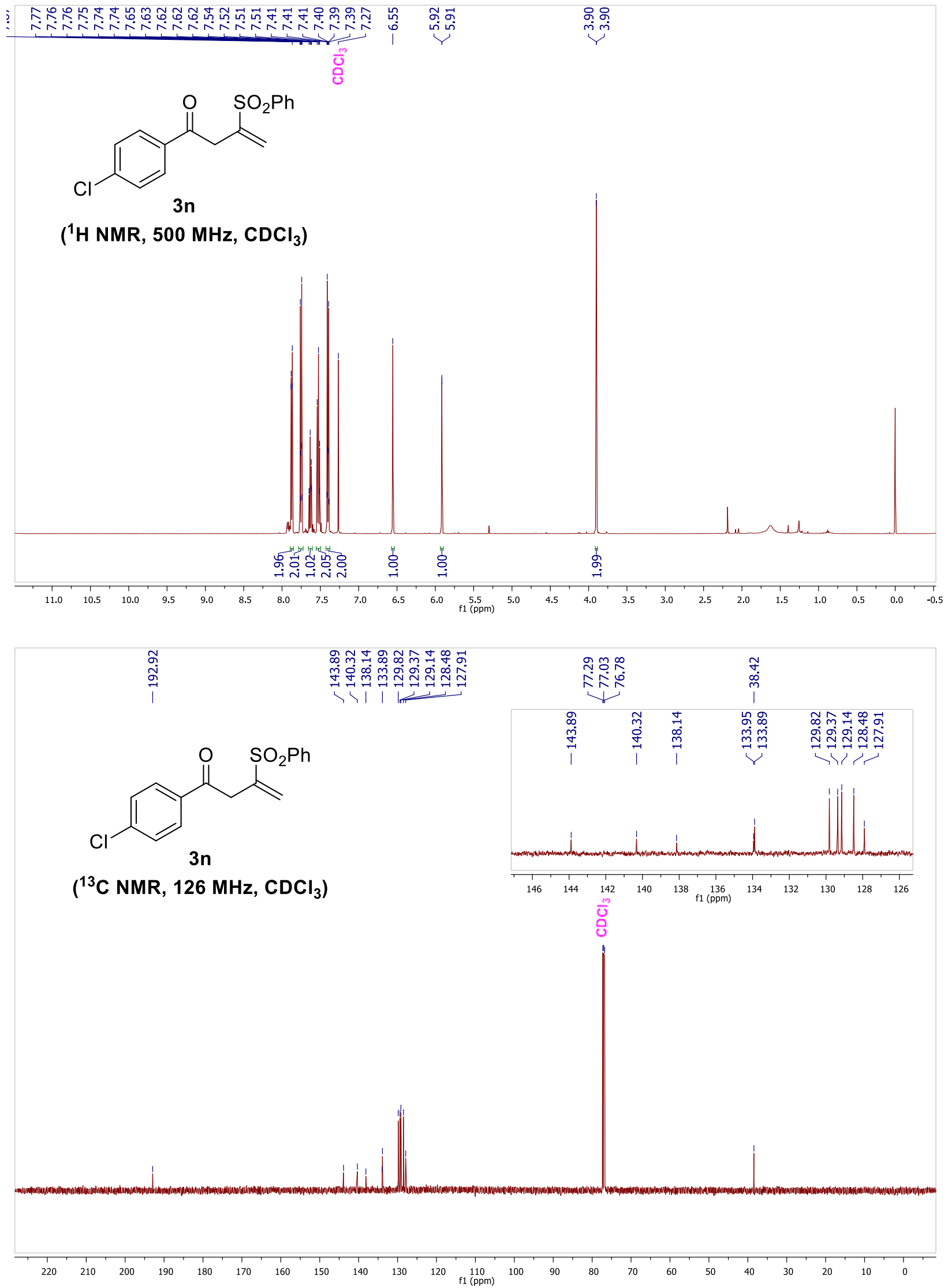

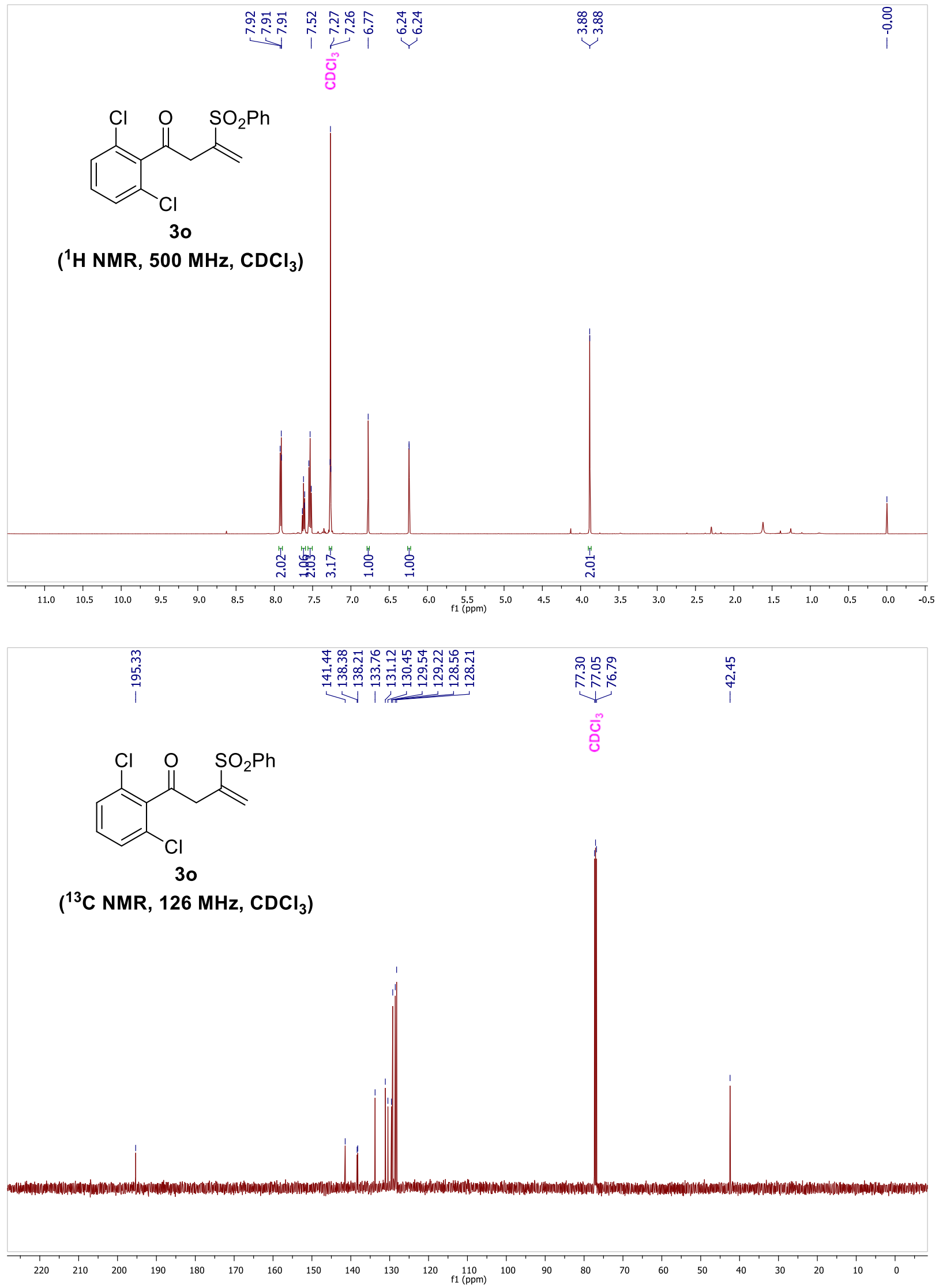

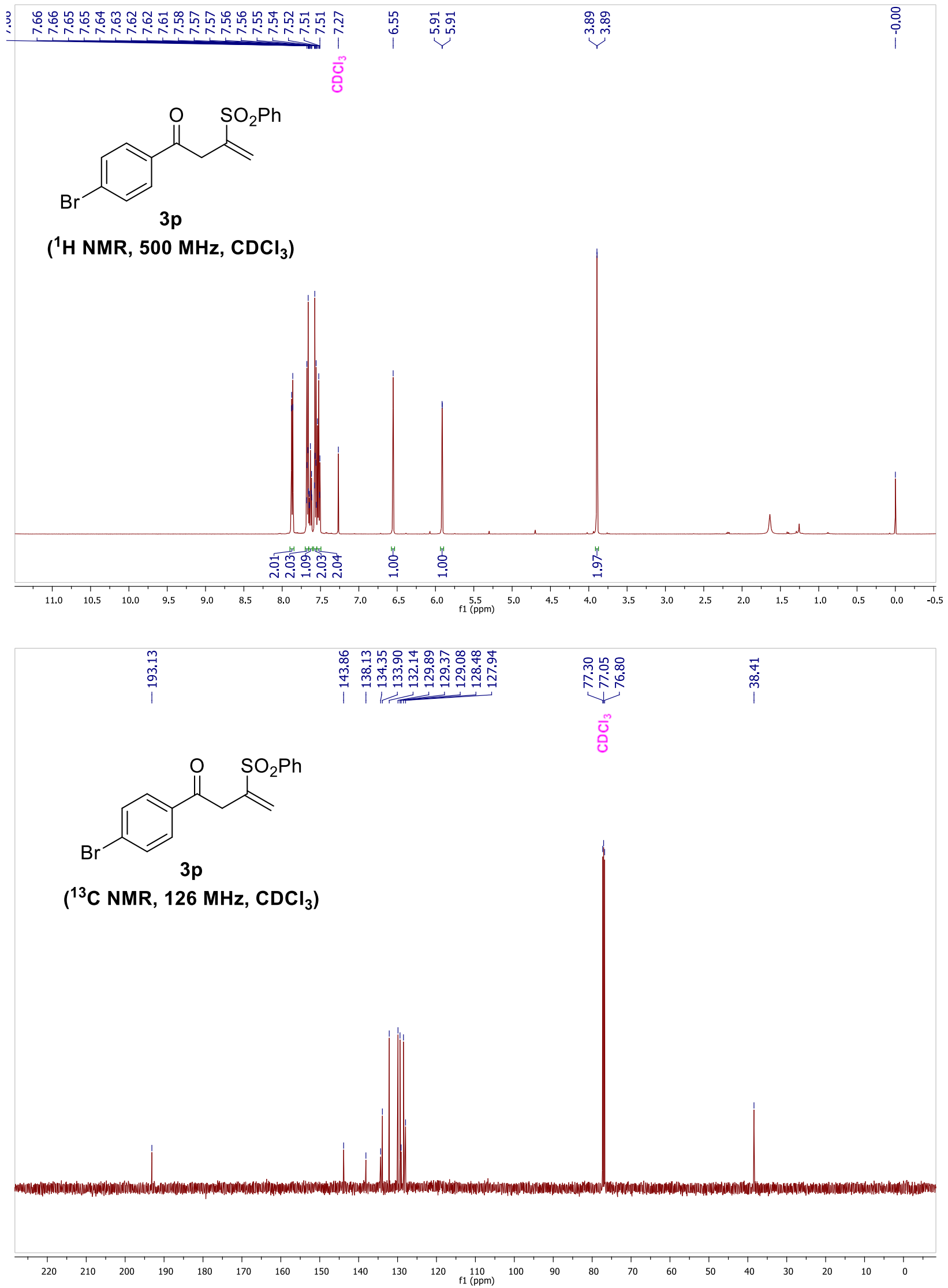

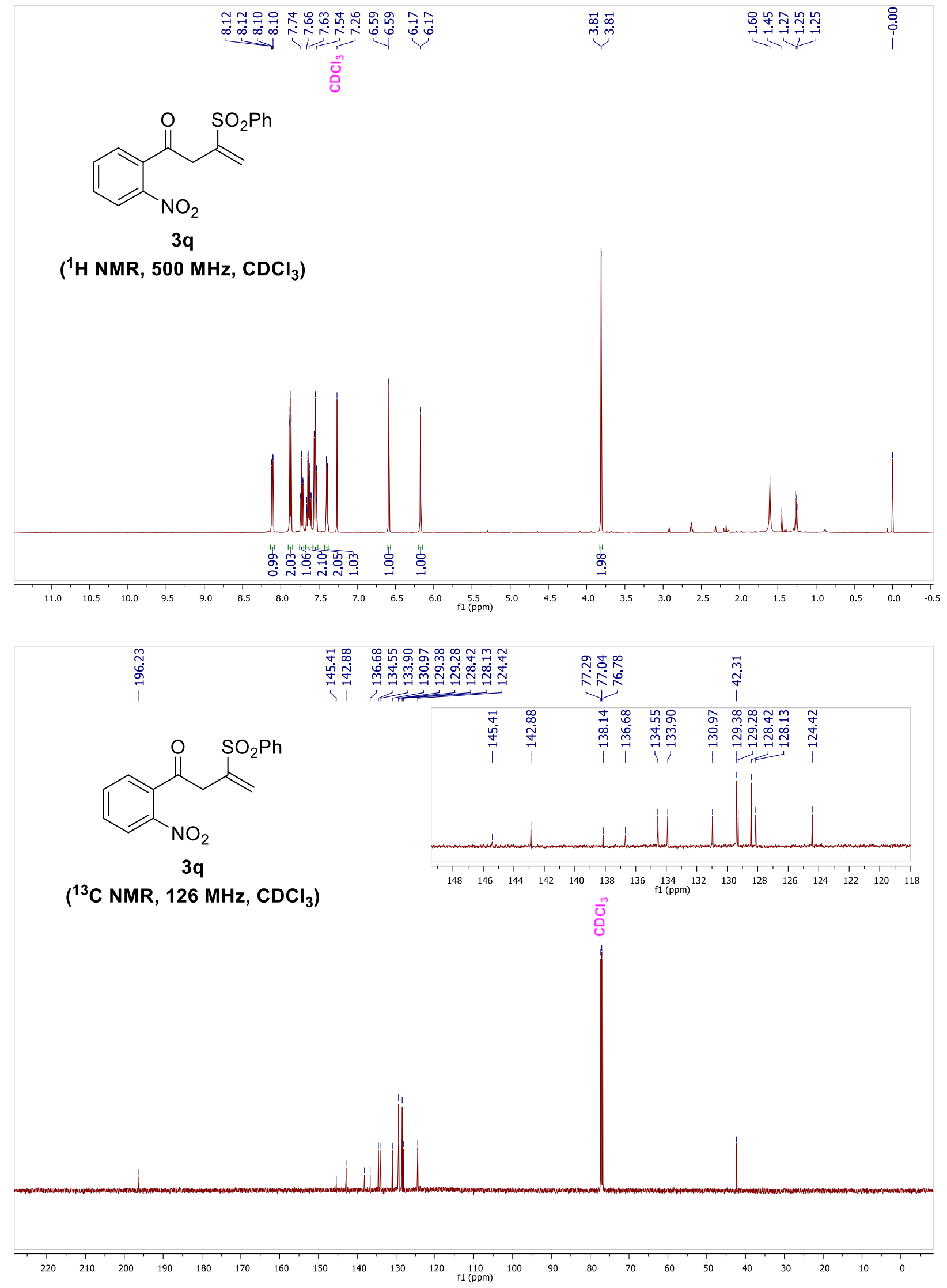

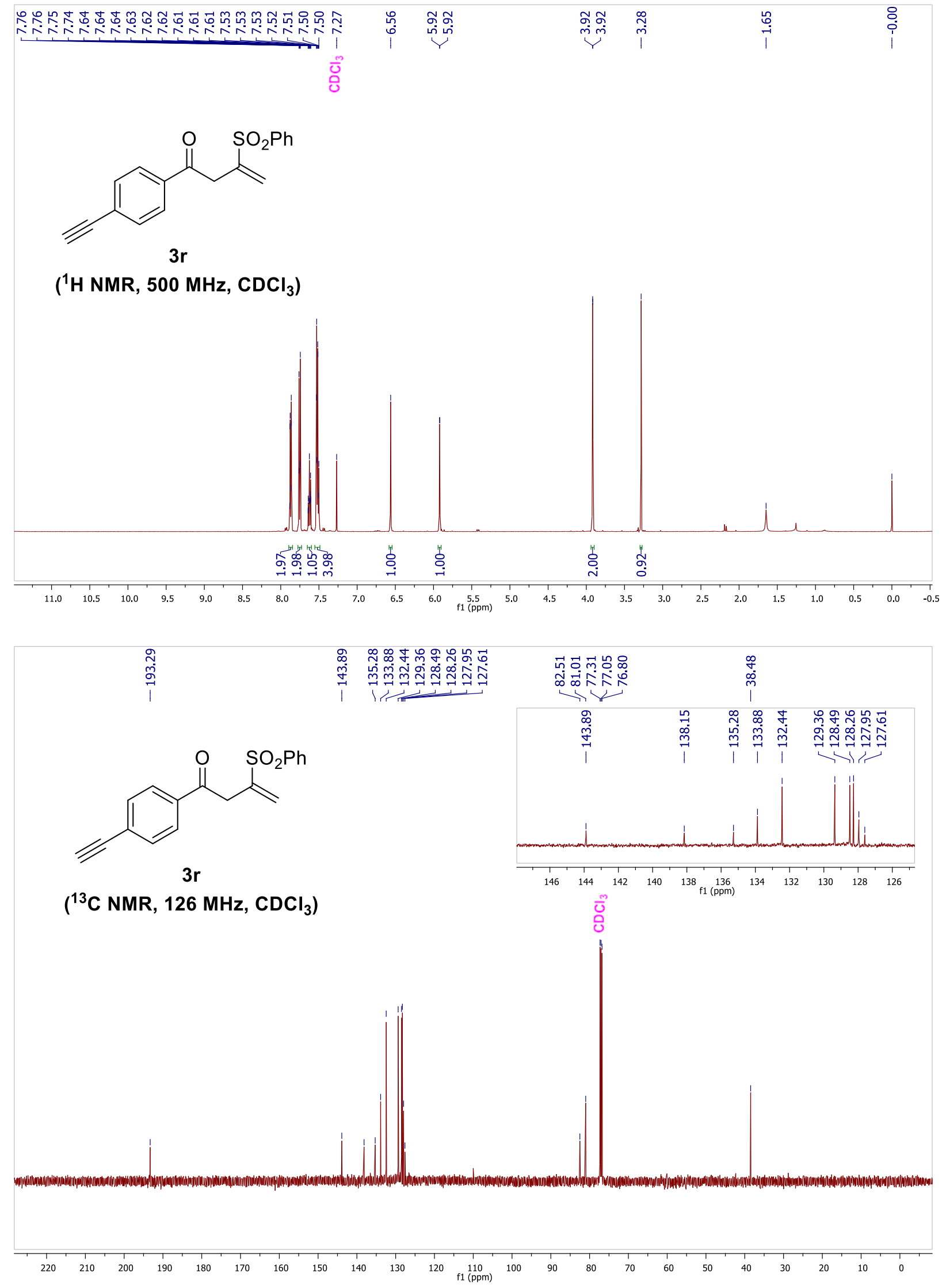

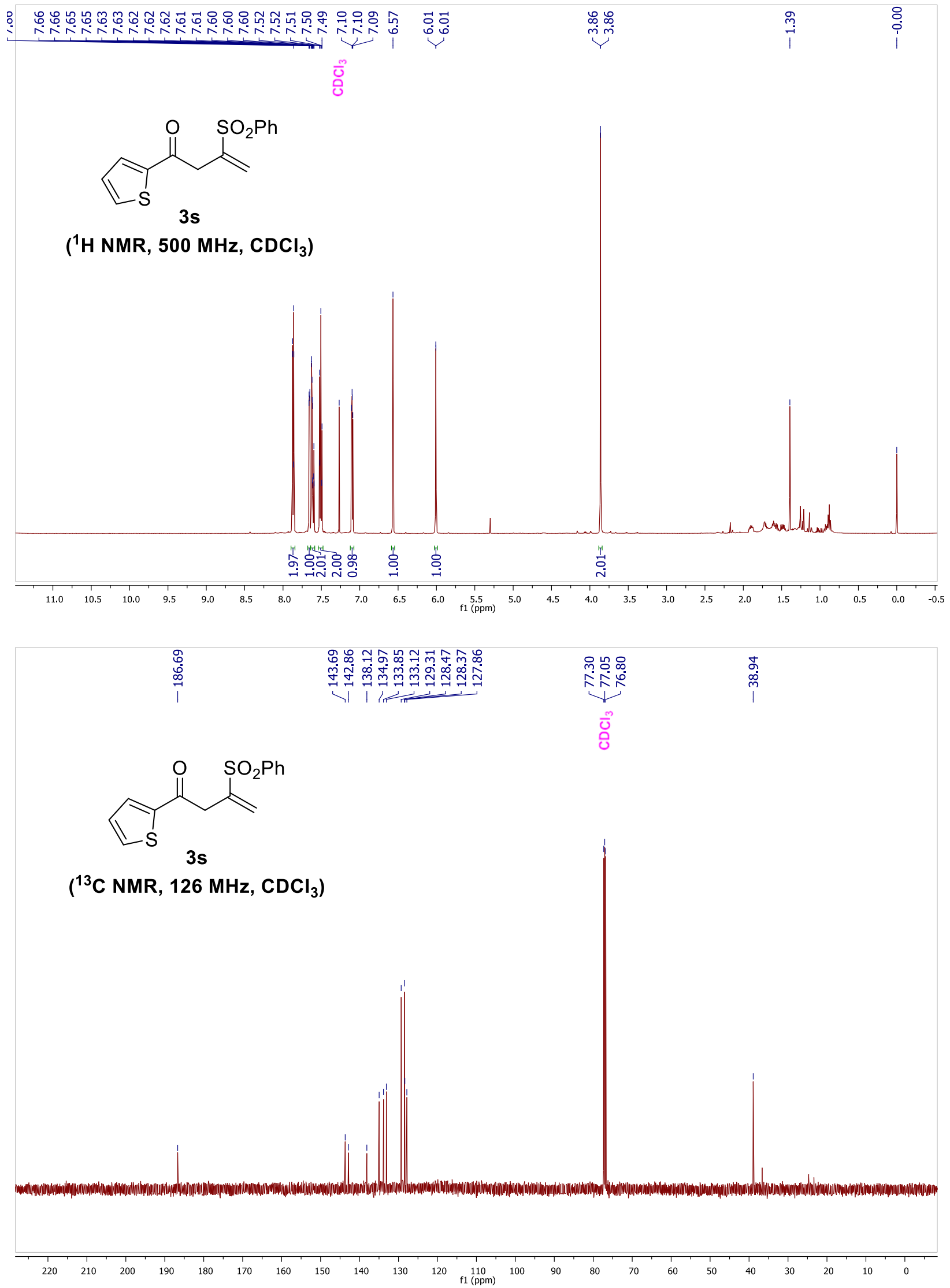

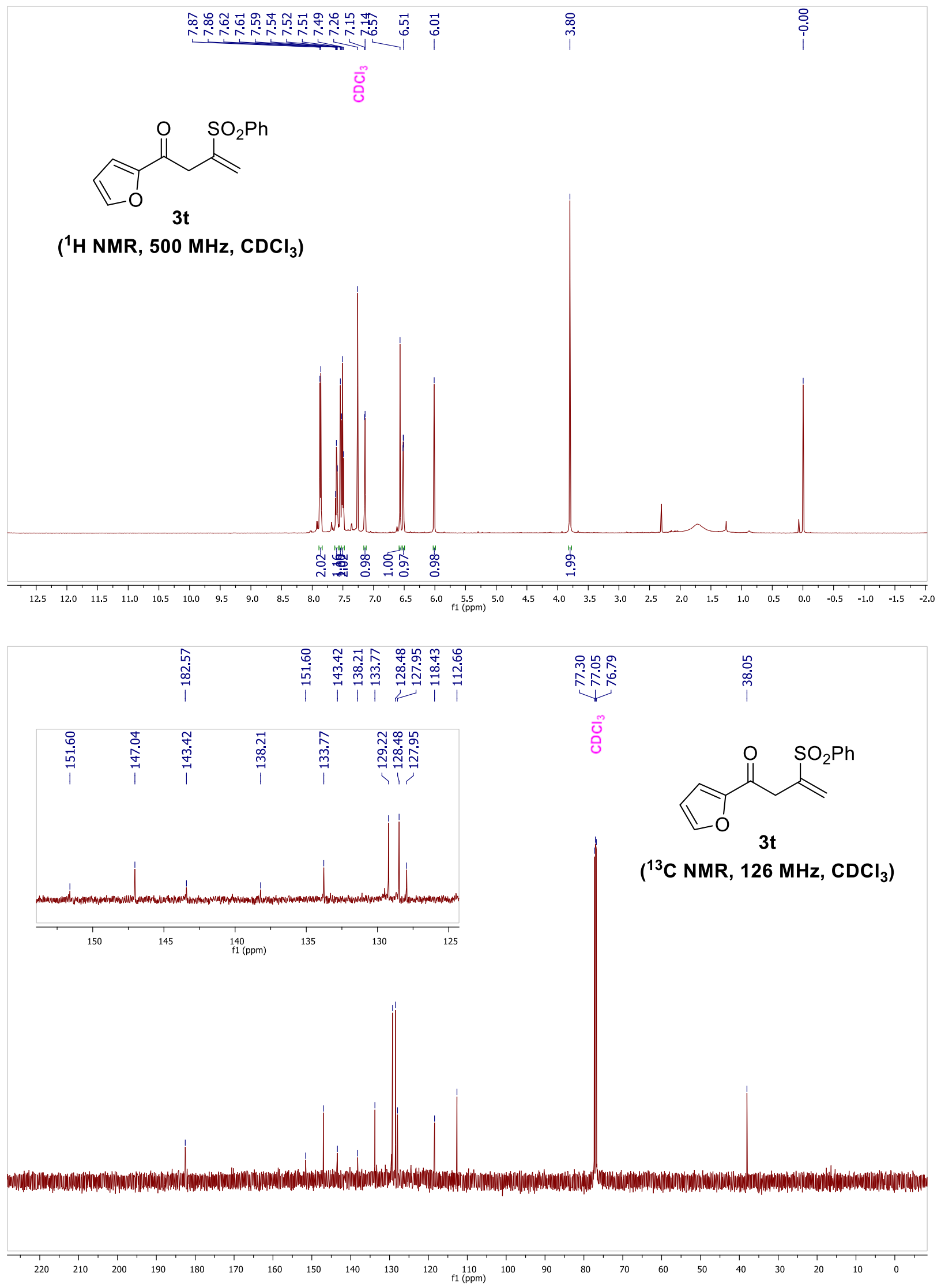

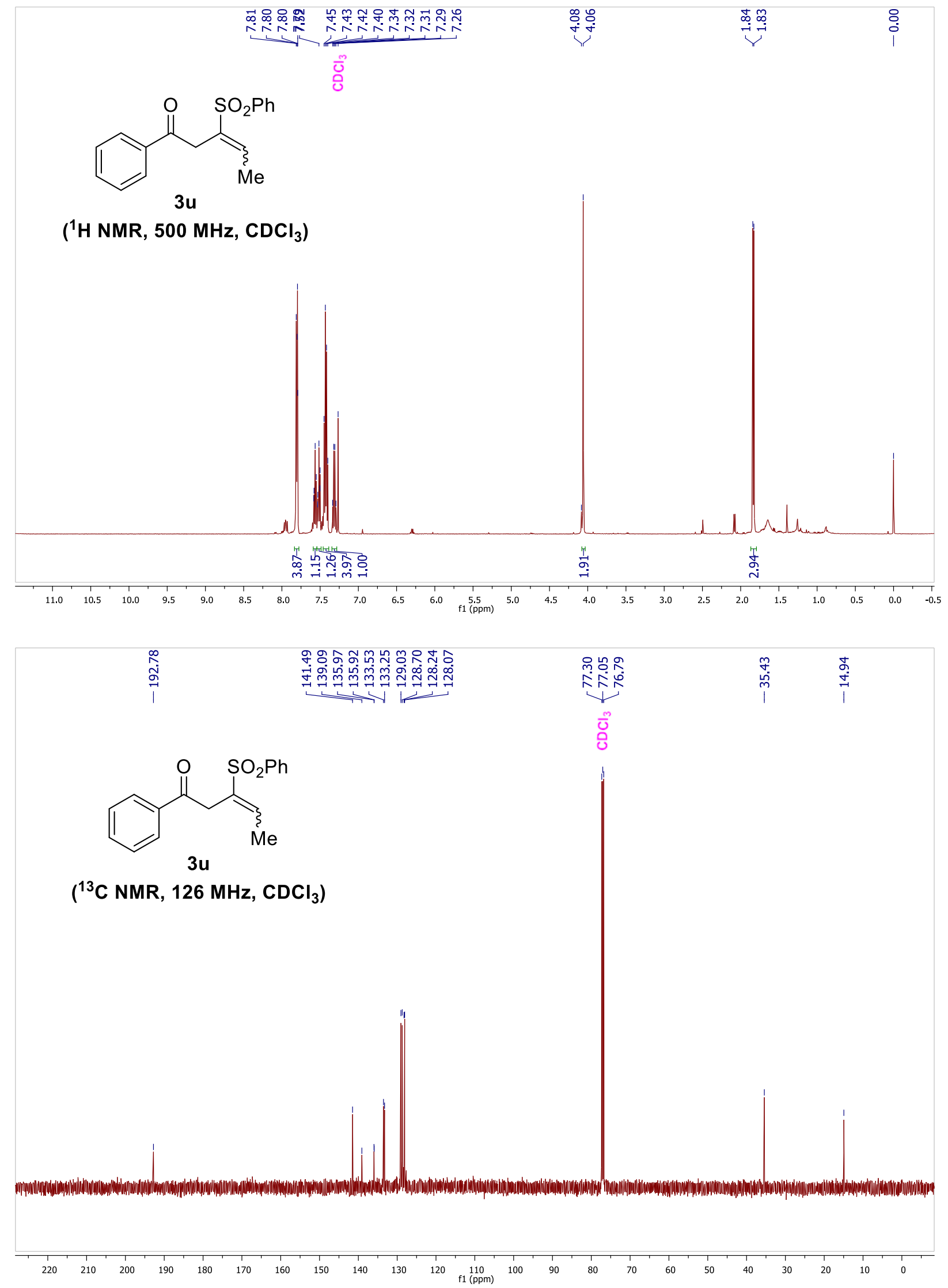

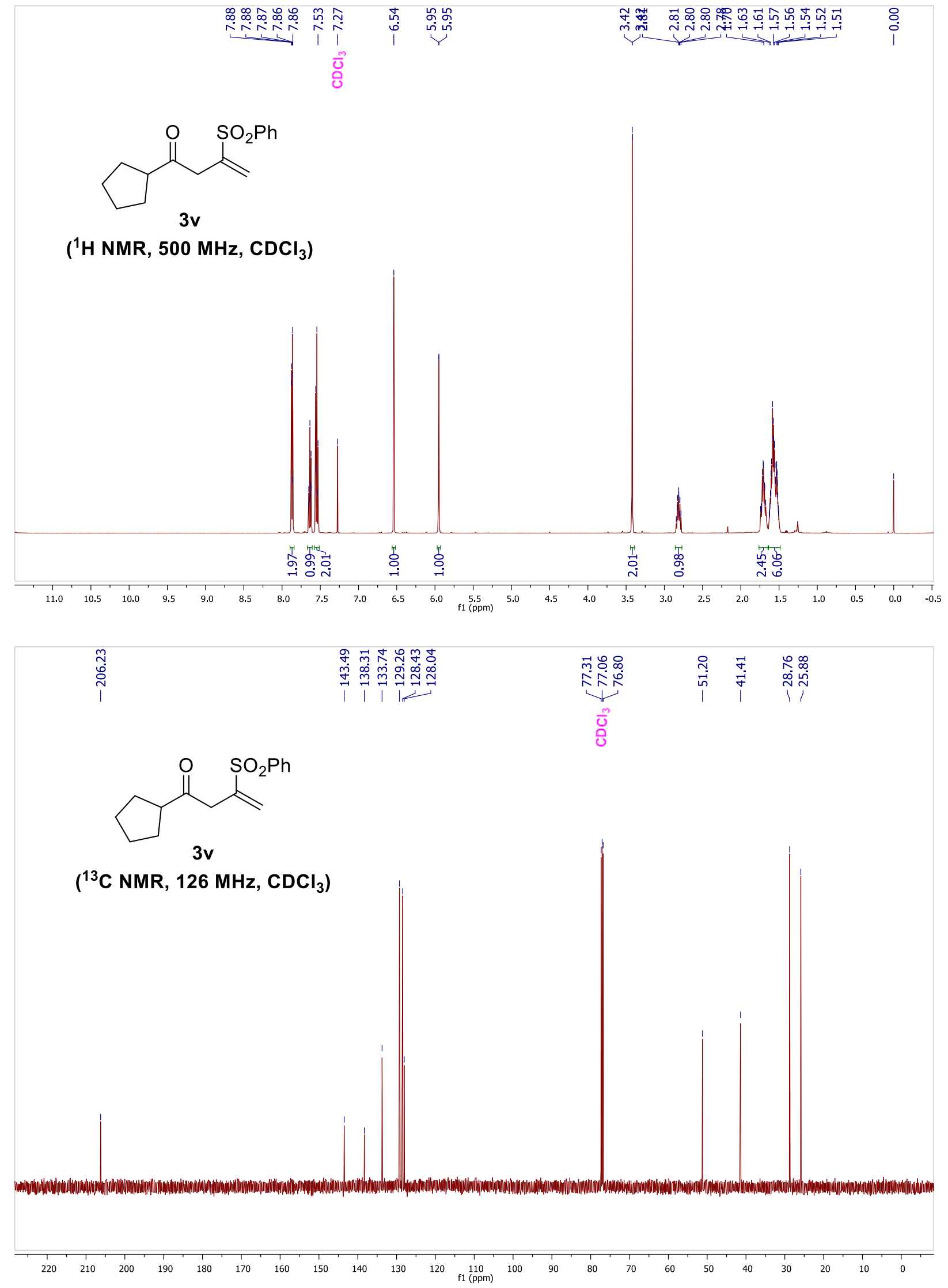

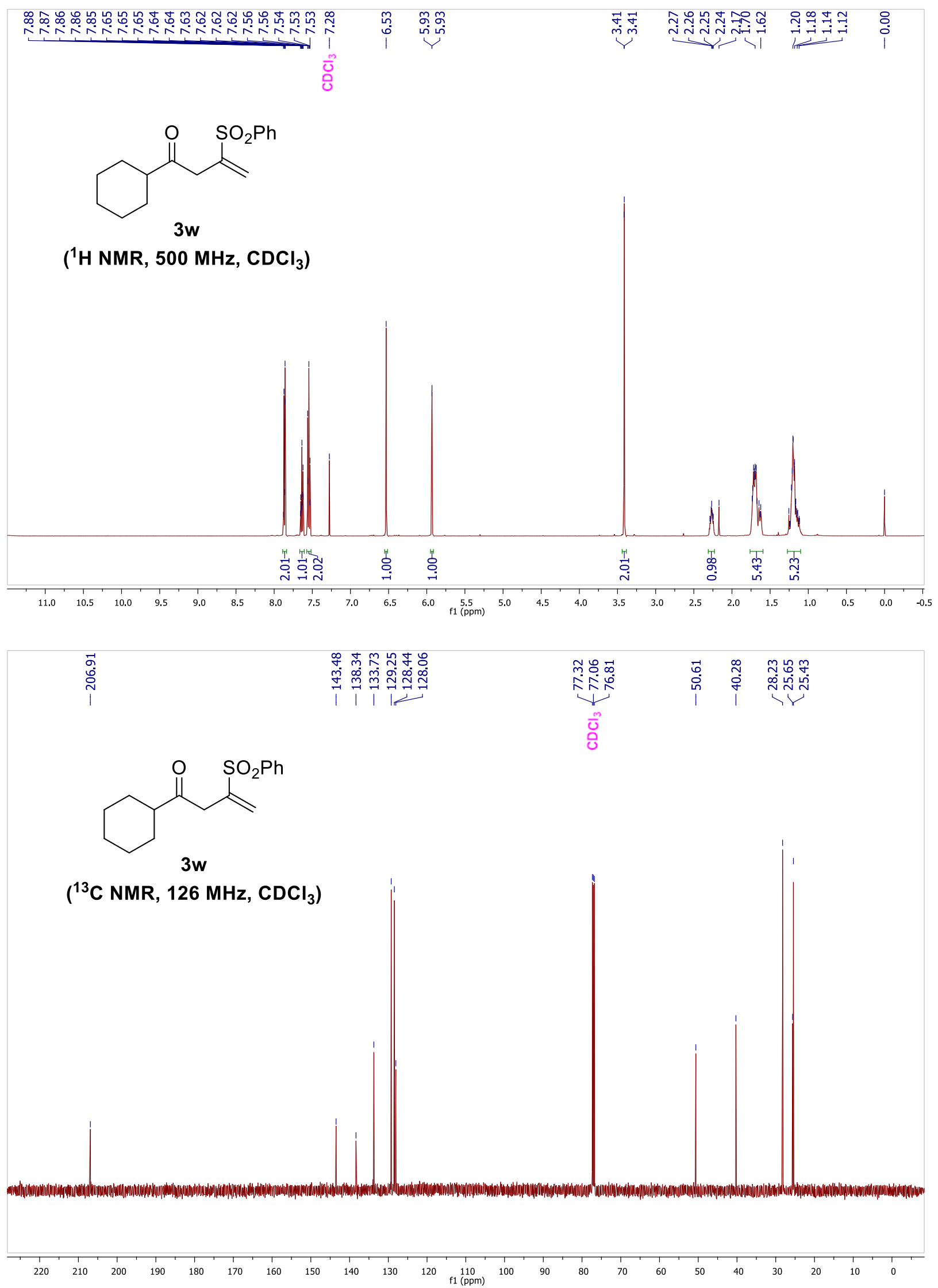

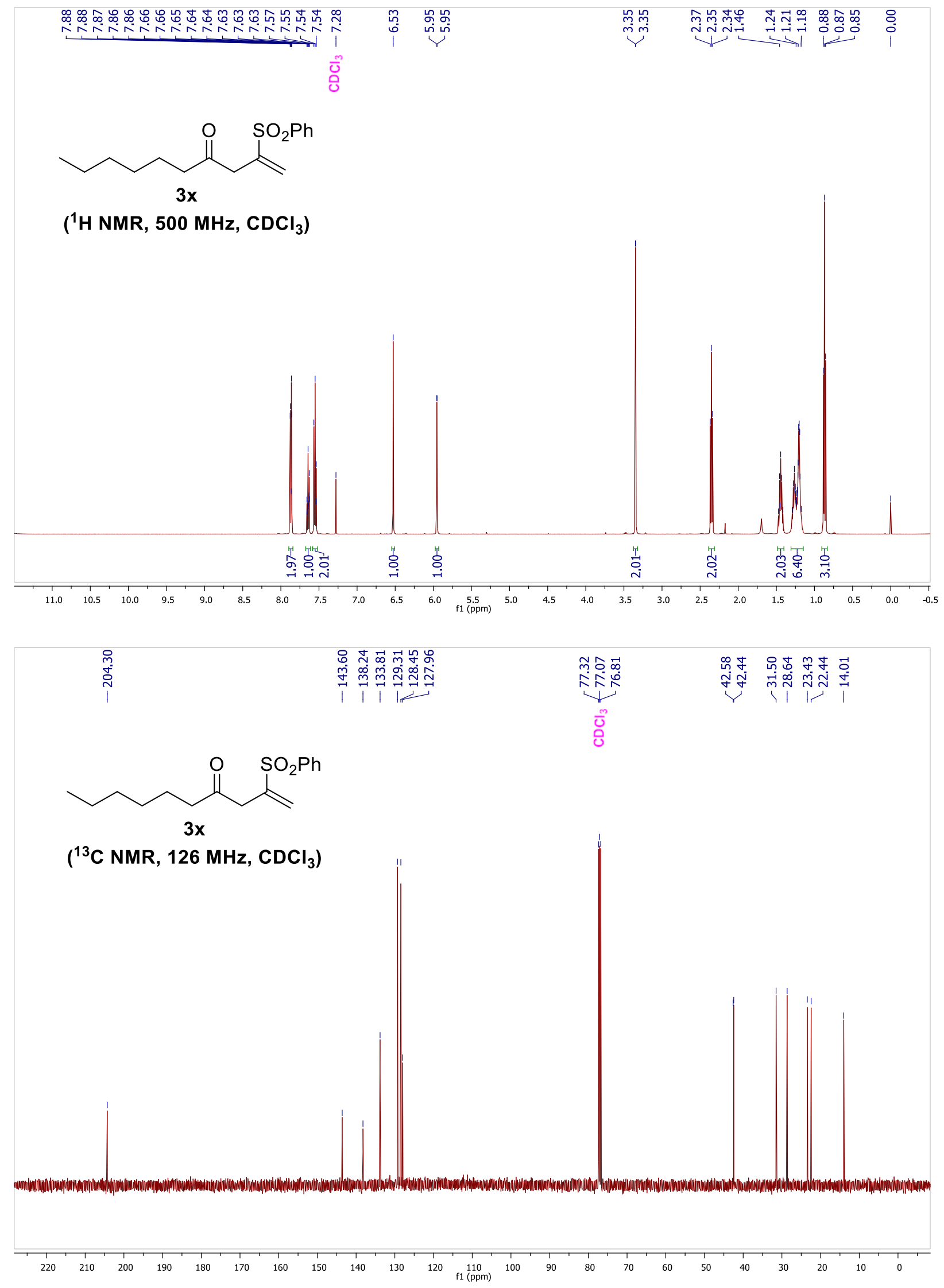

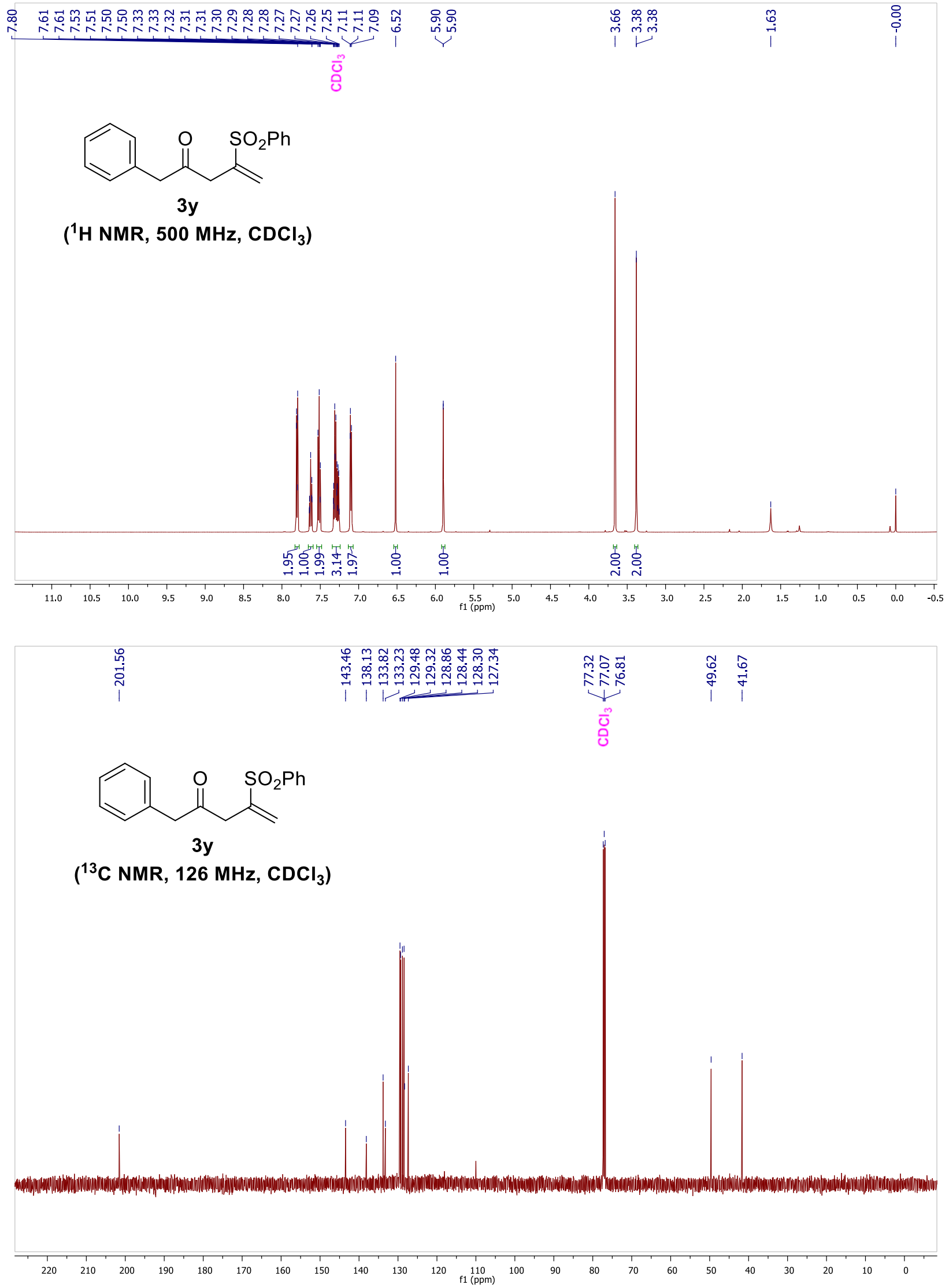

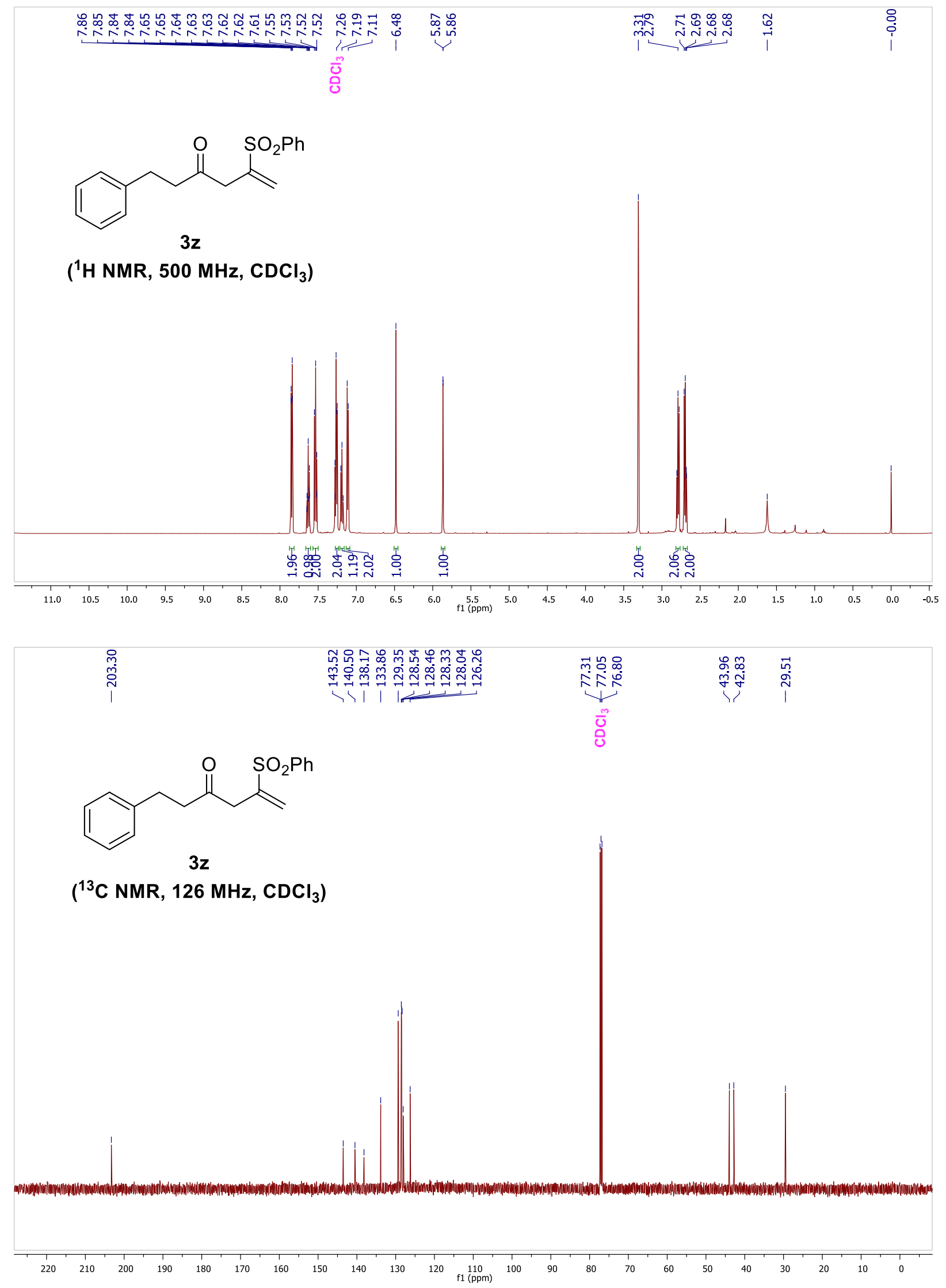

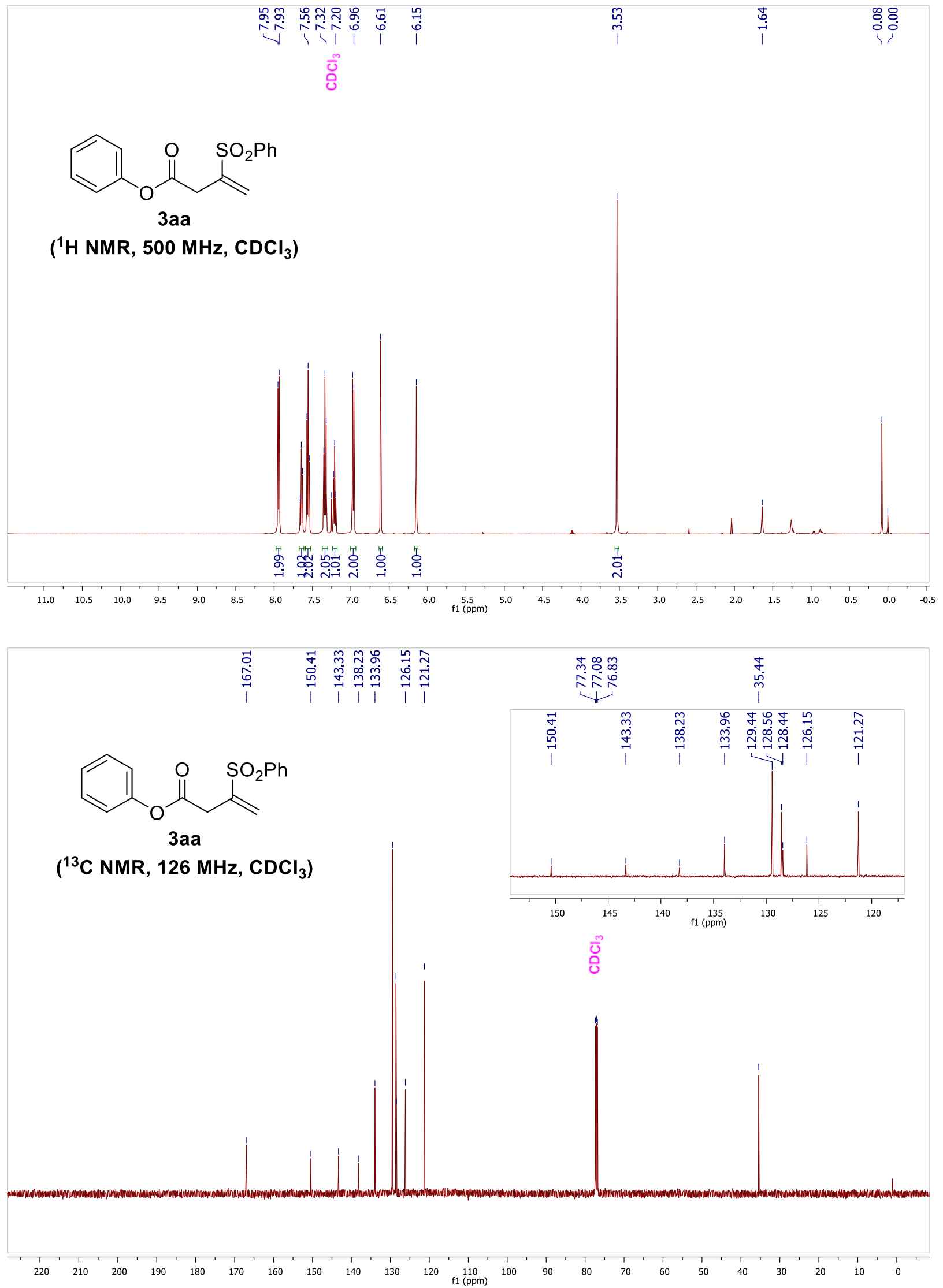

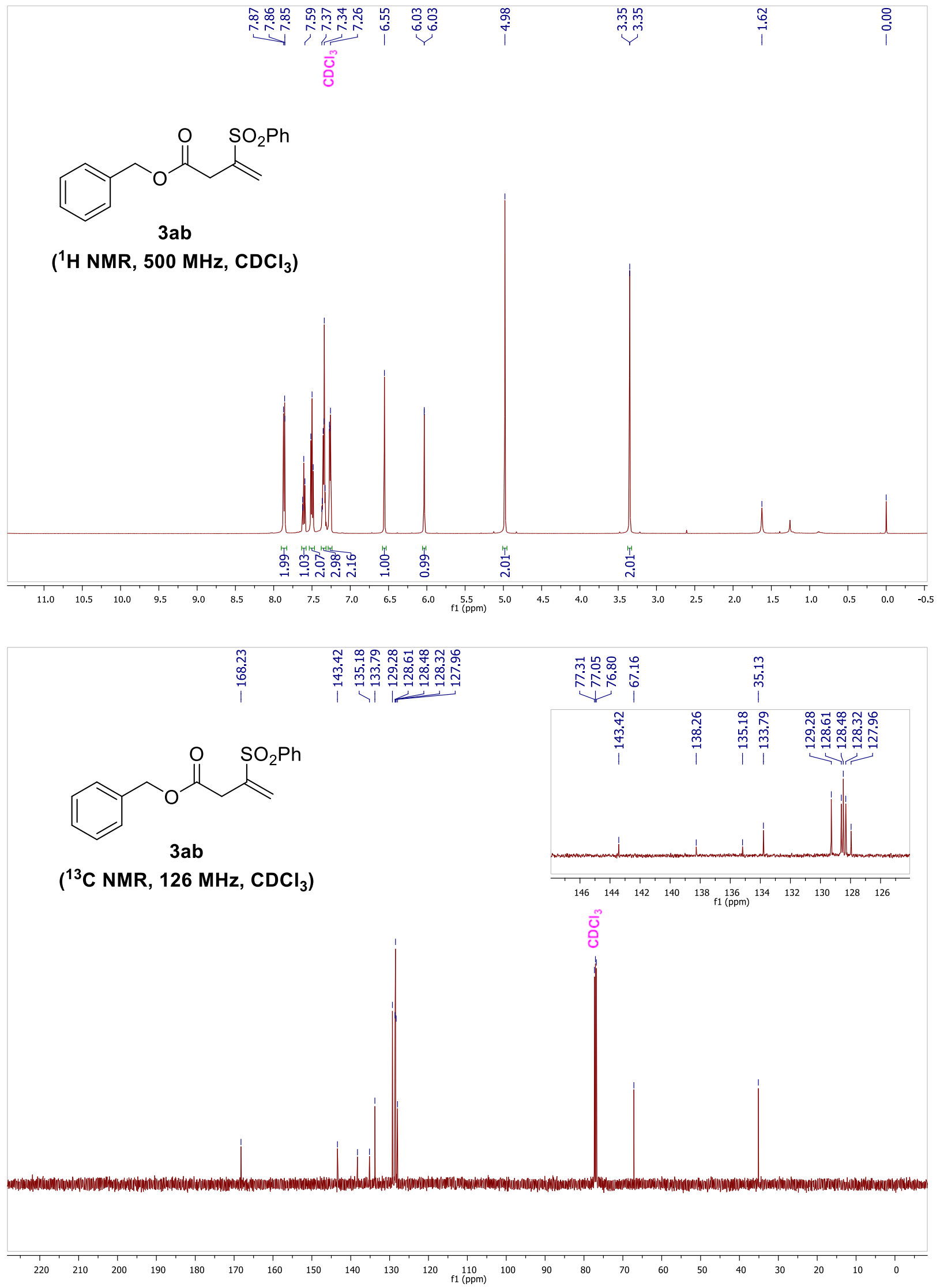

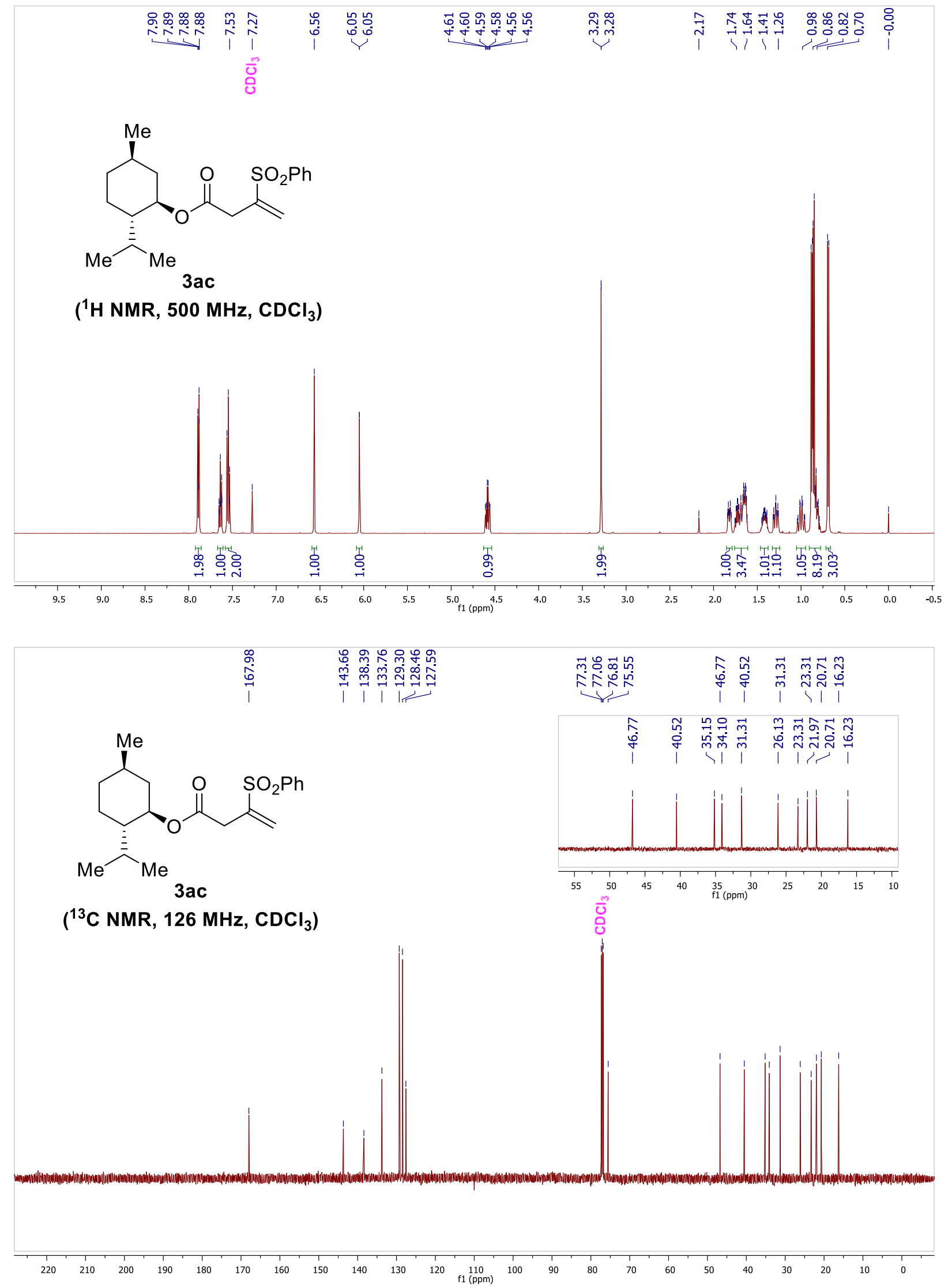

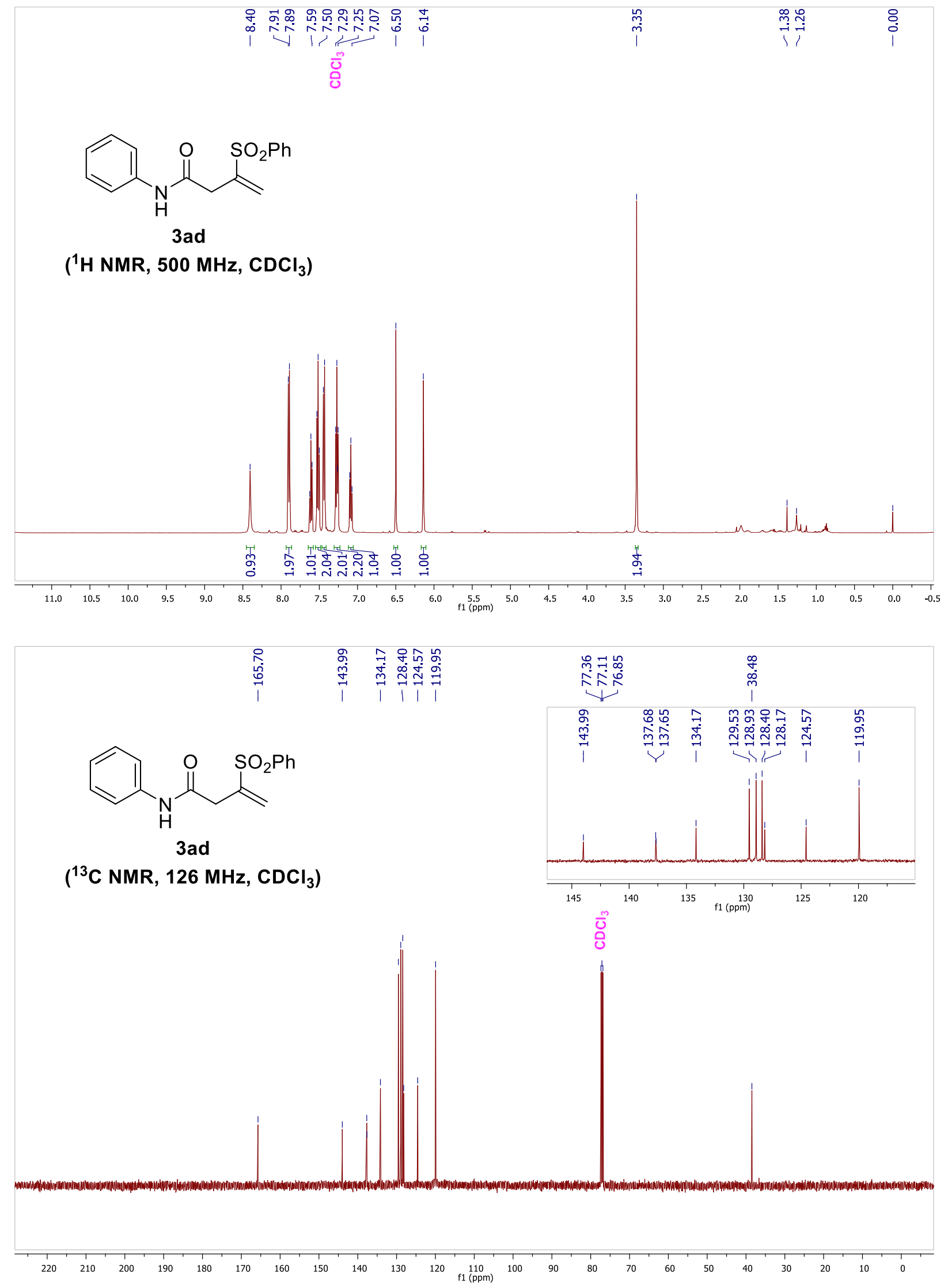

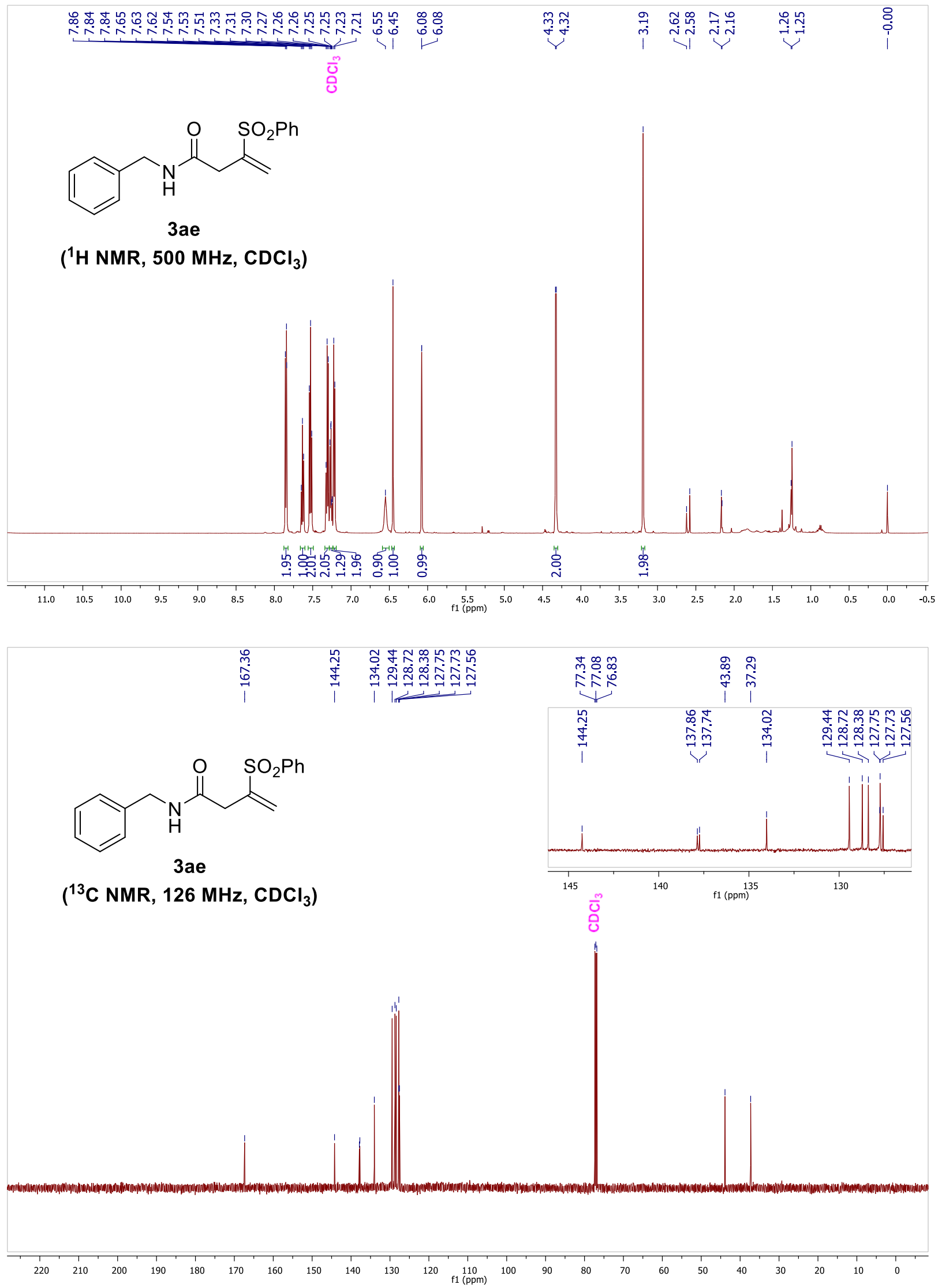

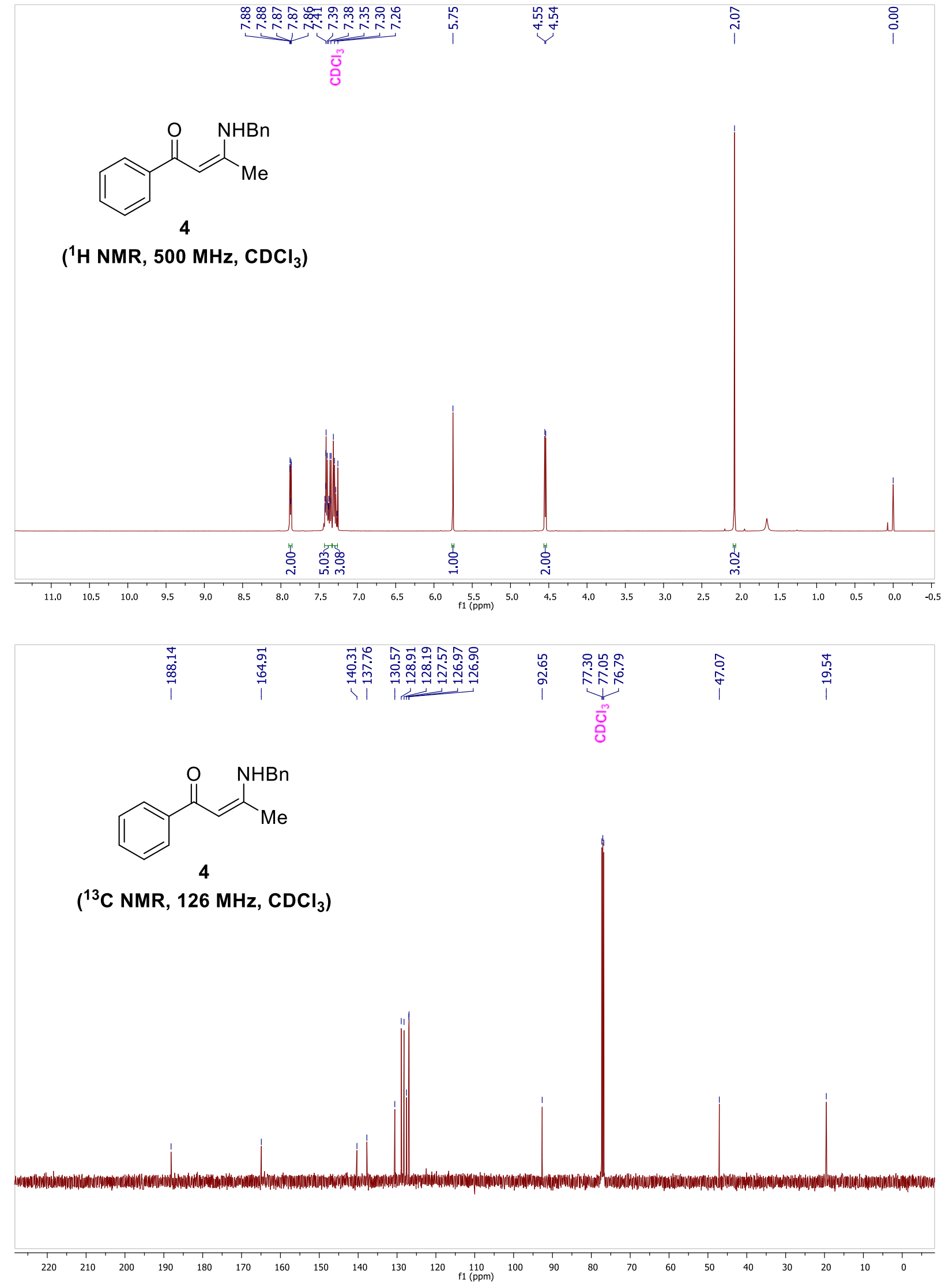

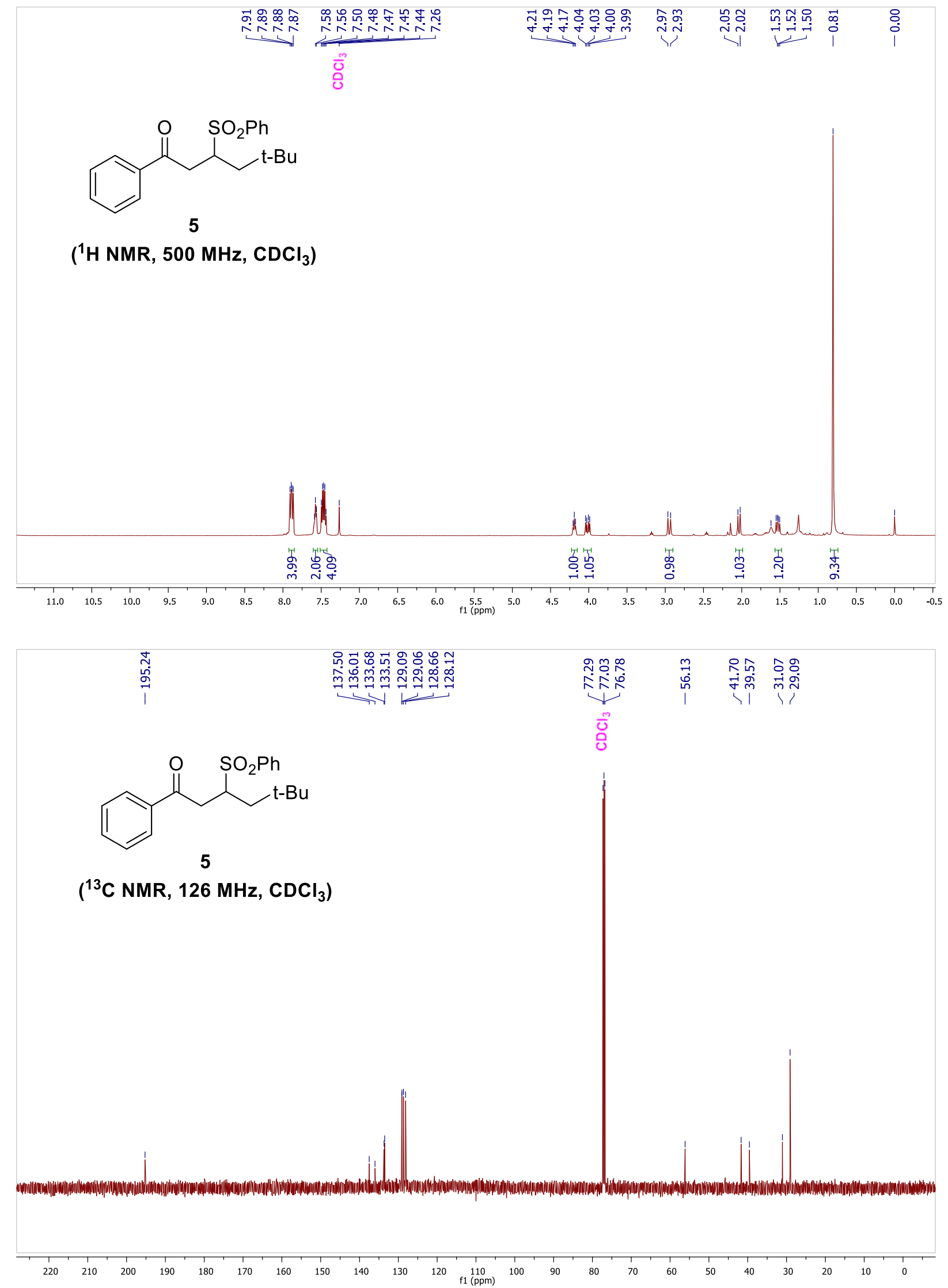

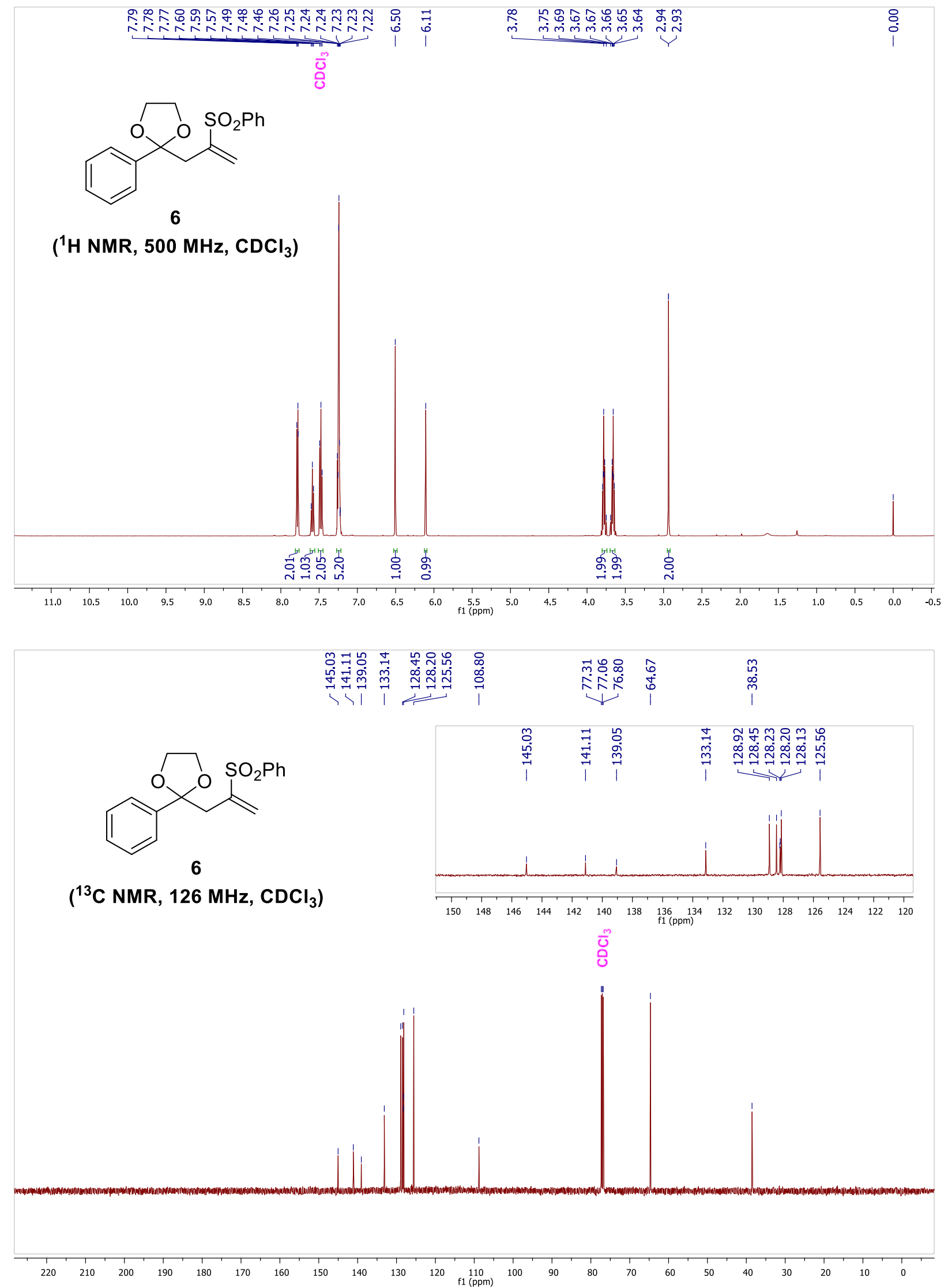

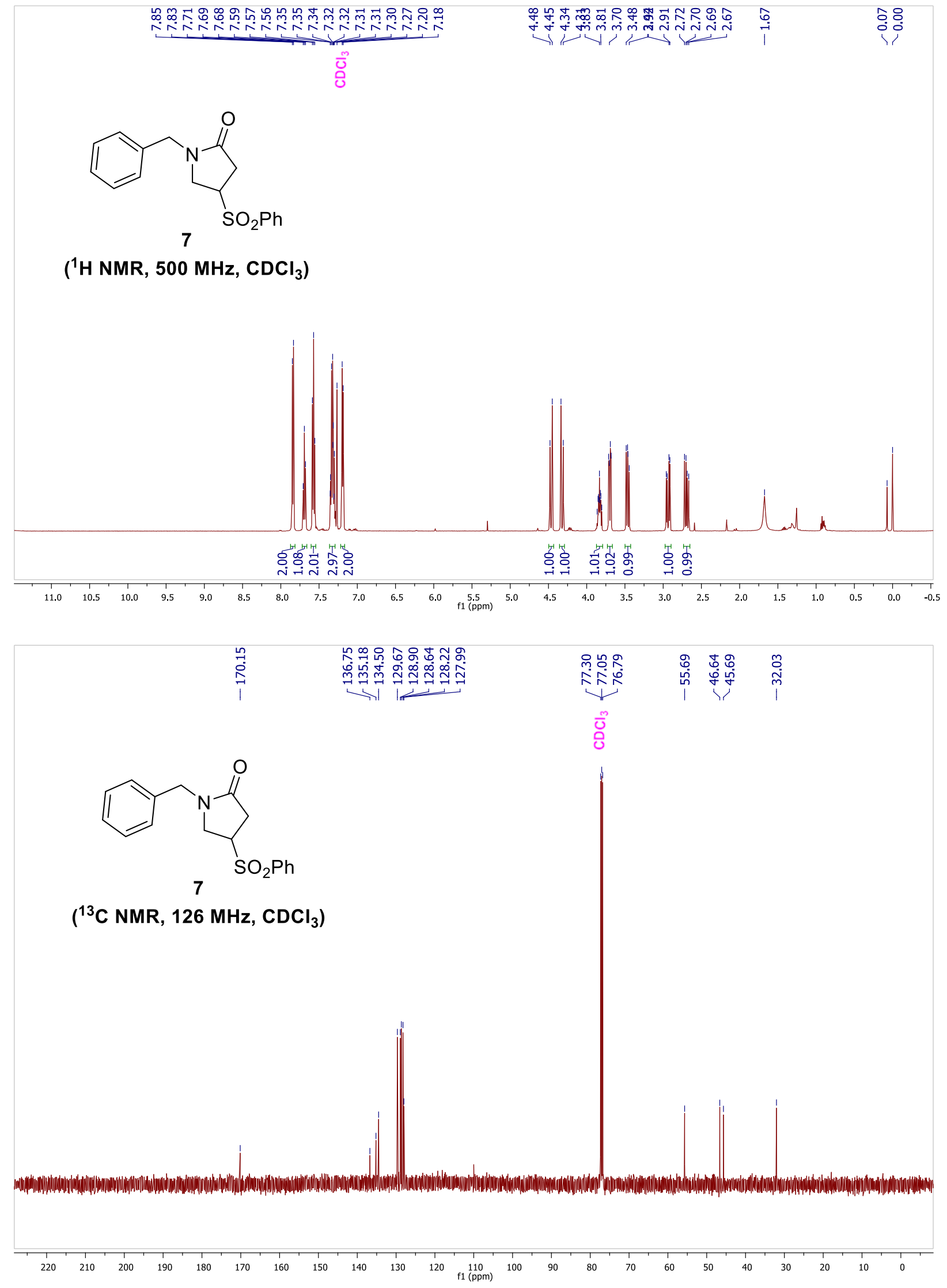

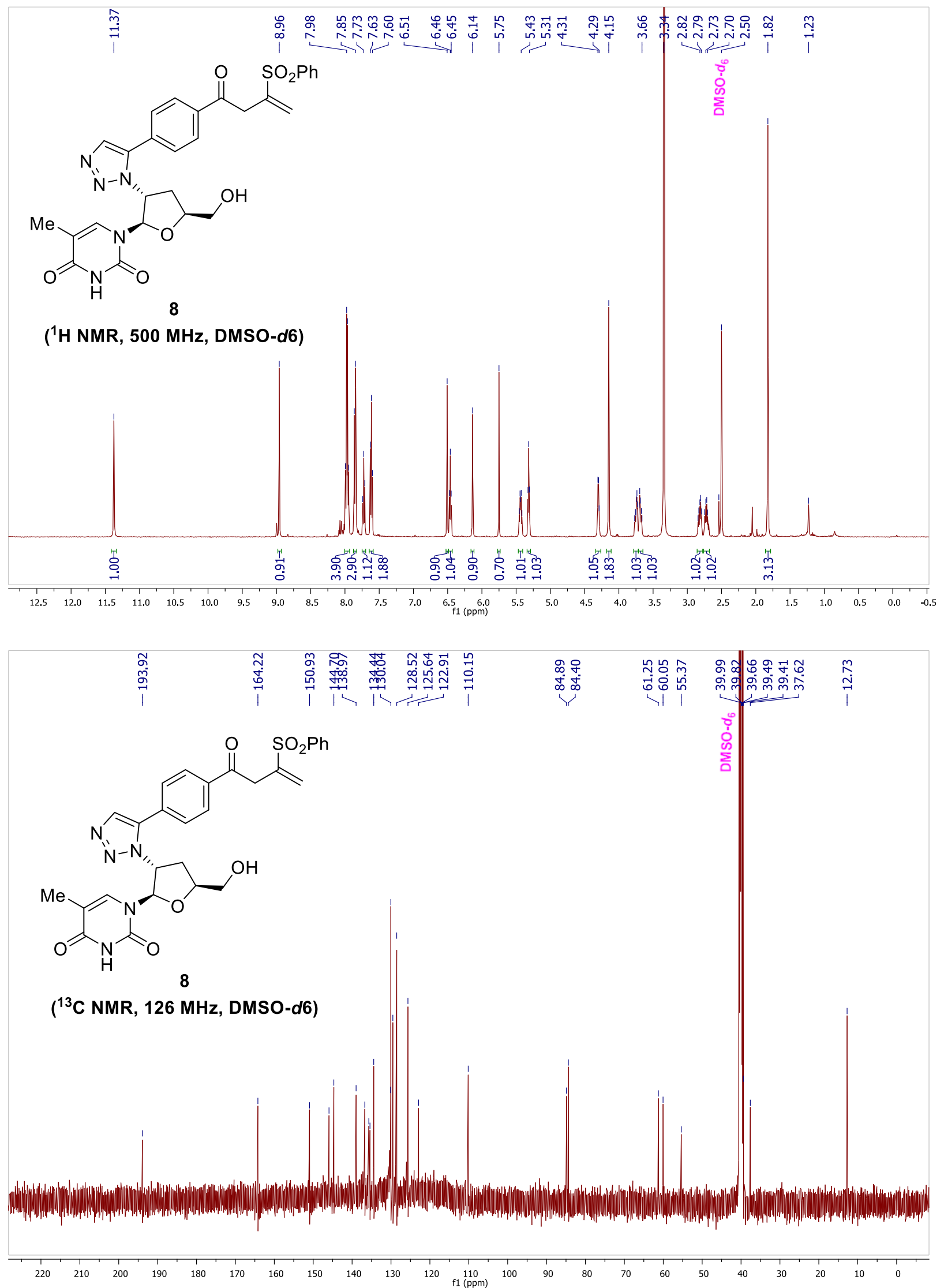